\title{
A Parametric Study of Lateral-Torsional Buckling in Pultruded FRP Beams Using Abaqus
}

\author{
Robert Nathaniel Baylor \\ West Virginia University, rbaylor@mix.wvu.edu
}

Follow this and additional works at: https://researchrepository.wvu.edu/etd

Part of the Civil Engineering Commons, and the Structural Engineering Commons

\section{Recommended Citation}

Baylor, Robert Nathaniel, "A Parametric Study of Lateral-Torsional Buckling in Pultruded FRP Beams Using Abaqus" (2021). Graduate Theses, Dissertations, and Problem Reports. 10216.

https://researchrepository.wvu.edu/etd/10216

This Problem/Project Report is protected by copyright and/or related rights. It has been brought to you by the The Research Repository @WVU with permission from the rights-holder(s). You are free to use this Problem/Project Report in any way that is permitted by the copyright and related rights legislation that applies to your use. For other uses you must obtain permission from the rights-holder(s) directly, unless additional rights are indicated by a Creative Commons license in the record and/ or on the work itself. This Problem/Project Report has been accepted for inclusion in WVU Graduate Theses, Dissertations, and Problem Reports collection by an authorized administrator of The Research Repository @ WVU. For more information, please contact researchrepository@mail.wvu.edu. 
A Parametric Study of Lateral-Torsional Buckling in Pultruded FRP Beams Using Abaqus

\author{
Robert Baylor
}

Problem report submitted to the Statler College of Engineering and Mineral Resources at West Virginia University

in partial fulfillment of the requirements for the degree of Master of Science in Civil Engineering

Hota GangaRao, Ph.D., Chair Roger Chen, Ph.D.

Udaya Halabe, Ph.D.

Wadsworth Department of Civil and Environmental Engineering

Morgantown, West Virginia 2021

Keywords: Lateral-torsional buckling, LTB, orthotropic beams, ABAQUS, FRP Copyright 2021 Robert Baylor 


\title{
ABSTRACT \\ A Parametric Study of Lateral-Torsional Buckling in Pultruded FRP Beams Using Abaqus
}

\author{
Robert Nathaniel Baylor \\ Constructed Facilities Center, West Virginia University
}

Fiber Reinforced Polymer (FRP) composites continue to gain popularity in civil and mechanical infrastructure due to a high strength-to-weight ratio, corrosion-resistance, and low maintenance requirements. FRP can also fulfill niche roles requiring non-conductivity and magnetic transparency. The longitudinal forming of pultruded FRP makes it a natural choice for lightweight beams. Although FRP composites have a high strength for their weight, the elastic and shear moduli for glass FRP may only be $1 / 7$ and $1 / 30$ that of steel, respectively. These low stiffnesses make FRP composite beams particularly susceptible to lateral-torsional buckling (LTB). In addition, the low shear to elastic stiffness amplifies shear deformation which can cause deviations from the LTB critical moment expression originally derived for steel beams.

The objective of this study is to better characterize the lateral-torsional buckling response of pultruded FRP beams through finite element analysis (FEA). A parametric study with a wide range of beam sizes, shapes, material properties, and boundary conditions is the primary focus of the report. In addition, the effect of asymmetrical axial response to stress on LTB is briefly discussed.

Orthotropic beams were modeled with general purpose shell element in ABAQUS to account for the shear deformation in the transverse direction and the lateral shear deformation in the flanges. Python scripts were developed to automate the modeling of wide flange, channel, and narrow rectangular beams of arbitrary dimensions and to apply all material properties, loadings, and boundary conditions in the parameter space. Linear eigen analyses and non-linear geometric Riks analyses were performed to determine critical LTB loads. Results from this study indicate that the moment gradient and load height factors for orthotropic wide flange and narrow rectangular section beams may use the same values as those for steel design. The channel sections exhibited significantly larger error when compared to the closed form expression.

While GFRP is often assumed to be symmetrical and have the same longitudinal elastic modulus for tensile and compressive stresses, this is not true for all FRP composites. To study this asymmetry on LTB, a WF was split at mid-height and separate longitudinal moduli applied to the halves. Despite the bending and twisting involved, the critical LTB moments is found to depend almost entirely on the compressive modulus. Thus, using only the tensile modulus to predict critical LTB will lead to errors proportional to the asymmetry. 


\section{Acknowledgments}

I would like to thank Dr. Hota GangaRao for providing me the opportunity to conduct my project and encouraging me to finish. I would also like to thank Dr. Roger Chen and Dr. Udaya Halabe for serving on my committee.

Finally, I would like to thank my fiance for her unending support. Without her encouragement throughout my studies, this would not have been possible. 


\section{Contents}

List of Figures $\quad$ vii

List of Tables $\quad x$

1 Introduction 1

2 Literature Review 2

3 LTB Derivations $\quad 12$

3.1 LTB Derivation by Energy Principles . . . . . . . . . . . . . . . . . . . . . . 12

3.2 LTB Derivation by Solving Differential Equations . . . . . . . . . . . . . . . . . . 15

4 Procedure $\quad 18$

4.1 Eigen Analysis $\ldots \ldots \ldots \ldots \ldots \ldots \ldots \ldots$

4.2 Riks Analysis . . . . . . . . . . . . . . . . . . . . 34

4.3 Material Definition . . . . . . . . . . . . . . . . . . . 36

$\begin{array}{lll}5 & \text { Model Validation } & 37\end{array}$

$\begin{array}{llr}6 & \text { Analysis } & 38\end{array}$

6.1 Longitudinal vs Transverse Modulus . . . . . . . . . . . . . . . . . . . . 38

6.2 Asymmetric Longitudinal Response on LTB . . . . . . . . . . . . . . . . . . 39

7 Wide Flange Beams $\quad 40$

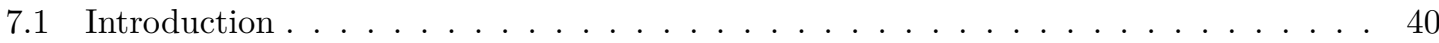

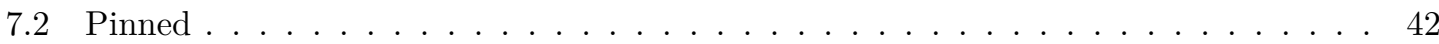

7.3 Minor Axis Fixed $\ldots \ldots \ldots \ldots \ldots \ldots \ldots \ldots \ldots$

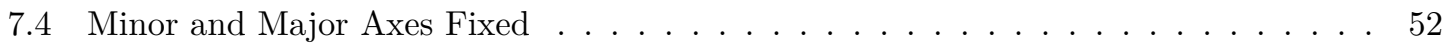

8 Channel Sections $\quad 55$

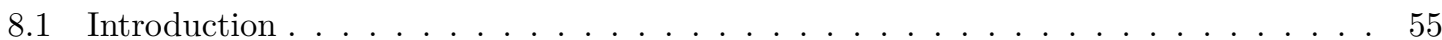




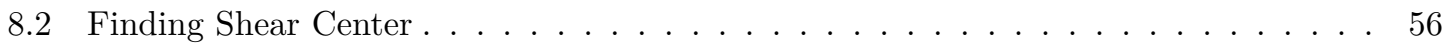

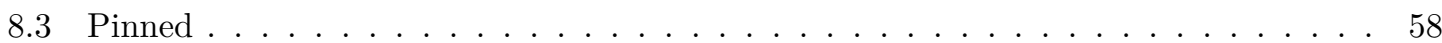

8.4 Minor Axis Fixed . . . . . . . . . . . . . . . . . . . . . 61

8.5 Minor and Major Axes Fixed . . . . . . . . . . . . . . . . . . . . 64

9 Narrow Rectangular Sections $\quad 66$

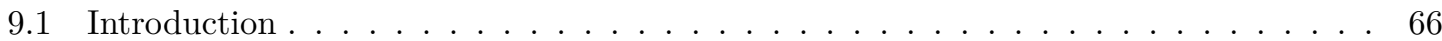

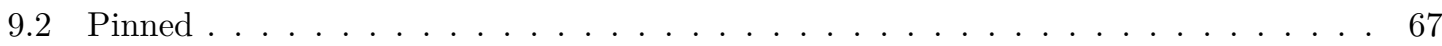

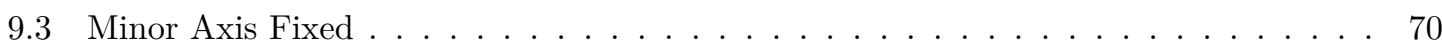

9.4 Minor and Major Axes Fixed . . . . . . . . . . . . . . . . . . . 74

10 Summary of Constants from Parametric Study $\quad 78$

$\begin{array}{ll}11 \text { Comparison to Experimental } & 79\end{array}$

12 Conclusion $\quad 82$

$\begin{array}{ll}\text { Appendix A Clark and Hill Constants } & 87\end{array}$

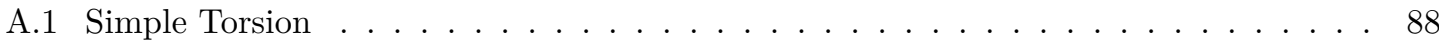

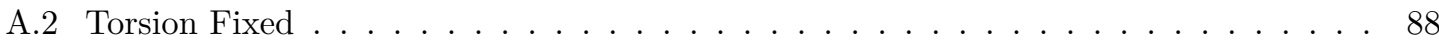

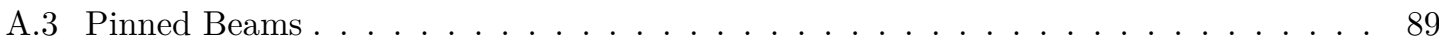

A.3.1 Pure Bending . . . . . . . . . . . . . . . . . . . . . . . 89

A.3.2 3 Point Loading . . . . . . . . . . . . . . . . . . . . . . . . . . 89

A.3.3 Uniform Distributed Loading _ . . . . . . . . . . . . . . . . . . . . . 90

A.4 Minor Axis Fixed . . . . . . . . . . . . . . . . . . . . . . 90

A.4.1 Pure Bending . . . . . . . . . . . . . . . . . . . . 90

A.4.2 3 Point Loading . . . . . . . . . . . . . . . . . . . . . . . 91

A.4.3 Uniform Distributed Loading . . . . . . . . . . . . . . . . . . . . . . . . . . 91

A.5 Major and Minor Axes Fixed _. . . . . . . . . . . . . . . . . . 92

A.5.1 3 Point Loading . . . . . . . . . . . . . . . . . . . . . 92 


\section{List of Figures}

3.1 WF in Bending About Major Axis . . . . . . . . . . . . . . . . . 15

3.2 Lateral Bending of WF Due to Major Axis Moment . . . . . . . . . . . . . . . 16

4.1 Specifying Modeling Space . . . . . . . . . . . . . . . . . . . . . . . . . 19

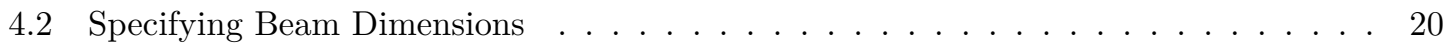

4.3 Defining and Assigning Material Properties . . . . . . . . . . . . . . . . 21

4.4 Defining and Assigning Section Properties . . . . . . . . . . . . . . . 23

4.5 Specify Analysis Type $(\mathrm{Step}) \ldots \ldots \ldots \ldots$. . . . . . . . . . . . . . 24

4.6 Partitioning Beams . . . . . . . . . . . . . . . . . . . . . 25

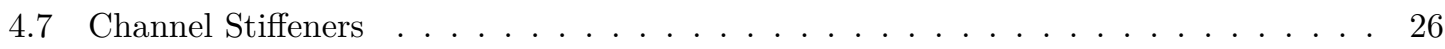

4.8 Load Application . . . . . . . . . . . . . . . . . . . . . . 27

4.9 Applying Boundary Conditions . . . . . . . . . . . . . . . . . . . . 29

4.10 Meshing Beams . . . . . . . . . . . . . . . . . . . . . . . . 30

4.11 Submitting Analysis Job . . . . . . . . . . . . . . . . . . . . 31

4.12 Sample LTB Result . . . . . . . . . . . . . . . . . . . . . . . 32

4.13 Determination of LTB Eigen Modes $\ldots \ldots \ldots$. . . . . . . . . . 33

4.14 Initial Perturbation for Riks Analysis . . . . . . . . . . . . . . . . . . 34

4.15 Effect of Perturbation Magnitude on LTB Response . . . . . . . . . . . . . . . 36

5.1 Convergence Test . . . . . . . . . . . . . . . . . . . . . . 37

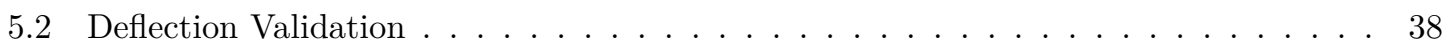

6.1 Effect of Transverse Elastic Modulus on LTB Capacity . . . . . . . . . . . . . . . . 39

6.2 Asymmetrical Longitudinal Elastic Modulus on LTB Capacity . . . . . . . . . . . . . 40

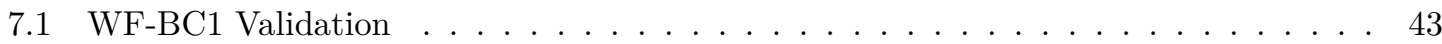

$7.2 \quad$ WF-BC1-Moment Plots . . . . . . . . . . . . . . . . . . . 44

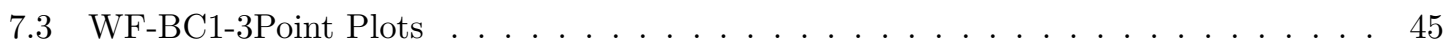

$7.4 \quad$ WF-BC1-3Point Riks vs Eigen Analysis . . . . . . . . . . . . . . . 46

$7.5 \quad$ WF-BC1-UDL Plots $\ldots \ldots \ldots \ldots \ldots \ldots \ldots$ 
7.6 WF-BC2 Validation . . . . . . . . . . . . . . . . . . 48

7.7 Visual Warping of $\mathrm{BC} 1$ and $\mathrm{BC} 2 \ldots \ldots \ldots \ldots \ldots \ldots \ldots$

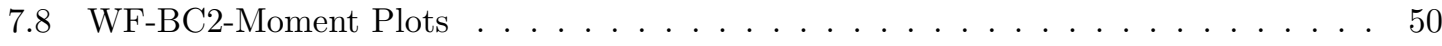

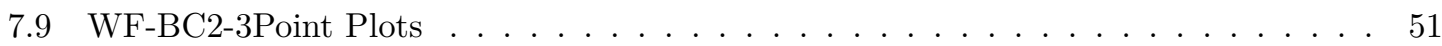

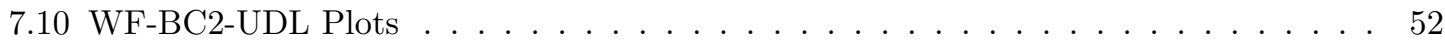

7.11 WF-BC3 Validation . . . . . . . . . . . . . . . . . . . 53

7.12 WF-BC3-3Point Plots . . . . . . . . . . . . . . . . . 54

7.13 WF-BC3-UDL Plots $\ldots \ldots \ldots \ldots \ldots \ldots \ldots \ldots$

8.1 Determination of Shear Center . . . . . . . . . . . . . . . . . 57

8.2 Effect of Perturbation on LTB Response for Channels . . . . . . . . . . . . . 58

8.3 C-BC1 Validation . . . . . . . . . . . . . . . . . . . . . . . 59

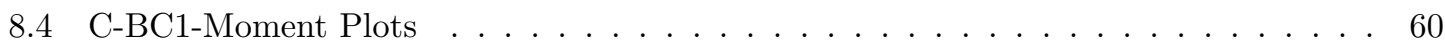

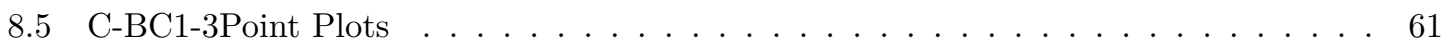

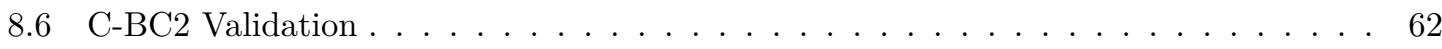

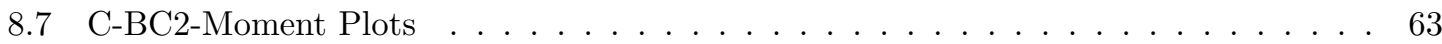

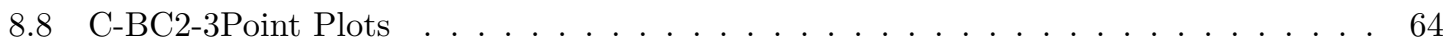

8.9 C-BC3 Validation . . . . . . . . . . . . . . . . . . . . 65

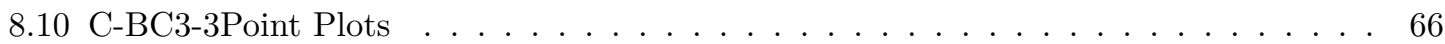

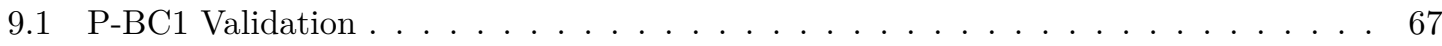

$9.2 \quad$ P-BC1-Moment Plots $\ldots \ldots \ldots \ldots \ldots \ldots$

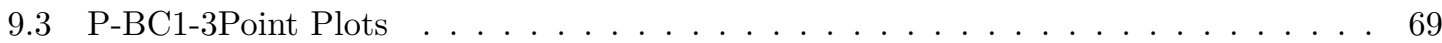

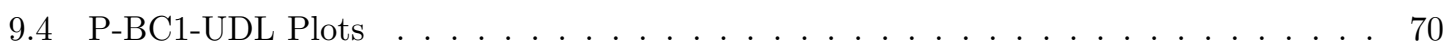

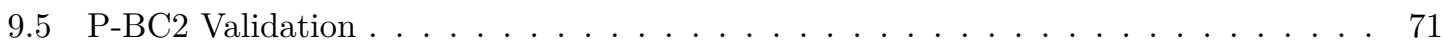

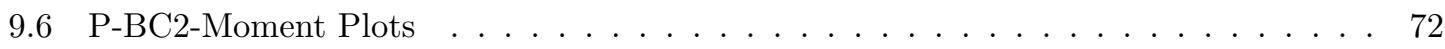

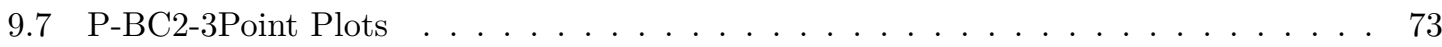

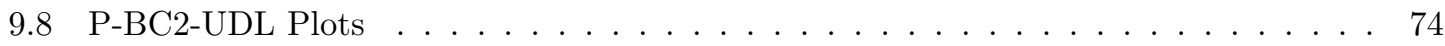

9.9 P-BC3 Validation . . . . . . . . . . . . . . . . . . . . . 75

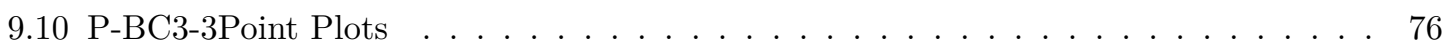




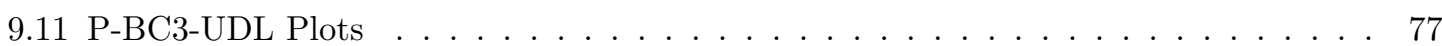




\section{List of Tables}

4.1 Materials Properties in the Parameter Space . . . . . . . . . . . . . . . . . 37

7.1 Wide Flange Dimensions for Parametric Study . . . . . . . . . . . . . . . . . . . 42

8.1 Channel Dimensions for Parametric Study . . . . . . . . . . . . . . . . . . . . 56

9.1 Narrow Rectangular Beam Dimensions for Parametric Study . . . . . . . . . . . 67

10.1 Parametric Study Summary . . . . . . . . . . . . . . . . . . . . 78

11.1 Comparison to Experimental $\mathrm{BC} 1 \mathrm{TF} \ldots \ldots \ldots \ldots \ldots$

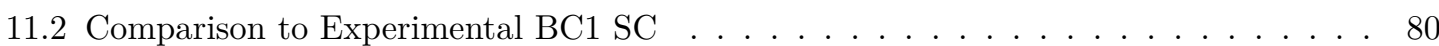

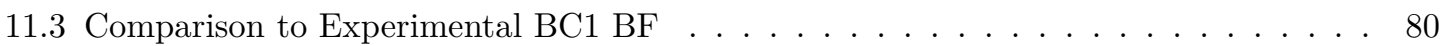

11.4 Comparison to Experimental $\mathrm{BC} 2 \mathrm{TF} \ldots \ldots \ldots \ldots \ldots$. . . . . . . . . 81

11.5 Comparison to Experimental $\mathrm{BC} 2 \mathrm{SC} \ldots \ldots \ldots \ldots$. . . . . . . . . . 81

11.6 Comparison to Experimental $\mathrm{BC} 2 \mathrm{BF} \ldots \ldots \ldots \ldots$. . . . . . . . . 82 


\section{Introduction}

Fiber reinforced polymer (FRP) composites have continued to gain adoption in civil and mechanical application due to a high strength to weight ratio, corrosive resistance, and low maintenance requirements. FRP can also fulfill niche roles requiring non-conductivity and magnetic transparency. The corrosive resistance makes FRP composites attractive for long term exposure of infrastructure to harsh environments. This can include bridge decks, exposed industrial buildings, marine and waterway structures, and even the reinforcement for concrete.

Due to the longitudinal nature of the pultruded FRP manufacturing process, it is a logical choice for creating composite beams. This process allows longitudinal products of near arbitrary length to be created. First, longitudinal (reinforcement) fibers and continuous fiber mat rovings are pulled through a series of forms that align the fibers into the required geometry. During this, the fibers may also go through a melted resin bath or resin impregnator. The fibers are then pulled through a heated die where temperature is regulated to initiate and control polymerization. While traveling through the die, the resin hardens and takes the form of the die. Manufacturing time can depend on the type of resin used. Of the many resin and reinforcement combinations used to make FRP, glass FRP (GFRP) is the most common.

Despite the high strength-to-weight ratio, FRP composites are known to have a low stiffness. GFRP only has roughly $1 / 7$ and $1 / 30$ the elastic and shear modulus of steel, respectively. This low elastic modulus and much lower shear modulus make GFRP composites particularly susceptible to a failure mode known as lateral-torsional buckling (LTB). This buckling mode can occur when a beam is in flexure about its major bending axis. Due to imperfections, the beam will twist and deflect laterally as it is loaded. These imperfections can include out-of-straightness, fiber kinks, asymmetrical fiber configurations, improper curing, and loads or supports placed slightly off from the shear center. As the loading nears the critical LTB limit, these deformations begin to grow more quickly until the beam finally fails. Because of this propensity to buckle while bending, the accurate prediction of LTB for pultruded FRP composites is crucial to the continued adoption of this relatively new engineered product. While a pre-standard exists for the design of FRP structures, 
basic lateral-torsional buckling continues to be an active research topic.

\section{Literature Review}

Lateral-torsional buckling is a complex buckling failure where a beam under bending about the major axis experiences an axial rotation about a point below the beam's shear center. Rotating about this point results in a combined lateral displacement and twist from the beams' initial state. The earliest references to LTB are $[24,17,30]$ only one of which the author could find. In [michel1899], Michell states that beams fail by LTB "very frequently" indicating this failure mode has been problematic for some time. In the first edition of Timoshenko's widely known "Theory of Elastic Stability" [29], LTB problems were solved directly from differential equations as well by energy principles. The solution given for a simply supported I-beam subjected to pure bending is shown below.

$$
M_{c r}=\frac{\pi \sqrt{B_{1} C}}{l} \sqrt{1+\pi^{2} \frac{a^{2}}{l^{2}}}
$$

where,

$$
\begin{aligned}
B_{1} & =\text { Lateral bending stiffness } \\
C & =\text { Torsional stiffness } \\
a^{2} & =\frac{D h^{2}}{2 C} \\
D & =\text { Lateral bending stiffness of single flange } \\
h & =\text { Flange center to center distance }
\end{aligned}
$$

If the notation is changed into more common standards of today this will present as:

$$
M_{c r}=\frac{\pi^{2} E I_{y}}{L^{2}} \sqrt{\frac{C_{w}}{I_{y}}\left(1+\frac{G J L^{2}}{\pi^{2} E C_{w}}\right)}
$$

The only difference from Equation 2.2 and what is still commonly used today is the moment 
gradient factor, $C_{b}$, and $L_{b}$ which is designated as an unbraced or effective length. Eurocode 3 [10] also uses effective length factors, $k$ and $k_{w}$, for different boundary conditions. For most practical boundary conditions, $k=k_{w}$ so the ratio $k / k_{w}$ in Eurocode 3 doesn't change the expression from what is used by the American Institute of Steel Construction [2].

Although the relation by Timoshenko was very close to modern form, Equation 2.3, there was still much work in the area of LTB over the next decades $[32,13,33,34$, and many others] on specific loading conditions, boundary conditions, and monosymmetric sections. In 1960, Clark and Hill [9] published a summary of current research to be used as a guide for design specifications for beams and girders subject to lateral-torsional buckling. The paper presented the elastic critical buckling formula, Equation 2.3, and a derivation of the equation and its parameters by use of energy principles. The parameters in the equations are also given for many load cases and boundary conditions which are still valid for steel WF and channel beams. Much of the work in this report will be compared to the parameters in their review. 


$$
\bar{M}=C_{1} \frac{\pi^{2} E I_{y}}{(K L)^{2}}\left[C_{2} g+C_{3} k+\sqrt{\left(C_{2} g+C_{3} k\right)^{2}+\frac{C_{W}}{I_{y}}\left(1+\frac{G J(K L)^{2}}{\pi^{2} E C_{W}}\right)}\right]
$$

where,

$$
\begin{aligned}
E & =\text { Elastic modulus } \\
G & =\text { Shear modulus } \\
I_{y} & =\text { Minor axis moment of inertia } \\
J & =\text { Torsion constant } \\
C_{W} & =\text { Warping constant } \\
L & =\text { Beam length } \\
K & =\text { Effective length factor } \\
g & =\text { Vertical eccentricity } \\
C_{1} & =\text { Moment gradient factor } \\
C_{2} & =\text { Load height factor } \\
C_{3} & =\text { Hoizontal asymmetry factor }
\end{aligned}
$$

The factor $k$ in Equation 2.3 is given by the integration over the beam's profile,

$$
k=e+\frac{1}{2 I_{x}} \int\left(x^{2}+y^{2}\right) d A
$$

where,

$$
\begin{aligned}
I_{y} & =\text { Major axis moment of inertia } \\
e & =\text { Horizontal eccentricity }
\end{aligned}
$$

In 1992 Mottram performed the first LTB studies on pultruded FRP I-beams, an experimental study with three I102/51/6 specimens and a numerical analysis $[18,19]$. In the numerical study, the Mottram cited [6] as justification that the isotropic, elastic LTB equation needed only a simple mod- 
ification of replacing the isotropic section and material properties with the appropriate orthotropic properties, shown in Equation 2.5. Mottram measured the longitudinal flexural modulus and the out-of-plane shear modulus following a graphical method by [3], see Equation 2.6. Mottram argued that the twisting response of I-beams justified that not only is $G_{x y}$ dependent on $G_{x z}=G_{y z}$ but that it is reasonable to use $G_{x z}$ as $G_{x y}$ in the orthotropic elastic LTB equation. Mottram used M16 bolts with nuts as columns between the flanges at the ends of the beams. The nuts were positioned such that flexure was induced in the flanges. This was argued to create a fixed restraint to lateral bending and warping of the flanges, although the critical loads were much closer to what the orthotropic version of Eurocode 3 predicts for a boundary condition with lateral bending fixed but warping free [18]. 


$$
M_{c r}=C_{1} \frac{\pi^{2} E_{z, y y} I_{y y}}{(k l)^{2}}\left\{\left[\left(\frac{k}{k_{w}}\right)^{2} \frac{I_{w}}{I_{y y}}+\frac{(k l)^{2} G_{x y} J}{\pi^{2} E_{z, y y} I_{y y}}+\left(C_{2} e\right)^{2}\right]^{0.5}-C_{2} e\right\}
$$

where,

$$
\begin{aligned}
E_{z, y y} & =\text { Longitudinal elastic modulus for minor axis bending } \\
G_{x y} & =\text { Shear modulus for twisting } \\
I_{y y} & =\text { Minor axis moment of inertia } \\
J & =\text { Torsion constant } \\
I_{w} & =\text { Warping constant } \\
l & =\text { Beam length } \\
k & =\text { Effective length factor } \\
k_{w} & =\text { Effective warping length factor } \\
e & =\text { Vertical eccentricity } \\
C_{1} & =\text { Moment gradient factor } \\
C_{2} & =\text { Load height factor }
\end{aligned}
$$

$$
\frac{w}{P l}=\frac{l^{2}}{48 E_{z} I}+\frac{1}{4 G_{x z}}
$$

where,

$$
\begin{aligned}
w & =\text { Vertical displacement at midspan } \\
P & =\text { Applied load } \\
E_{z} & =\text { Longitudinal elastic modulus } \\
G_{x z} & =\text { Shear modulus for vertical deformation }
\end{aligned}
$$

Brooks and Turvey [8] compared theoretical and computational critical LTB loads for GFRP, cantilevered I sections against full size test results. The cantilevered sections were loaded until the rotation at the free end reached $3^{\circ}$ or more. Brooks and Turvey determined the longitudinal and 
shear section moduli using Timoshenko beam theory and a 3-Point bending test. The moduli was calculated from the maximum deflection of the simple beam,

$$
\frac{4 A w}{P L}=\frac{1}{12 E_{b_{i}}}\left(\frac{L}{r_{i}}\right)^{2}+\frac{1}{G_{b_{i}}}
$$

Brooks and Turvey also used shell elements in ABAQUS to model the cantilever beams. The finite element analysis (FEA) had an average error of $26.4 \%$ for cantilevers $1250 \mathrm{~mm}$ long that reduced slightly to $23.0 \%$ for $1750 \mathrm{~mm}$ long beams compared to the experimental data. The FEA prediction was more comparable to the expression from Nethercot [20], 10\% error. The authors suggested adding initial out of straightness and pre-buckling deformations with an arc length method to more accurately model lateral-torsional buckling behavior.

The effects of shear deformation on composite beams have been studied by $[26,16,25]$ and others. Shearbourne and Kabir [26] studied the effects of transverse shear deformation on LTB with an arbitrary lamination architecture for a simply supported I beam with concentrated or uniformly distributed loading. Terms for transverse shear deformation were added into the energy equation for the LTB of an I beam. This resulted in a shear correction factor for the critical LTB loads, shown below for the concentrated load case. This shear factor for all the WF shapes in this Report was calculated to be approximately one. Thus, transverse shear deformation is neglected for this work.

$$
\gamma=\sqrt{1-\frac{\pi^{2}}{l^{2}} \frac{K_{y y}}{I_{y y}\left(K_{c c}+\frac{\pi^{2}}{l^{2}} K_{y y}\right)}}
$$

Lopez-Anido and GangRao [16] studied the stresses induced by shear deformation and shear lag in composites, resulting in an expression for an effective longitudinal modulus. Sapkás and Kollár[25] studied the effects of both lateral and torsional shear deformation on LTB. They derived expressions that modified the minor axis bending stiffness and the warping stiffness for cantilever and simply supported beams. They applied concentrated end moments, uniformly distributed loads, 3 point loads, and 4 point loads to the beams. The developed expressions, shown in Equation Equations 2.9 and 2.10, were compared to both FEA simulations performed with ANSYS and to 
published experimental data. An error term, $\alpha$, was also derived for the LTB moment if these shear effects were not taken into account for a WF beam, shown in 2.11. $\alpha$ ranged from insignificant to $64 \%$ for the shorter beams with the material from row (4) in Table 4.1. This error can be seen in the box plots throughout Section 6. The shear correction from Sapkás and Kollár are applied for both WF and C shapes in this study with the results shown in Table 10.1.

While there was general improvement in the scatter plots across all conditions for WF and C shapes, C shapes had significant reduction in average error from the $M_{f i t}$ vs. $M_{\lambda}$. These results are presented in Section 10.

$$
\begin{aligned}
& \widehat{E I}_{z z} \longrightarrow\left(\frac{1}{\widehat{E I}_{z z}}+\frac{\pi^{2}}{(k l)^{2}} \cdot \frac{1}{\widehat{S}_{y y}}\right)^{-1} \\
& \widehat{E I}_{\omega} \longrightarrow\left(\frac{1}{\widehat{E I}_{\omega}}+\frac{\pi^{2}}{(k l)^{2}} \cdot \frac{1}{\widehat{S}_{\omega \omega}}\right)^{-1}
\end{aligned}
$$

where,

$$
\begin{aligned}
& x=\text { Minor axis bending stiffness } \\
& y=\text { Warping stiffness } \\
& k=1 \text { For a simply supported beam } \\
& l=\text { Full length of the beam }
\end{aligned}
$$

$$
\alpha=1-\frac{1}{1+\frac{\pi^{2}}{10}\left(\frac{b_{f}}{l}\right)^{2} \frac{E x}{G_{x y}}}
$$

Barbero and Raftoyiannis[5] investigated the stability of Pultruded I-beams. The authors studied the general case of I-beam instability, distortional buckling, which includes the coupling of local and lateral-torsional buckling modes. This was performed by calculating the first and second variations in the potential energy, $\delta V$ and $\delta^{2} V$. Like a ball at the top of a hill, the beams become unstable when the second variation transitions from positive to negative. Barbero and Raftoyiannis solved for when second variation was zero. First, the potential energy of the system was calculated using, 


$$
V=\frac{1}{2} \int_{V} \sigma_{i j} \epsilon_{i j} d V-\sum_{k} P_{k} q_{k}
$$

Then, Von-Karman non-linear strains and Classical Lamination Theory was used to describe the kinematics of the system. After an equation for the second variation of potential energy was obtained, it was solved using the Raleigh-Ritz method by using a displacement function for the web and the prebuckled shape of the I-beam. This was done for five geometries of I-beams in combination with construction by continuous strand mat layers or by angle-ply layers $(+\theta,-\theta)$ with three fiber volume fractions of $15 \%, 30 \%$, and $50 \%$. Barbero and Raftoyiannis found that as the height of the the webs were increased, the buckling mode transitions from pure lateral torsional buckling to distortional buckling.

Nguyen et al. published a series of papers on lateral-torsional buckling for WF and $\mathrm{C}$ shapes including a finite element analysis [21], an experimental analysis [23], and a study focused on design parameters such as reduction factors and plateau length [22]. The FEA study used S8R shell elements from ABAQUS to study the influences of boundary conditions, load height, and geometric imperfections. Both an Eigen analysis and a non-linear analysis with a modified Riks method was employed to study the buckling behavior. Two boundary conditions of simply supported beams were analyzed: warping free and warping restrained by a rigid plate at the ends of the beam. The second case is different from the three boundary conditions applied in this report where warping is only restrained in conjunction with major axis bending. It was shown for the beams analyzed that restrained warping increased critical load by up to $50 \%$ for $\mathrm{L} / \mathrm{h}=10$. In the experimental study by Nguyen et al., the loading disc designed by Flint [11] was recreated to ensure concentric loading for wide flange and channel shapes at different load heights. One WF and three C profiles were tested with 5 different lengths, 3 different load heights, and 2 boundary conditions. The two boundary conditions are simply supported (EC1) and simply supported with lateral bending fixed (EC2). Both cases were assumed to allow free warping. The critical buckling load was determined by Southwell plots and compared to Eurocode 3 with $\mathrm{k}=1$ and $\mathrm{k}=0.5$ for EC 1 and 2, respectively. The theoretical buckling loads were fairly conservative due to the use of manufacturer 
supplied material properties. In the final study focused on determining design parameters, material properties determined by coupon testing were used instead of the manufacturer supplied properties.

Ahmadi [1] studied lateral-torsional buckling of anisotropic laminated thin-walled rectangular composite beams for a variety of loading conditions and layups, including a steel-FRP composite beam. Ahmadi derived the differential LTB equations starting from standard composite constitutive equations, see Equations 2.13 and 2.14 for pure bending and concentrated loading, respectively. While the equation for the pure bending case is readily solved by analytical means, the solution for the 3 Point load case is more complex and involves Bessel functions. To overcome this, Ahmadi used an iterative technique to determine the value for $\psi_{1}$.

$$
\begin{gathered}
\beta^{\prime \prime}+\kappa^{2} \beta=0 \\
\beta^{\prime \prime}+\psi_{1}^{2} x^{2} \beta=0 \\
\psi_{1}^{2}=\frac{P^{2} / 4}{4 h^{2}\left[D_{Y} D_{T}-D_{Y T}^{2}\right]} \\
\kappa^{2}=\frac{M_{0}^{2}}{4 h^{2}\left[D_{Y} D_{T}-D_{Y T}\right]}
\end{gathered}
$$

where,

$$
\begin{aligned}
x & =\text { Longitudinal coordinate of the beam } \\
\beta & =\text { Angle of twist } \\
D_{Y} & =\text { Composite lateral stiffness } \\
D_{T} & =\text { Composite twisting stiffness } \\
D_{Y T} & =\text { Composite lateral-twisting coupling stiffness }
\end{aligned}
$$

For an orthotropic plate $D_{Y T}=0$ and $D_{Y}$ and $D_{T}$ are as shown below.

$$
\begin{gathered}
D_{Y}=\frac{E_{11} t^{3}}{12\left(1-\nu_{12} \nu_{21}\right)} \\
D_{T}=\frac{G_{12} t^{3}}{12}
\end{gathered}
$$


After applying appropriate boundary conditions and solving, both differential equations led to buckling load equations of similar form but with different coefficients, see Equations 2.19 and 2.20. Although the coefficient $\psi_{1}$ is dependent on the geometric and elastic properties of the beam as given by Equation 2.15, Ahmadi found that the coefficient converged to a single value 3.39E-5 for a beam that was $\mathrm{L}=500 \mathrm{~mm}$ for every layup investigated.

$$
\begin{gathered}
M_{0 c r}=\frac{\pi h}{L} \sqrt{4\left[D_{Y} D_{T}-D_{Y T}^{2}\right]} . \\
P=2 \psi_{1} h \sqrt{4\left[D_{Y} D_{T}-D_{Y T}^{2}\right]} .
\end{gathered}
$$

$\psi_{1}$ was normalized to the beam length resulting in Equation 2.21. The coupling term $D_{Y T}^{2}$ is negligible compared to $D_{Y} D_{T}$ for the beams in this Report. Neglecting $D_{Y T}^{2}$ and rewriting with elastic and geometric properties for a unidirectional composite gives Equation 2.22. This shows the importance of the longitudinal and shear stiffness to lateral-torsional buckling resistance. It should also be noted Timoshenko's expression for the LTB of a narrow rectangular beams also has a similar factor of $16.93[29]$.

$$
P=\frac{16.94 h}{L^{2}} \sqrt{4\left[D_{Y} D_{T}-D_{Y T}^{2}\right]}
$$

Applying this to an orthotropic plate results in:

$$
P=\frac{16.94 h}{L^{2}} \sqrt{4\left[\frac{E_{L} G_{L T} t^{6}}{144\left(1-\nu_{12} \nu_{21}\right)}\right]} .
$$

Rewriting this again in terms of sectional constants, $\mathrm{J}$ and Iy, the resulting expression differs from the isotropic version only by the 2nd order terms of Possion's ratios.

$$
P=\frac{16.94 h}{L^{2}} \sqrt{\frac{E_{L} I_{y} G_{L T} J}{1-\nu_{12} \nu_{21}}}
$$




\section{LTB Derivations}

Lateral Torsional Buckling is an instability that may occur to members bending about their major axis. During flexure, the compression flange may become unstable as a column in compression does. However, because the compression flange is restrained by the web and tension flange, the compression flange can only buckle about the profile's minor axis. If a beam is without imperfections and the loading is exactly concentric, the beam may buckle suddenly and without warning at or past the critical load. This is bifurcation buckling and is a rare occurrence. More commonly, while the load is increasing, the beam will start to deflect laterally and twist slowly. These deflections will grow quickly in the vicinity of the critical load until LTB occurs.

The two classical methods used to derive the critical LTB moment are directly solving the constitutive differential equations from equilibrium conditions and applying energy principles to a buckling beam. The first method requires solving differential equations for each specific loading and boundary condition. The second method is seen more as an approximation. The accuracy of this method depends on applying a shape function that matches the true behavior of the beam. Both methods have been used by [29] but the derivation from [9] has general expressions for the moment gradient, load-height, and effective length factors. Both derivations are reproduced in Sections 3.1 and 3.2 .

\subsection{LTB Derivation by Energy Principles}

A derivation for LTB by energy principles is shown here as was presented by [9]. This is the first derivation known by the author to present expressions for parameters of the critical LTB moment equation in terms of normalized bending moments and shape functions. The energy terms from left to right in Equation 3.1 are the change in strain energy specifically from buckling, lateral bending of the full section, warping/lateral bending of flanges, twisting, bending of a deformed section, bending of non-symmetrical sections, and gravitational energy of the load relative to shear center.

$$
V=\frac{1}{2} \int_{0}^{L}\left[E I_{y} u^{\prime \prime}+E C_{W} \beta^{\prime \prime 2}+G J \beta^{2}+2 M \beta^{\prime \prime}+2 k M \beta^{\prime 2}+p g \beta^{2}\right] d z
$$




$$
\begin{aligned}
V & =\text { Potential energy } \\
E & =\text { Modulus of elasticity } \\
I_{y} & =\text { Weak axis moment of inertia } \\
u & =\text { Lateral displacement } \\
C_{w} & =\text { Torsional warping constant } \\
\beta & =\text { Twist } \\
G & =\text { Shear modulus } \\
J & =\text { Torsion constant } \\
M & =\text { Moment } \\
p & =\text { Applied load } \\
g & =\text { Load height relative to shear center vertically }
\end{aligned}
$$

As the beam deforms and twists, a lateral moment develops as $M \sin (\beta)=M \beta$ which relates to the lateral deflection by

$$
E I_{y} u^{\prime \prime}=M \beta
$$

Relating the applied load to the bending moment,

$$
p=-M^{\prime \prime}
$$

Next, the longitudinal coordinate and bending moment are normalized.

$$
\begin{aligned}
& Z=z / L \\
& M=\bar{M} m
\end{aligned}
$$

Applying these substitutions and setting the potential energy to zero for a buckled condition, the 
energy equation becomes:

$$
\begin{aligned}
0=\frac{\bar{M}^{2}}{E I_{y}} \int_{0}^{1} m^{2} \beta^{2} d Z & -\frac{\bar{M}}{L^{2}}\left[g \int_{0}^{1} \frac{d^{2} m}{d Z^{2}} \beta^{2} d Z+2 k \int_{0}^{1} m\left(\frac{d \beta}{d Z}\right)^{2} d Z\right] \\
& -\frac{G J}{L^{2}} \int_{0}^{1}\left(\frac{d \beta}{d Z}\right)^{2} d Z-\frac{E C_{W}}{L^{4}} \int_{0}^{1}\left(\frac{d^{2} \beta}{d Z^{2}}\right)^{2} d Z \\
k & =e+\frac{1}{2 I_{x}} \int_{A}\left(x^{2}+y^{2}\right) d A
\end{aligned}
$$

This is just a quadratic equation for the maximum bending moment of the beam, $\bar{M}$, during buckling. Also note, the factor $k$, described by Equation $3.2 \mathrm{~b}$, is zero for profiles symmetrical about the horizontal axis.

$$
\begin{gathered}
C_{1}=\frac{\int_{0}^{1}\left(\frac{d \beta}{d Z}\right)^{2} d Z}{\sqrt{\int_{0}^{1} m^{2} \beta^{2} d Z \int_{0}^{1}\left(\frac{d^{2} \beta}{d Z^{2}}\right)^{2} d Z}} \\
C_{2}=-\frac{1 / 2 \int_{0}^{1} \frac{d^{2} m}{d Z^{2}} \beta^{2} d Z}{\sqrt{\int_{0}^{1} m^{2} \beta^{2} d Z \int_{0}^{1}\left(\frac{d^{2} \beta}{d Z^{2}}\right)^{2} d Z}} \\
C_{3}=\frac{\int_{0}^{1} m \frac{d \beta}{d Z}^{2} d Z}{\sqrt{\int_{0}^{1} m^{2} \beta^{2} d Z \int_{0}^{1}\left(\frac{d^{2} \beta}{d Z^{2}}\right)^{2} d Z}} \\
K^{2}=\pi^{2} \frac{\int_{0}^{1} \frac{d \beta}{d Z}{ }^{2} d Z}{\int_{0}^{1}\left(\frac{d^{2} \beta}{d Z^{2}}\right)^{2} d Z}
\end{gathered}
$$

Substituting these constants into (3.2a) gives the closed form expression:

$$
\bar{M}=C_{1} \frac{\pi^{2} E I_{y}}{(K L)^{2}}\left[C_{2} g+C_{3} k+\sqrt{\left(C_{2} g+C_{3} k\right)^{2}+\frac{C_{W}}{I_{y}}\left(1+\frac{G J(K L)^{2}}{\pi^{2} E C_{W}}\right)}\right]
$$

The constants $C_{1}, C_{2}$, and $C_{3}$ depend only on the moment distribution and twist along the beam while the constant $K$ only depends on the twist. 


\subsection{LTB Derivation by Solving Differential Equations}

This section follows the derivation by [31] starting from basic beam theory but with more current notation. Figure 3.1 shows a simply supported WF section in bending about its major axis by a moment $M_{0}=M_{x}$ with a small torsional rotation and lateral deflection. The x,y,z coordinates represent the global system and the x', y', z' coordinates represent the beam's local coordinate system. The deflection from the $\mathrm{x}$ and $\mathrm{y}$ axes is $-\mathrm{u}$ and $-\mathrm{v}$, respectively and twist along the beam is $\phi$. Deflection from major axis bending is calculated with the small angle assumption, shown in Equation 3.5.

Figure 3.1: WF in bending about major axis

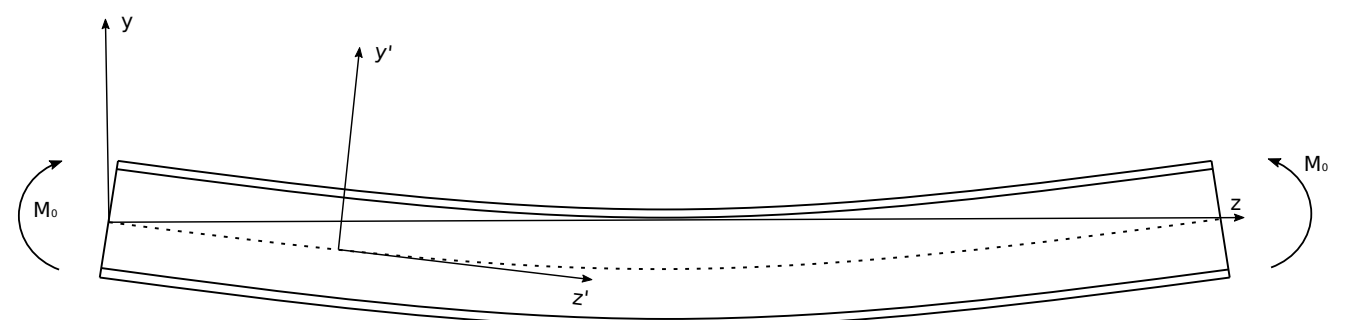

$$
E_{L} I_{x} \frac{d^{2} v}{d z^{2}}=M_{x}^{\prime}=M_{0} \cos \phi \approx M_{0}
$$

$E_{L}$ is used to emphasize that the major bending moment is resisted by the longitudinal tensile and compressive strains developed along the beam. A bending modulus of elasticity $E_{b}$, may be more appropriate in the case that there is significant difference between the tensile and compressive $E_{L}$. Likewise, the bending in the lateral direction is given by,

$$
E_{L} I_{y} \frac{d^{2} u}{d z^{2}}=M_{y}^{\prime}=M_{0} \sin \phi \approx M_{0} \phi
$$

Next, the governing equation for torsion is needed. For sections with flanges, there are two types of torsion: St. Venant torsion and warping torsion, shown in Equation 3.7 from left to right. St. Venant torsion is associated with the whole cross-section twisting uniformly and is also referred to 
as pure torsion. In contrast, warping torsion creates non-uniform stresses through lateral bending of the flanges in opposite directions. The warping component of the torsion equation also contains $E_{L}$ because the warping resistance is related to lateral bending of the flanges. Although warping occurs when the flanges are bending laterally in opposite directions, these bending stresses are resisted by tensile and compressive stresses developed along the length of the flanges.

$$
M_{z}^{\prime}=G J \frac{d \phi}{d z}-E_{L} C_{w} \frac{d^{3} \phi}{d z^{3}}
$$

From Figure 3.2, the torsional moment acting on the beam is proportional to $M_{0}$ by the lateral slope $d u / d z$

Figure 3.2: Lateral bending of WF due to major axis moment

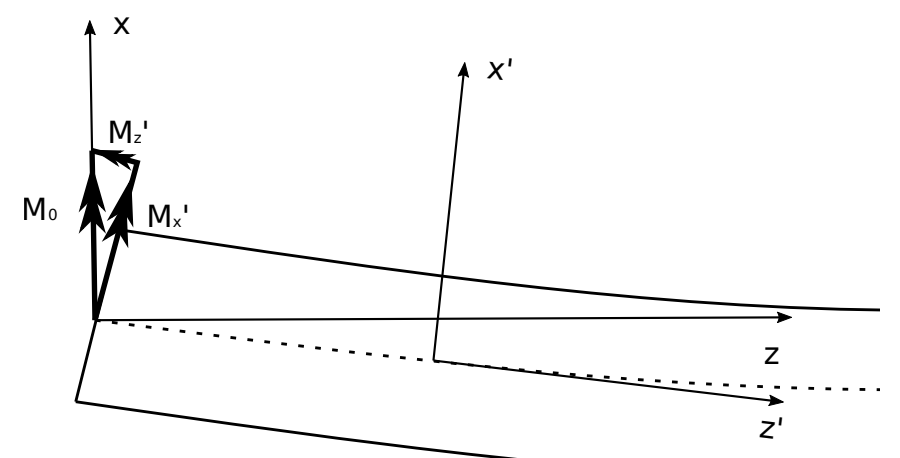

$$
M_{z}^{\prime}=-\frac{d u}{d z} M_{0}
$$

Combining Equations 3.7 and 3.8 gives the torsional differential equation,

$$
-\frac{d u}{d z} M_{0}=G J \frac{d \phi}{d z}-E_{L} C_{w} \frac{d^{3} \phi}{d z^{3}}
$$

Differentiating Equation 3.9 and combining with Equation 3.6 gives the 4th order differential equation for twist, 


$$
E_{L} C_{w} \frac{d^{4} \phi}{d z^{4}}-G J \frac{d^{2} \phi}{d z^{2}}-\frac{M_{0}^{2} \phi}{E_{L} I_{y}}=0 .
$$

The solution to this differential has the form,

$$
\phi=A_{1} e^{n z}+A_{2} e^{-n z}+A_{3} \cos (q z)+A_{4} \sin (q z)
$$

For a simply supported and torsionally free beam, the following boundary conditions apply.

$$
\begin{aligned}
& \phi(z=0)=\phi(z=L)=0 \\
& \left.\frac{d^{2} \phi}{d z^{2}}\right|_{z=0}=\left.\frac{d^{2} \phi}{d z^{2}}\right|_{z=L}=0
\end{aligned}
$$

Applying these $\mathrm{BCs}$ results in

$$
\sin (q L)=0
$$

where the lowest mode that satisfies is $q=\pi / L$. Applying the definition for $q$ results in

$$
-q+\sqrt{q^{2}+n^{2}}=\frac{\pi^{2}}{L^{2}}
$$

Solving this for a torsionally free and simply supported beam gives the classic closed form expression for the critical lateral-torsional buckling moment. It is emphasized that the parallel modulus of elasticity should be used for orthotropic beams bending.

$$
M_{c r}=\frac{C_{b} \pi}{L} \sqrt{E_{L} I_{y} G J+\frac{\pi E_{L}^{2}}{L} I_{y} C_{w}}
$$




\section{Procedure}

For the parametric study, orthotropic beams were modeled and analyzed with the commercial finite element analysis software ABAQUS. To analyze the entire parameter space, Python scripts were written to automate the process. These scripts created the geometry and applied the orthotropic material properties, loads, and boundary conditions. The scripts also specified the type of analysis (Eigen vs Riks) and if/how any perturbations. Because of the size of the parameter space, each Eigen shape also had to be analyzed for congruence with LTB. This was done by assuming a shape function for the boundary conditions. Requiring a strong agreement to the shape function also allowed for the disqualification of any local buckling modes.

\subsection{Eigen Analysis}

While the parametric study was automated in ABAQUS, this section describes the Eigen analysis procedure if performed manually through the user interface Complete ABAQUS Environment (CAE). To begin modeling a structure through the CAE interface, the modeling space as well as the type of elements are specified. Since lateral-torsional buckling is inherently a 3D phenomenon, a 3D space is chosen. Deformable elements are also required as deformation and strains are important to LTB failure. Two dimensional shell elements are used through this Report because they are much less computationally intensive than solid elements while still being accurate for this analysis. The beam will be created by extruding a sketched profile, so 'Extrusion' is also selected as shown in Figure 4.1.

The next step is to draw the profile of the beams. An example of both a WF and C beam are shown in Figure: 4.2. Both of these profiles will have an overall height of 3" once their flange thicknesses are taken into account. For the WF beam, the horizontal lines drawn represent the interior side of the flanges. However for the $\mathrm{C}$ beam, the horizontal lines indicate the exterior side of the flanges. This is explicitly shown in Figure 4.4. Once the profiles are described, specifying the extrusion depth is the last physical dimension to input. 
Figure 4.1: Selecting a deformable 3D body composed of shell elements

\begin{tabular}{|c|c|c|}
\hline \multicolumn{3}{|l|}{$\Leftrightarrow$ Create Part } \\
\hline \multicolumn{3}{|l|}{ Name: $\mid-1$} \\
\hline \multicolumn{3}{|c|}{ Modeling Space } \\
\hline \multicolumn{3}{|c|}{ ( ) 3D $\bigcirc 2 \mathrm{D}$ Planar $\bigcirc$ Axisymmetric } \\
\hline \multicolumn{2}{|l|}{ Type } & Options \\
\hline \multicolumn{2}{|c|}{ O Deformable } & \\
\hline \multicolumn{2}{|c|}{ Discrete rigid } & None available \\
\hline \multicolumn{2}{|c|}{ Analytical rigid } & \\
\hline \multicolumn{3}{|c|}{ O Eulerian } \\
\hline \multicolumn{3}{|l|}{ Base Feature } \\
\hline Shape & \multicolumn{2}{|l|}{ Type } \\
\hline O Solid & \multicolumn{2}{|c|}{ Planar } \\
\hline O Shell & \multicolumn{2}{|c|}{ Extrusion } \\
\hline Wire & \multicolumn{2}{|c|}{ Revolution } \\
\hline$O$ Point & \multicolumn{2}{|c|}{ Sweep } \\
\hline \multicolumn{3}{|c|}{ Approximate size: 200} \\
\hline Continue... & & Cancel \\
\hline
\end{tabular}


Figure 4.2: Sketches of beam profiles and specification of beam length

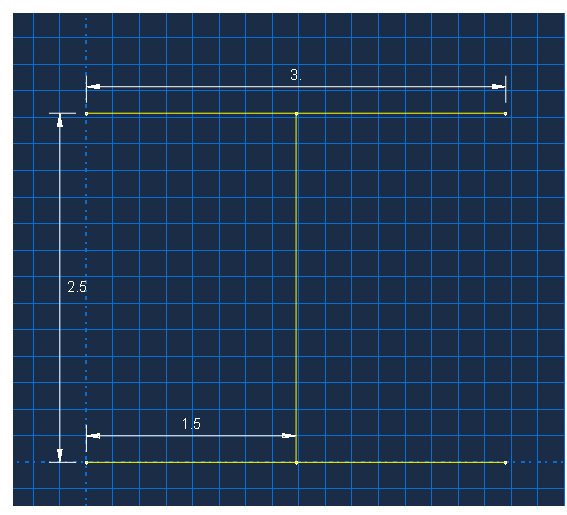

(a) WF Profile

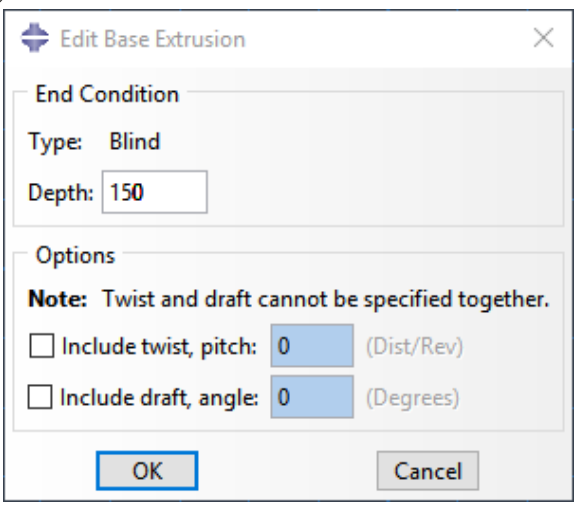

(c) Specifying beam length

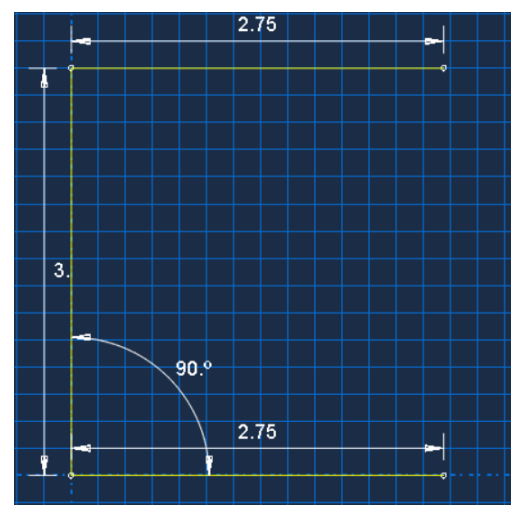

(b) C Profile

Note: Both sections shown have the same height of 3" but the lines drawn represent the inside of the flanges for the WF and outside for the $\mathrm{C}$ profile. 
Figure 4.3: Defining and assigning material properties to a WF beam

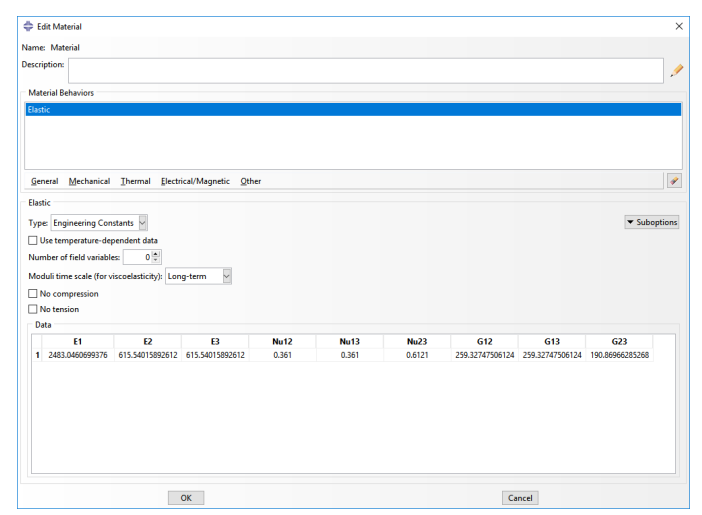

(a) Define Orthotropic Beam Characteristics

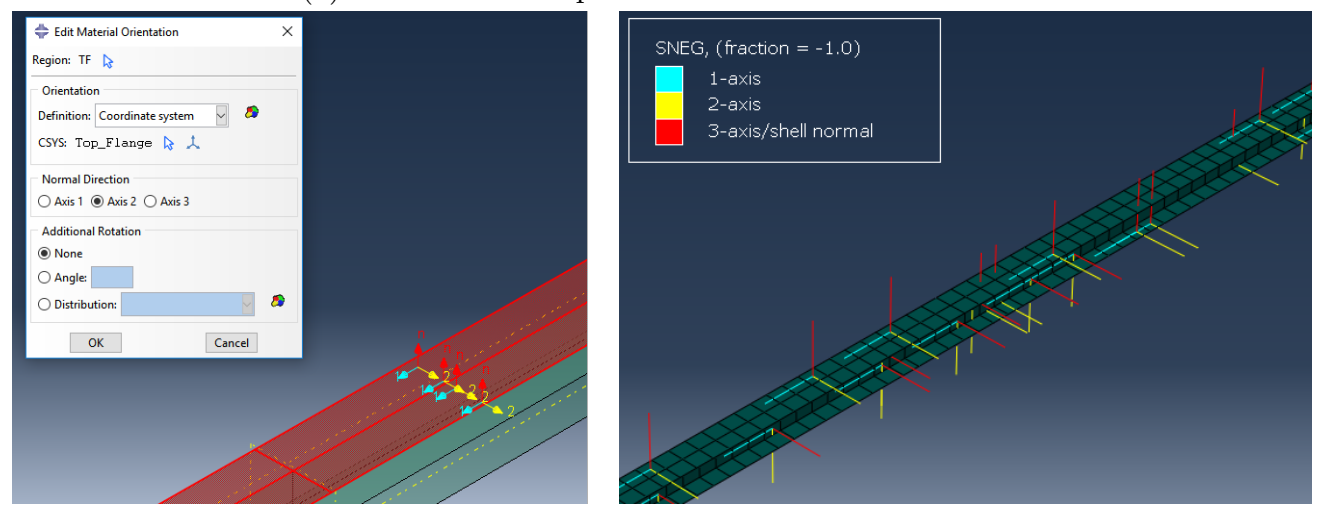

(b) Assigning material orientation with 1- (c) Confirming orientation is applied corAxis parallel to beam. rectly to entire beam

Note: The 1-Axis is fiber direction and 2/3-Axes are transverse directions.

Next, the moduli of elasticity and Poisson's ratios are specified through the material properties dialog. This is done by choosing an elastic material and inputting the 'Engineering Constants' which consists of the moduli of elasticity $\left(E_{1}, E_{2}\right.$, and $\left.E_{3}\right)$, Poisson's ratios $\left(v_{12}, v_{13}\right.$,and $\left.v_{23}\right)$, and the moduli of rigidity $\left(G_{12}, G_{13}\right.$, and $\left.G_{23}\right)$. The material directions are as follows: the 1-Axis is the longitudinal direction, the 3 -axis is perpendicular to the shell element, and the 2 -axis can be found by right hand rule. Since pultruded FRP members are orthotropic, $E_{2}=E_{3}, v_{12}=v_{13}$, and $G_{12}=G_{13}$. To ensure the proper direction of the material properties, a material orientation is assigned to each part of the virtual member. The directions can be visually confirmed as shown in 
Figure 4.3(c).

With the material specified, a section assignment can be made. In this step, the material is assumed to be homogeneous, i.e. the fibers and resin are uniformly distributed through the flanges and web. In reality, the flanges may be different from the web and both may be non-uniform across their widths. Through the dialog in Fig. 4.4(a), the shell thickness is specified and a defined material is selected. When assigning the section, a shell offset can be applied which allows for precise joining of sections. The shell offset defines which part of the shell that the drawn section represents (bottom surface, middle surface, or middle of the shell). In Figure 4.4(b), the highlighted section is defined as the bottom of the top flange on an WF beam. Figures 4.4(c) and 4.4(d) show the shell offset definitions used for WF and $\mathrm{C}$ beams, respectively. 
Figure 4.4: Defining and Assigning Section Properties

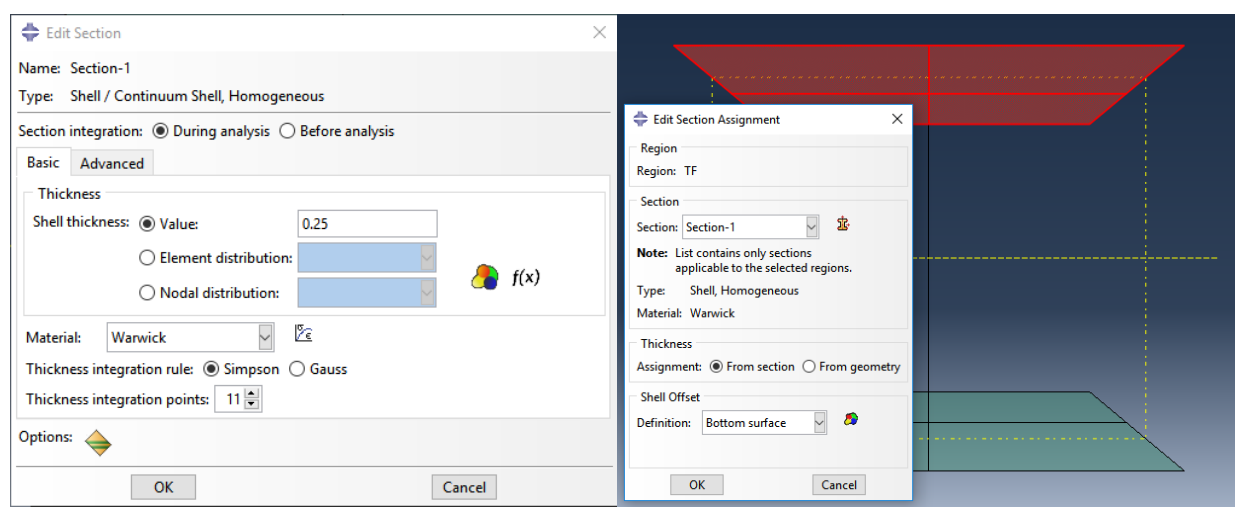

(a) Defining a section property to be ap- (b) Assigning the section property to the plied to the beam. top flange of a WF beam. Note that this section of the beam is offset so as to not

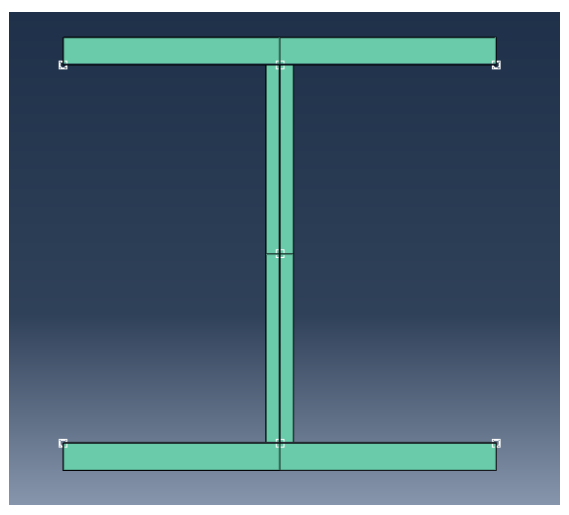

(c) WF profile showing nodes offset. overlap with other parts of the beam.

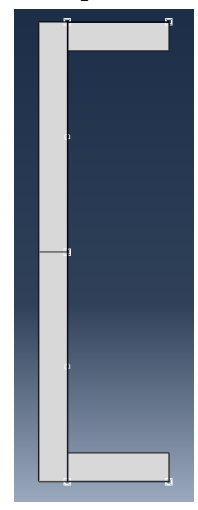

(d) C profile showing nodes offset.

Before loads and boundary conditions can be applied, the type of analysis/step must be chosen. Two analysis types are performed in this Report, an Eigen analysis and a Riks analysis. The Eigen analysis solves the linear system shown in Equation 4.1 [27]. A Riks analysis applies loads incrementally instead of solving directly for a single Eigen value. For each step in a Riks analysis, the displacement and stiffness matrices must be updated. This is computationally intensive but is more representative of a beam buckling. That is, as a beam is loaded it undergoes deformation. If the deformation is significant, the beam may respond differently to further loading. This is referred to as a geometric non-linearity. The Riks analysis is discussed more in Section 4.2. The Eigen 
analyses allowed for a larger parameter space to be studied and is the focus of this Report. A comparison between the two analyses is also performed. The step creation dialog for both analyses is shown in Figure 4.5.

$$
\left(K_{0}^{N M}+\lambda_{i} K_{\Delta}^{N M}\right) v_{i}^{M}=0
$$

where,

$$
\begin{aligned}
K_{0}^{N M} & =\text { Stiffness matrix of base state } \\
K_{\Delta}^{N M} & =\text { Load stiffness matrix due to applied load } \\
\lambda_{i} & =\text { Eigen values } \\
v_{i}^{M} & =\text { Buckling mode shape } \\
M a n d N & =\text { Degrees of freedom of the model } \\
i & =\text { Buckling mode number }
\end{aligned}
$$

Figure 4.5: Specifying the analysis type to perform

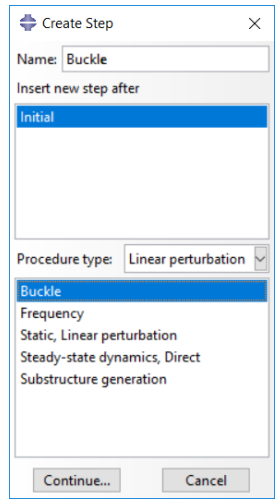

(a) Eigen

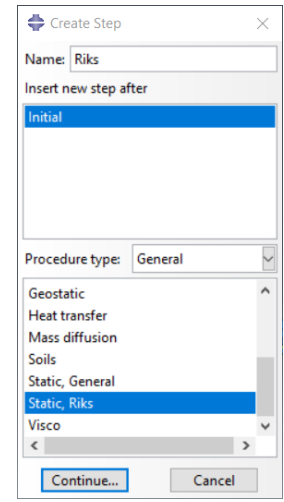

(b) Riks

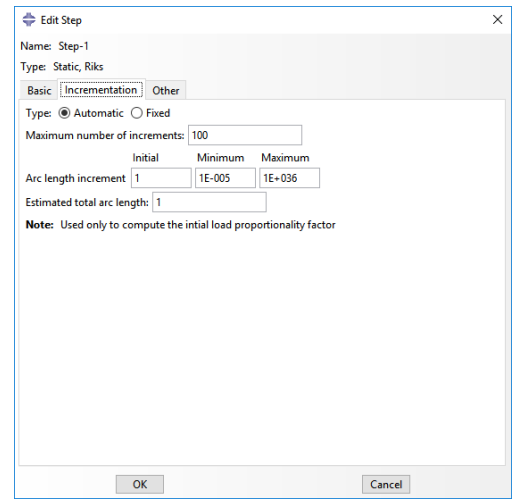

(c) Parameters for Riks analysis

Applying a point load in ABAQUS requires a node present in the location desired. To ensure this, the simulated beams were partitioned so two edges would cross at this location. This is shown in Figure 4.6 for a load at the top of WF beam and at the centroid. After partitioning, a 
concentrated force in the vertical direction could be specified where desired. A buckling analysis in ABAQUS determines Eigen values that are normalized to the base load specified, i.e. if a base load of $10 \mathrm{~K}$ is applied and an Eigenvalue of 5 is returned, then the actual buckling load is $50 \mathrm{~K}$. For this analysis, there was no need to use a non-unity value for the base load. Figure 4.8(c) shows a unity load applied to a WF beam at mid span and at the centroid. Point loads were applied at five different heights, $T F,(0.75,0.5,0.25) H$, and $B F$. The height of the loads applied to the flanges of the wide flange beams, $\mathrm{TF}$ and $\mathrm{BF}$, were not equal to $\mathrm{H}$ and 0 , respectively. This was due to the offsets used for the reference surface of the flanges.

Figure 4.6: Partitioning beams so that a point load can be applied in the desired location.

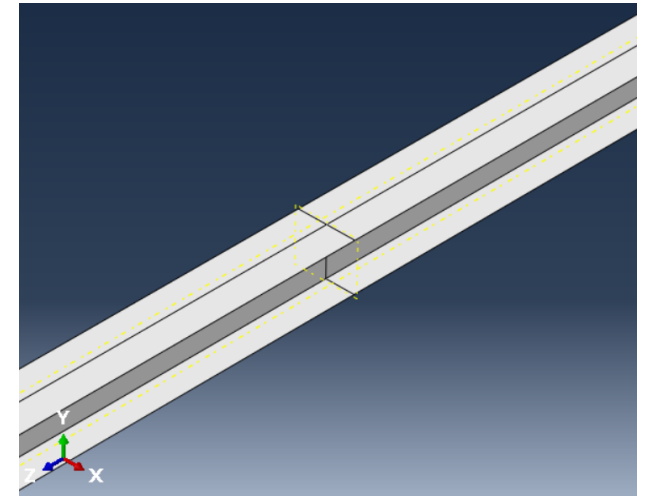

(a)

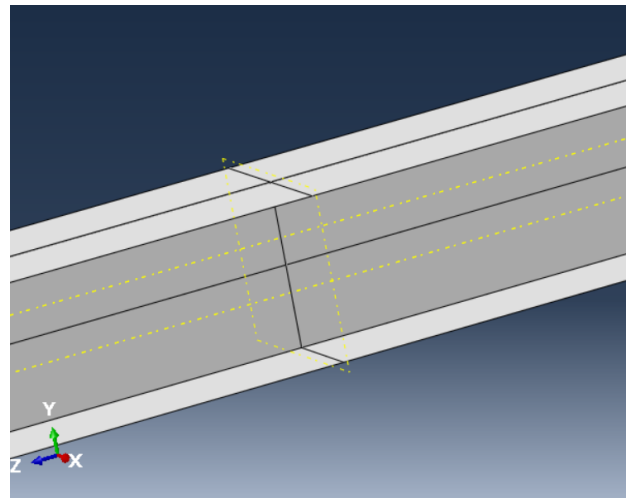

(b) 
Figure 4.7: Stiffeners are applied to the web of channel beams to apply loads and supports at the shear center

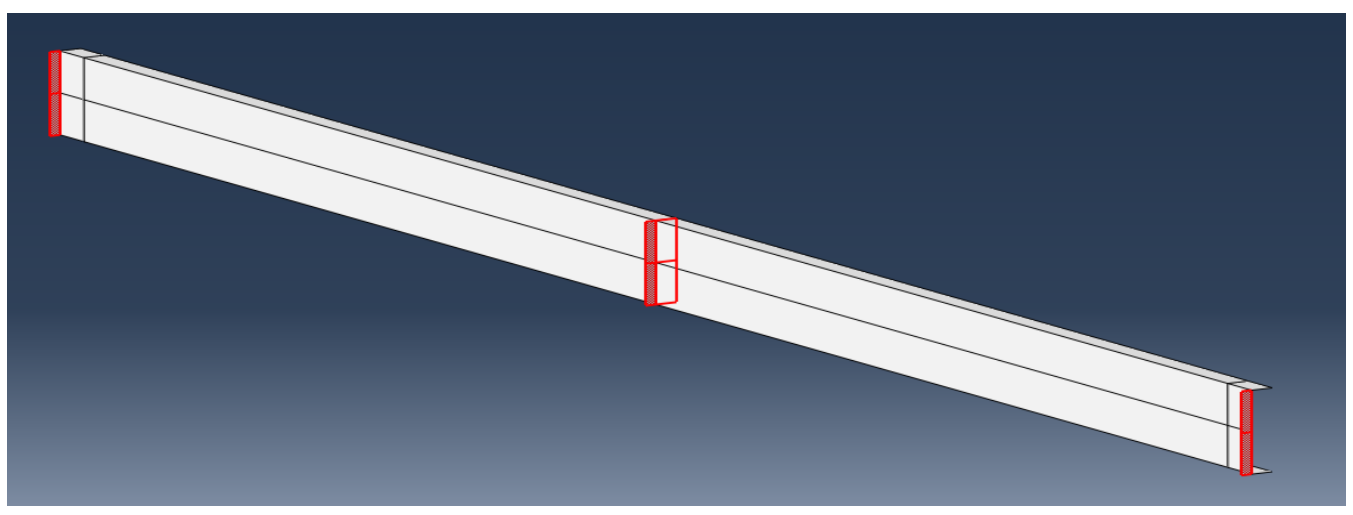

(a) Stiffeners at supports and midspan

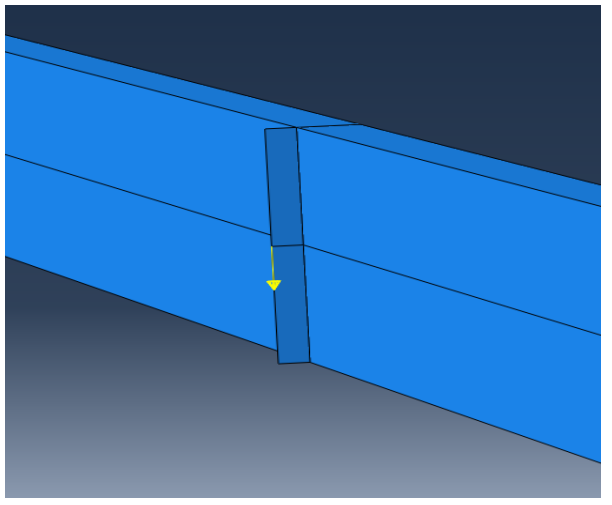

(b) Point load application at shear center of channel

Because the shear center to channels is not on the cross-section, applying concentric loads is a challenge. Similar to experimental setups, an attachment is added so the load may be applied in the correct location. The stiffener applied at mid-span also goes through the web and supports the flanges. This extra web and flange support at mid-span also helped prevent local buckling and provided more consistent results for determining when a beam exhibited LTB.

In addition to 3-point loading, a pure bending load and a uniformly distributed load were also used to study LTB. The pure bending loading was accomplished by applying point loads on the ends of the flanges in the longitudinal direction. Three nodes were used on both ends of each flange as shown in $4.8(\mathrm{~d})$. The node in the center had twice the load as those on the corners of the 
flanges. Because of the offset of the reference surfaces for the flanges, the resulting moments for wide flange and channel sections were $\left.M=2 \dot{P(H}-2 t_{f}\right)$ and $M=2 P \dot{H}$, respectively. The uniformly distributed load, shown in Figure 4.8(e), was created with a body force. A body force is distributed over a volume so additional partitions had to be made. These partitions were centered around the three interior quarter points $(0.25,0.5,0.75) H$ and distributed through $10 \%$ of the height.

Figure 4.8: Selection and application of loads

\begin{tabular}{|c|c|c|}
\hline 늠 Create Load & & $x$ \\
\hline Name: FII & & \\
\hline Step: Buckle & 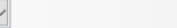 & \\
\hline Procedure: Static, Linea & jerturbation & \\
\hline Category & Types for Selected Step & \\
\hline () Mechanical & Concentrated force & |^ \\
\hline Thermal & Moment & \\
\hline Acoustic & Pressure & \\
\hline Fluid & Shell edge load & \\
\hline Flectricla & Surface traction & \\
\hline Electrical/Magnetic & Body force & \\
\hline Mass diffusion & Line load & \\
\hline Other & Gravity & \\
\hline & Pipe pressure & \\
\hline & Generalized plane strain & $v$ \\
\hline Continue... & & \\
\hline
\end{tabular}

(a) Load selection

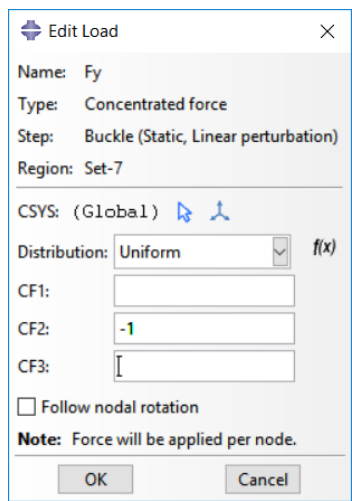

(b) Unit load

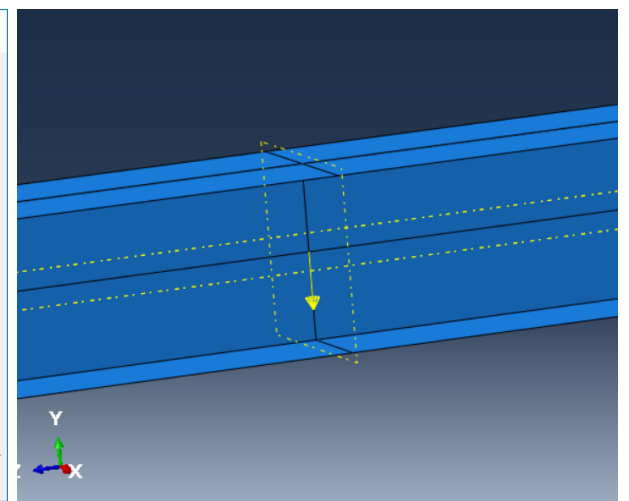

(c) 3 Point load

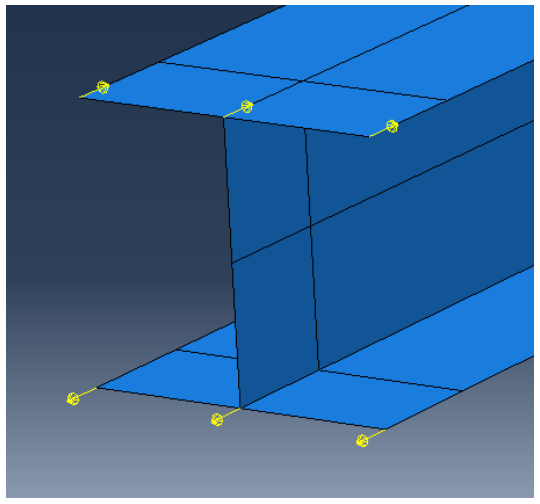

(d) Pure bending load

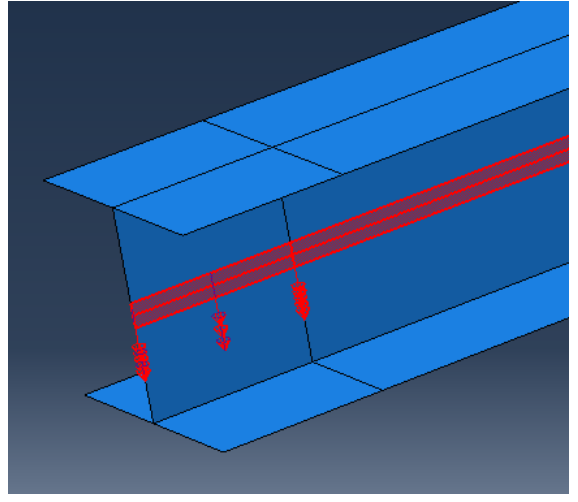

(e) Uniformly distributed load

Note: In Pure bending load case (d), loads in center have twice the value as the loads on the end for uniform loading along the flange.

Next, one of three sets of the boundary conditions were applied, see Figure 4.9. The first, BC1, was a pinned setup with the member supported vertically at the shear center. Here, the web was restrained laterally to prevent twisting but not warping. The second condition, $\mathrm{BC} 2$, has the minor 
axis fixed. Here, the entire cross-section in two places was restrained laterally on each end of the beam. For wide flange and channel profiles, the two lateral supports had a separation equal to $2 \%$ of the beam's length. For rectangular sections, a $4 \%$ separation was required to ensure adequate fixity. $\mathrm{BC} 1$ and $\mathrm{BC} 2$ both had a single longitudinal support at mid-height to prevent full body motion. The third boundary condition, BC3, provided fixity for both minor and major flexural axes. For wide flange and channel sections, this was accomplished by restricting longitudinal displacement of the flanges. Rectangular sections had longitudinal restraints along the full height of the beam. While the longitudinal support of the flanges provided a significant degree of lateral fixity for WF and C profiles, rectangular profiles needed more support. For consistency, the same lateral supports from $\mathrm{BC} 2$ were applied to $\mathrm{BC} 3$ for all three profiles. 
Figure 4.9: Applying boundary conditions

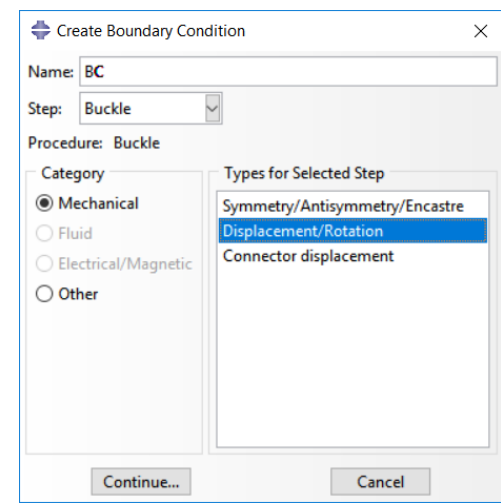

(a) Boundary condition selection

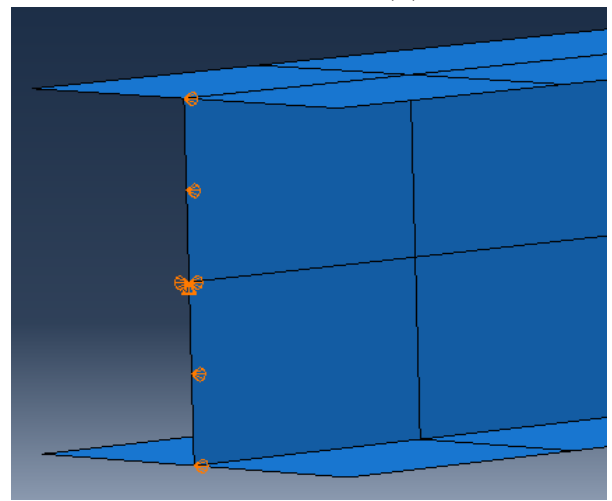

(b) $\mathrm{BC} 1$

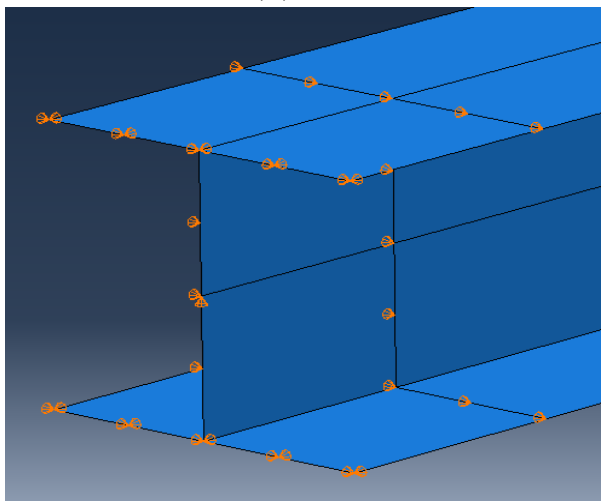

(d) BC3

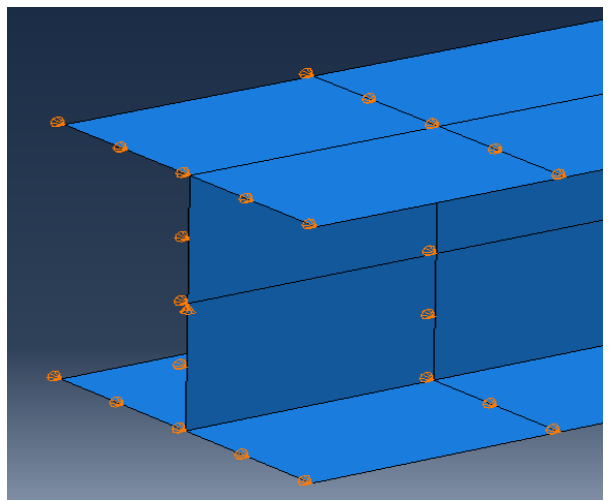

(c) $\mathrm{BC} 2$

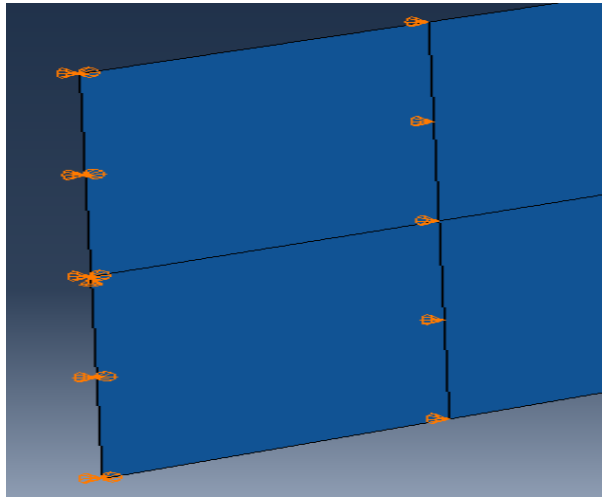

(e) BC3 on a rectangular beam

Next was to discretize the beam so that ABAQUS could numerically solve the defined problem. First, seeds were applied to the beam followed by the mesh, see Figure 4.10. Increasing the number of 
seeds/elements will result in a more accurate result at the cost of computation time. A convergence test was done to find an acceptable range of required nodes. This is shown in Figure 5.1. In order to automate this process, a bisection method was scripted to ensure the number of nodes used were in the range of 600 to 800 . After the seeds are applied, a mesh is applied on the seeds, Figure 4.10 (b).

Figure 4.10: Applying seeds and mesh

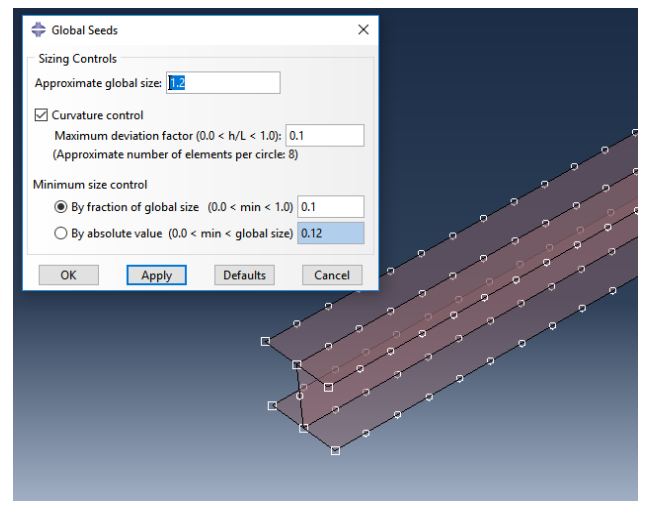

(a)

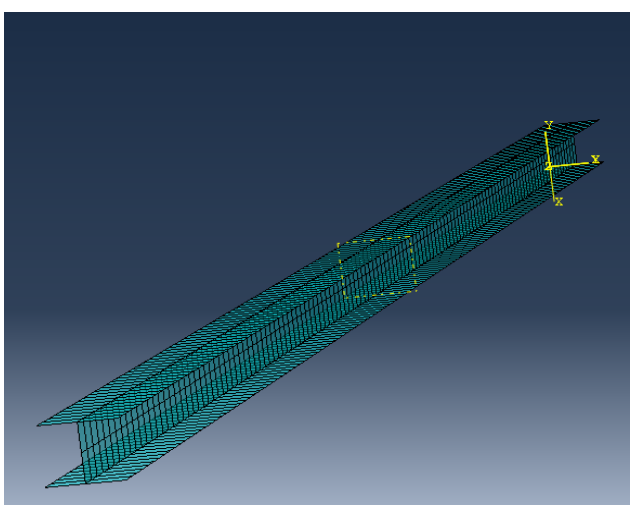

(b)

The last step is to create and submit a job. The dialog for job creation is shown in Figure 4.11. Through this dialog, different computational parameters can be specified, such as how many processors to use, how much memory, when to start the run, and more. These parameters don't affect the results of the simulation. Creating a job writes all the data for the model, materials, and loading necessary for an analysis into a inp file. 
Figure 4.11: Submitting analysis job

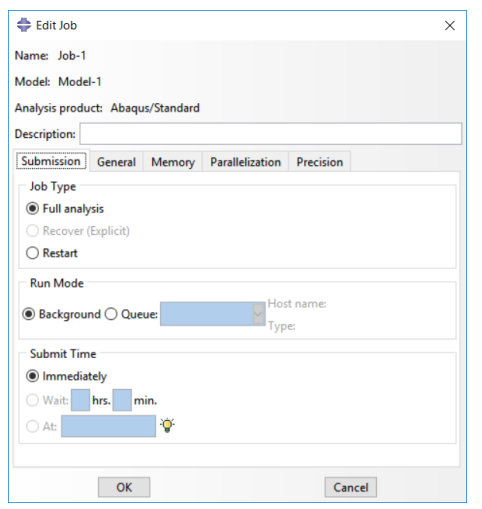

After the job is submitted and completed, the Eigen value and Eigen shapes are returned. However, not all beams will undergo a pure LTB failure without localized distortions. For the beams that do, the LTB mode must be identified from the other buckling failures in the set of returned Eigen modes. Individually, an Eigen shape can be visually inspected for verification of LTB failure. To do this systematically for all the beams modeled, the twist of the beam through the span at mid-height was compared to two different shape functions, shown below. The first equation applies to the simple torsion condition of $\mathrm{BC} 1$ and the second was used for fixed torsion in $\mathrm{BC} 2$ and BC3. The twist of the beam for each Eigen shape was fit to the applicable shape function and the standard error was calculated. If the standard error was less than 0.008 and the amplitude and frequency remained acceptable then the Eigen mode was classified as LTB.

$$
\begin{aligned}
& \beta=A \sin (\pi Z) \\
& \beta=A \sin ^{2}(\pi Z)
\end{aligned}
$$


Figure 4.12: Example of LTB results from Eigen analysis

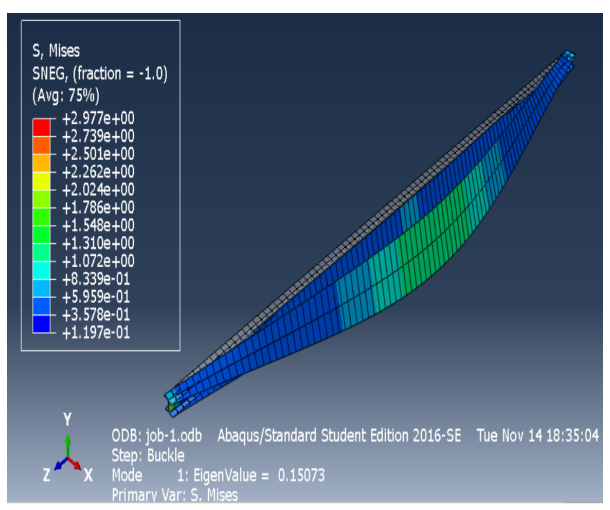


Figure 4.13: Determination of LTB Eigen modes

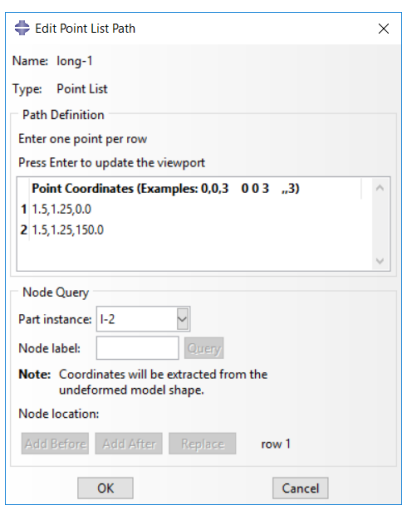

(a) Defining path

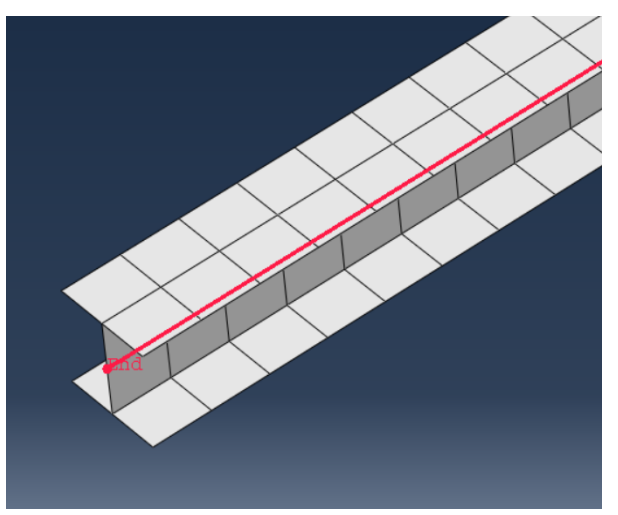

(b) Visualization of path on WF

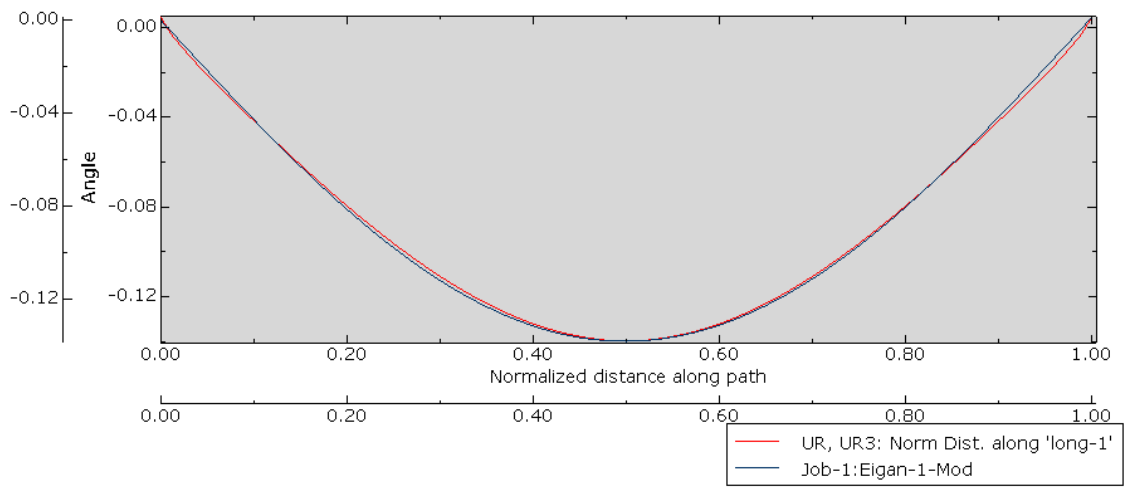

(c) Comparing twist to Eigen shape

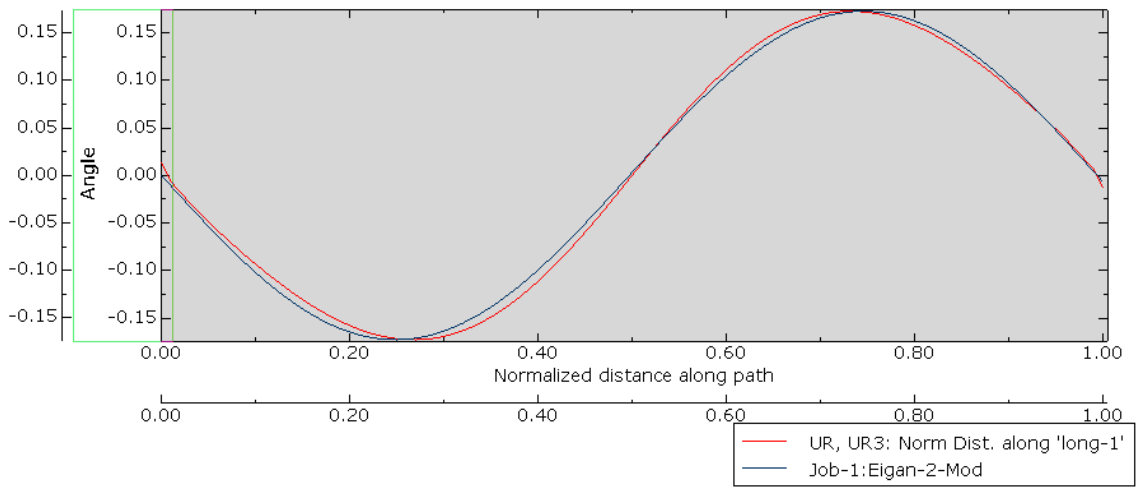

(d) Example of non-LTB mode 


\subsection{Riks Analysis}

In addition to a linear Eigen analyses, an arc length non-linear method was employed to help resolve any geometric nonlinearities that may arise during the buckling process. The modified Riks method is a quasi-static incremental loading of beams. For each incremental load, the beam is allowed to deform. With this change in geometry, there is also a change in the stiffness matrix. The program will simultaneously alter the loading and geometry/stiffness such that the beam remains in equilibrium. As this process continues, a compounding effect may arise if the stiffness of the model continues to decrease creating larger and larger deformations. This is known as geometric nonlinearity. With the large deflections associated with a buckling failure, the impact of geometric nonlinearity can be significant. Due to the incremental loading of the beam, this analysis is much more computationally intensive than the simpler Eigen analysis. Because of this, Riks analyses were not the main focus of this work but were used for benchmarking against the linear Eigen analysis.

Figure 4.14: Initial perturbation for Riks analysis

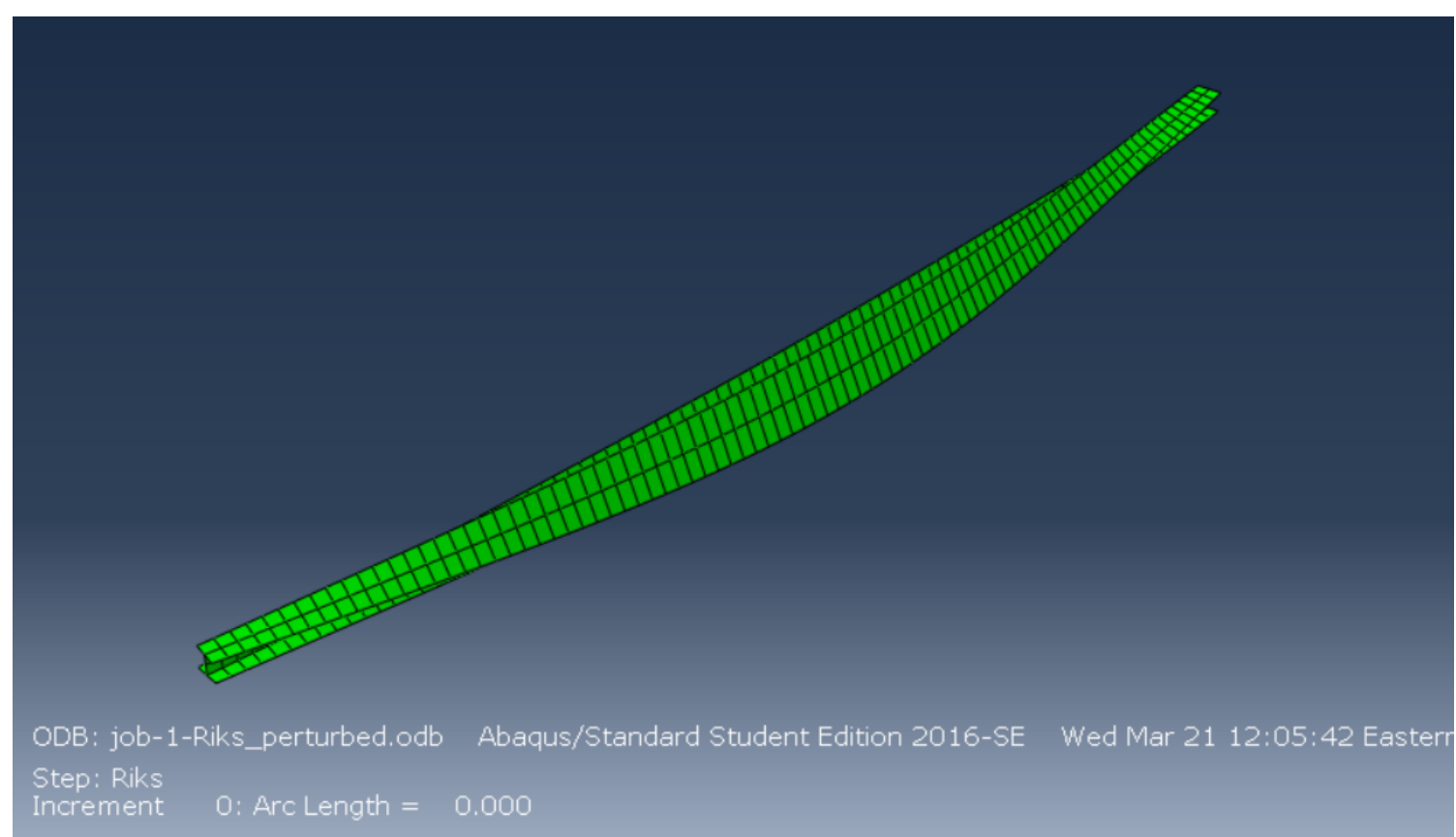

Note: Initial perturbation shown with 10x deformation scale 
Much of the procedure for creating the Riks analysis is the same as for the Eigen value analysis. Figures 4.5(b) and 4.5(c) show the selection of the 'Static Riks' step from the 'General Procedure' type and some typical parameters used for the analysis. While the incremental loading of the Riks analysis accounts for nonlinearity step to step, the Nlgeom option in the 'Basic' tab of Figure 4.5(c) can account for geometric nonlinearity that occurs from large deformations within a single step. This can be important as loading approaches the critical buckling value. Nlgeom was used for the Riks analyses in this Report.

The main difference in procedure between the two analyses is including imperfections in the model for the Riks analysis. In a perfect system where a beam has no imperfections and the loading has no eccentricity, there will be no buckling, only simple beam bending. Computationally, this perfect setup can occur easily for beams with symmetric cross-sections and fiber layups. To aid in the initiation of buckling, imperfections were added to the system. Figure 4.15 shows the effect of imperfections on buckling. In this study, the lowest LTB mode from the Eigen analysis was used to perturb the base state of the Riks analysis. If a LTB mode wasn't detected, the first Eigen shape was used as the perturbation.

First the Eigen analysis model was copied with a new Riks step created. Then initial deformations were applied through the input file after creating a job. In the input file, either the *IMPERFECTION keyword can be specified with links to the output file from the Eigen analysis, or the coordinates of the nodes can be perturbed directly. In this work, the keyword was inserted and a perturbation fraction of 0.01 was used. An exaggerated case of this is shown Figure 4.14 where the model was deformed by a factor of 10 times the lowest LTB Eigen shape. 
Figure 4.15: Effect of perturbation on LTB response

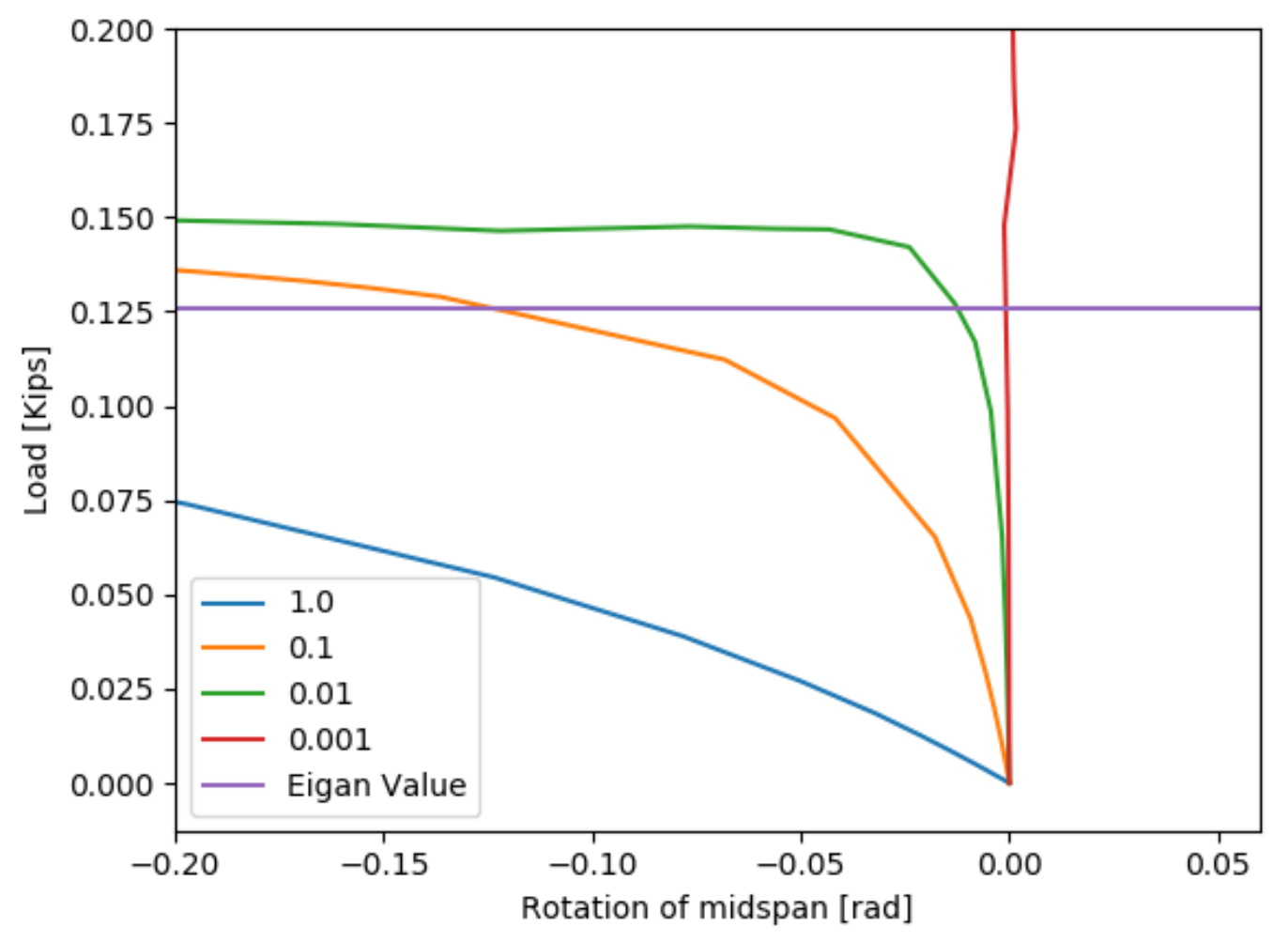

Note: Applied perturbation is the displacements of the LTB mode from the Eigen analysis.

\subsection{Material Definition}

The material properties used for the parametric study are shown in Table 4.1. These properties were obtained by the analysis tools from cadec-online.com by Barbero for designing FRP materials. They were modeled after glass-poly and carbon-poly materials with fiber volume fractions of $\sim 20 \%$ and $\sim 65 \%$. Although they do not represent any specific physical samples, they were chosen to create a wide parameter range for the study. This online tool has since gone offline and is no longer available but the methods used are from [4]. 
Table 4.1: Material properties used for the parametric study

\begin{tabular}{cccccc}
\hline$E_{1}[\mathrm{GPa}]$ & $E_{2}[\mathrm{GPa}]$ & $G_{12}[\mathrm{GPa}]$ & $G_{23}[\mathrm{GPa}]$ & $\nu_{12}$ & $\nu_{23}$ \\
\hline 17.12 & 4.24 & 1.79 & 1.32 & 0.361 & 0.612 \\
47.99 & 12.21 & 4.91 & 4.00 & 0.324 & 0.524 \\
48.72 & 4.25 & 1.64 & 1.29 & 0.351 & 0.649 \\
150.69 & 10.97 & 3.31 & 3.51 & 0.295 & 0.563 \\
\hline
\end{tabular}

\section{Model Validation}

A convergence test was performed to determine an adequate mesh size to provide accuracy at a reasonable computational cost. This was only done for the tallest and longest WF beam in this study which would be the most affected by an unrefined mesh. This was a 12" deep WF beam with a length of $600 "$. The results of the convergence test, shown in Figure 5.1, show acceptable precision above 400 nodes, with the range 600 to 800 used in this study.

Figure 5.1: Convergence of critical load as node mesh is refined.

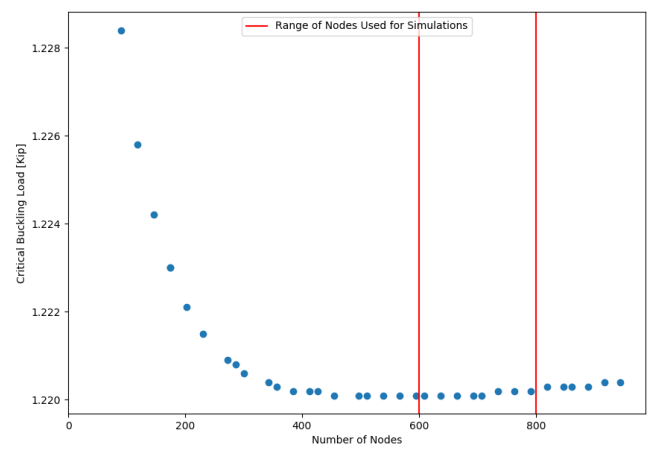

Another test to validate the FEA loading and boundary condition setup is to look at the displacement of the beam under loading. The max deflection and displacement curves indicate if the boundary conditions are working as intended. This test was performed with a simply supported orthotropic beam that is 3" deep and 105" long with 3 Point loading, shown in Figure 5.2. Due to the relatively weak shear modulus of FRP beams, shear deformation is important for even slender beams. The figure shows that Timoshenko beam theory matches much better than Euler beam 
theory, $2.6 \%$ vs $28 \%$ error respectively.

Figure 5.2: FEA deflection of 3" deep by 105" long orthotropic FRP beam compared to Euler and Timoshenko beam theories.

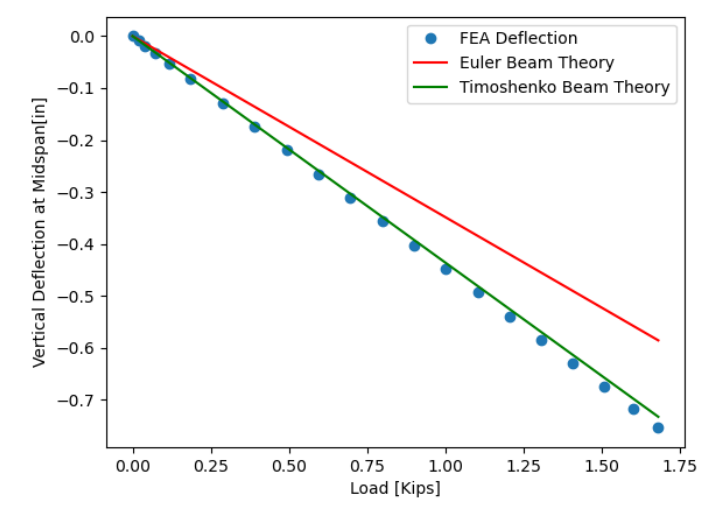

\section{Analysis}

\subsection{Longitudinal vs Transverse Modulus}

To test the recommendation of [12] to use the transverse elastic modulus for LTB prediction, a small set of runs were performed where $E_{T}$ was varied by factors from $1 / 2$ to 5 from original material property, row one of Table 4.1. The results are shown in the figure below where $E_{T}$ varies from 308 to $3080 \mathrm{ksi}$ and $M_{\lambda}$ only changed by $2.3 \%$ compared to the critical load for the original property.

While it is easy to vary only the transverse modulus for a FEA, the material properties are linked in the physical world. As reported by [7], $E_{T}$ for pultruded GFRP may be approximated by $E_{L} / 2.45$. Thus, the critical bending moment may be roughly proportional to $E_{T}$ for GFRP composite beams. However, the FEA performed in this work does not indicate that it is a mechanism for LTB. 
Figure 6.1: Effect of transverse modulus on $M_{\lambda}$

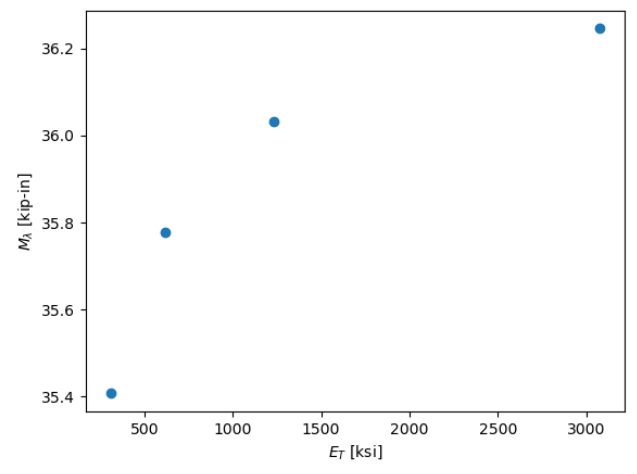

\subsection{Asymmetric Longitudinal Response on LTB}

Just as FRP materials have different physical responses for stresses in different directions, they also exhibit different responses for compressive vs tensile stresses. Different resin, fiber type, and fiber volume combinations will all affect the degree to which the compressive and tensile elastic moduli deviate from each other. However, the longitudinal moduli for GFRP are often assumed to be similar enough to use only the tensile modulus. This assumption may introduce unnecessary errors when studying LTB with GFRP composites and could create unconservative designs for more asymmetric composites. Khan et al. [14] did compression and tension testing on GFRP and CFRP rods. Within their small sample $(n=3)$, they found the GFRP and CFRP rods had a modulus ratios $n=E_{c} / E_{t}$ of 0.75 and 0.53 , respectively. Conversely, Yu et al. [35] measured a significantly higher than unity modulus ratio of $n=1.95$. In 2019, Khorramian et al. proposed a new test for determining compressive characteristics of GFRP bars and did a series of compression tests. The measured compression modulus was found to be close to the manufacturers reported tensile elastic modulus but a measured tensile modulus was not reported. The modulus ratio ranged from 0.97 to 1.20 with an average of 1.04 . Using a measured tensile modulus would have likely lowered this ratio.

Using shell elements over beam elements allows for non-uniform designs within the cross-section. To test the effect of $E_{L_{c}}$ deviating from $E_{L_{t}}$ a WF beam was modeled with two different materials 
as shown in 6.2(a). The material properties applied are from Table 4.1, row 4 . The $E_{x}$ was modified to compare $E_{L_{c}}$ and $E_{L_{t}}$ while all the other properties were held constant. The results from this are shown in Figure 6.2(b). As to be expected, lateral-torsional buckling is controlled by $E_{L_{c}}$ while altering $E_{L_{t}}$ had minimal impact. Over a range of (0.5 to 1.5$) E_{t}, P_{\lambda}$ only changed by about $3 \%$. This variance can be explained by the shear center deviating from the center of gravity and causing the load to become non-concentric.

Figure 6.2: Effect of asymmetrical longitudinal elastic modulus on LTB capacity

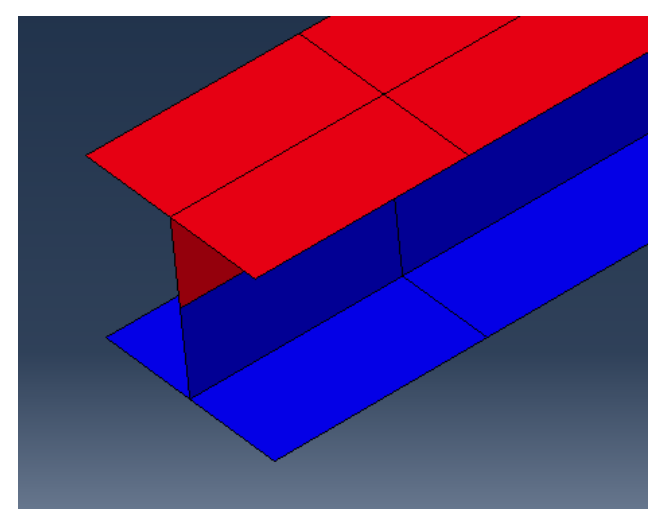

(a) WF beam with two $E_{L}$ assignments

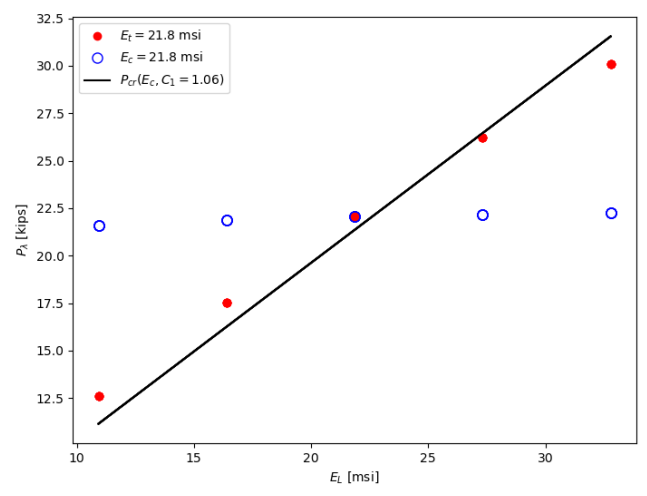

(b) $P_{\lambda}$ vs $E_{L_{t}}$ and $E_{L_{c}}$

\section{Wide Flange Beams}

\subsection{Introduction}

The purpose of this section is to analyze orthotropic wide flange beams with finite elements computationally for a variety of boundary and load conditions. These results will then be compared to past experimental works. The beams are being simulated through ABAQUS with Eigen and Riks analyses as described in Sections 4.1 and 4.2, respectively.

There are four unknown variables in the LTB formulation by [9] related to how a beam is supported and loaded: $C_{1}, C_{2}, C_{3}$, and $K$. The moment gradient factor, $C_{1}$ modifies the capacity of a beam loaded with non-uniform bending moments relative to the pure bending case, see Section 
3.1. The factor $C_{2}$ is important when the applied load height is above or below the shear center of the beam. Applying the load above the shear center lowers the beam's resistance to LTB and lowering the load height increases resistance. $C_{3}$ is only applicable for profiles asymmetric about the major axis and therefore not applicable to this work. The effective length factor, $K$, modifies the beam length for specific boundary conditions.

Sections 7.2-7.4 show the results from the parametric study of wide flange beams with the three different boundary conditions applied. Each section may have up to three types of load cases with up to four plots to describe the data. The first plot shows the fit of the classical model vs the critical Eigen moment, $M_{\lambda}$. The algorithm used for these fitting is LMFIT, ref(lmfit), a non-linear leastsquares minimization and curve fitting interface that utilizes and extends methods of scipy.optimize. For each of these plots, the parameters $C_{1}$ and $C_{2}$ are determined by fitting except for the pure bending load cases where $C_{2}$ is not applicable. These fit parameters are shown in the legend of the plot as well as their standard error. Because the range of $M_{\lambda}$ often spans more than one magnitude, the cost function used in fitting was based on the percent error from the model instead of absolute differences. Otherwise, the residuals from the larger critical moments would dominate the fitting process. These larger critical moments are also more likely to stray from the model due to effects such as shear deformation and local buckling.

The second plot in the grouping is a box and whisker plot to further describe how the classical model fit the data for the different $\mathrm{L} / \mathrm{H}$ ratios used. A missing box indicates that no beams at that $\mathrm{L} / \mathrm{H}$ ratio were classified as having a LTB failure. Usually this is due to local buckling distorting the LTB mode or precluding it all together. The local buckling causes the twist of the beam to deviate from the expected shape function and prevents classification of LTB. The beams that failed to meet these requirements were not used in any calculations or comparisons. As expected this was most common with the smaller ratios of $\mathrm{L} / \mathrm{H}$.

The third plot in the grouping is a logarithmic histogram plot of $M_{\lambda}$ which shows where the bulk of critical moments are occurring for each setup. Some groupings have a fourth plot that compares the critical Eigen moments to the pure bending load case. The median of these distributions, $C_{b}$, agrees well with the moment gradient factors for steel published in [9]. However, $C_{b}$ 
differs significantly from the fit value of $C_{1}$. This error is consistent for each load case and shape combination and would likely be reduced with a Riks analysis.

Table 7.1: Wide flange dimensions for parametric study

\begin{tabular}{cccc}
\hline$H$ & $b_{f}$ & $t_{w}$ & $t_{f}$ \\
\hline 3 & 3 & 0.25 & 0.25 \\
4 & 4 & 0.25 & 0.25 \\
6 & 6 & 0.25 & 0.25 \\
6 & 6 & 0.38 & 0.38 \\
8 & 8 & 0.38 & 0.38 \\
8 & 8 & 0.50 & 0.50 \\
10 & 10 & 0.38 & 0.38 \\
10 & 10 & 0.50 & 0.50 \\
12 & 12 & 0.50 & 0.50 \\
\hline
\end{tabular}

Note: Dimensions are taken from The Pultex ${ }^{\circledR}$ Pultrusion Design Manual [28]. All dimensions are in inches.

\subsection{Pinned}

This section shows the analysis results for pinned WF orthotropic beams. Figure 7.1 shows the vertical displacement, lateral displacement and twist through the span of a WF beam at mid-height. These displacements are generated by three separate point load cases applied at the centroid of the beam, a vertical, lateral, and torque. The resulting displacement curves are consistent with the boundary conditions for a pinned beam, shown below.

$$
\begin{aligned}
& v(0)=v(L)=\left.\frac{d^{2} v}{d z^{2}}\right|_{z=0}=\left.\frac{d^{2} v}{d z^{2}}\right|_{z=L}=0 \\
& u(0)=u(L)=\left.\frac{d^{2} u}{d z^{2}}\right|_{z=0}=\left.\frac{d^{2} u}{d z^{2}}\right|_{z=L}=0 \\
& \phi(0)=\phi(L)=\left.\frac{d^{2} \phi}{d z^{2}}\right|_{z=0}=\left.\frac{d^{2} \phi}{d z^{2}}\right|_{z=L}=0
\end{aligned}
$$


Figure 7.1: Validation of $\mathrm{BC} 1$ for WF shapes
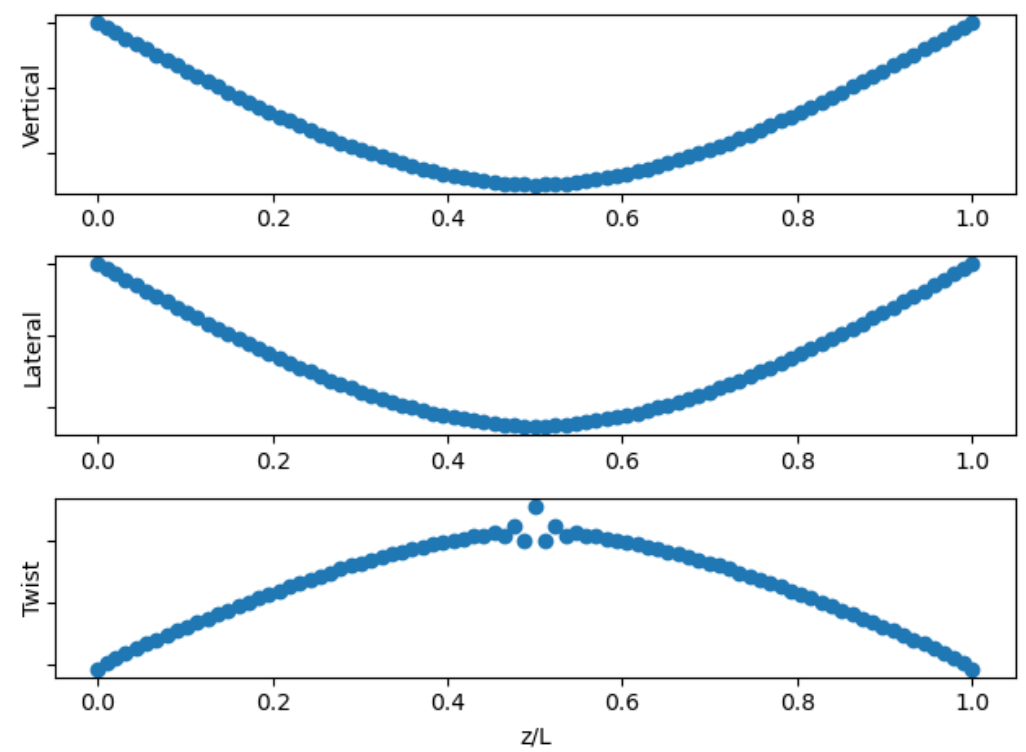

The pure bending condition is the simplest lateral-torsional buckling case to solve analytically, as shown in Section 3.2. To generate the pure bending condition, equal but opposite moments are applied on the beam's ends as shown in Figure 4.8(d). Six concentrated loads are used to create the moment on each end. The loads on the web have twice the load of flange ends. Because the reference surface of the flanges' shell elements are offset inwards, the loads are applied in the plane of the flanges' inner surface. Out of a parameter space of 180 beams analyzed under pure bending with BC1 boundary conditions, 98 displayed an LTB Eigen shape in the first 6 modes of linear analysis. The fitting for $C_{1}$ was $17 \%$ smaller than the expected 1.0, shown in Figure 7.2 
Figure 7.2: Results for wide flange section with $\mathrm{BC} 1$ and a pure bending loading condition

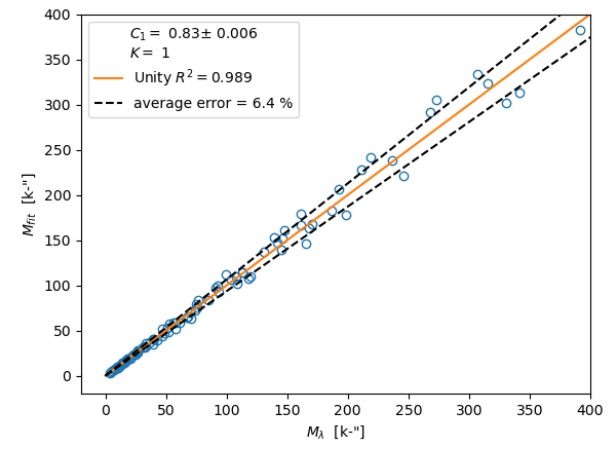

(a) Classical model vs. FEA critical moments

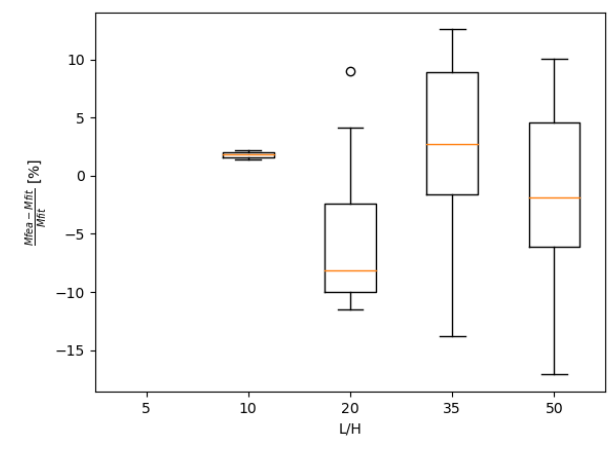

(b) Percent error vs. $L / H$

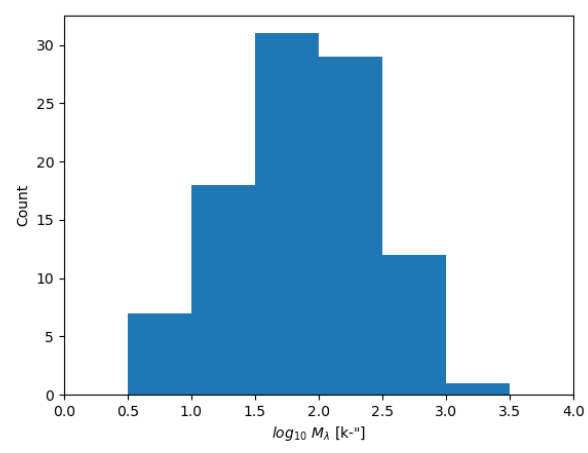

(c) Distribution of $M_{\lambda}$

For the WF-BC1-3Point setup, 900 beams were analyzed and 527 had an Eigen shape classified as LTB. The results are summarized in Figure 7.3. $C_{1}$ and $C_{2}$ were fit to values of 1.06 and 0.57 which have an error of 21.4 and 3.6\%, respectively. The ratio of critical Eigen moments of 3-point loading to pure bending agrees much better with $C_{b}=1.36$. In addition to the Eigen analysis, a Riks analysis was performed for this setup. A comparison of the critical buckling loads are shown in Figure 7.4. The median critical load for the Riks analysis was $18 \%$ higher than for the Eigen analysis. If this difference is applied to $C_{1}$ from the Eigen analysis, then the parameter would increase to $C_{1}=1.06 \times 1.18=1.25$ which has an error of $8.1 \%$ compared to the $C_{b}$ for steel. 
Figure 7.3: Results for wide flange section with $\mathrm{BC} 1$ and 3 Point loading condition

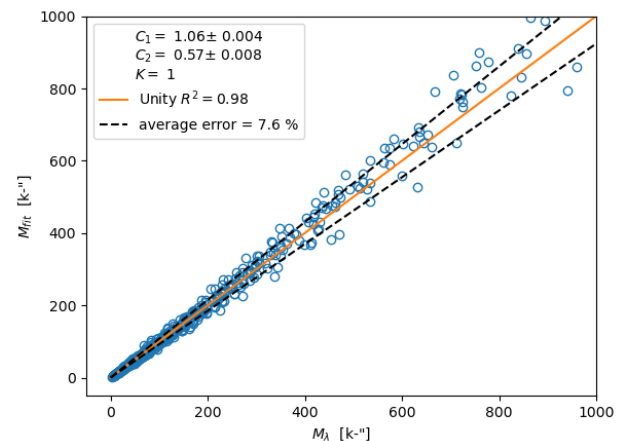

(a) Classical model vs. FEA critical moments

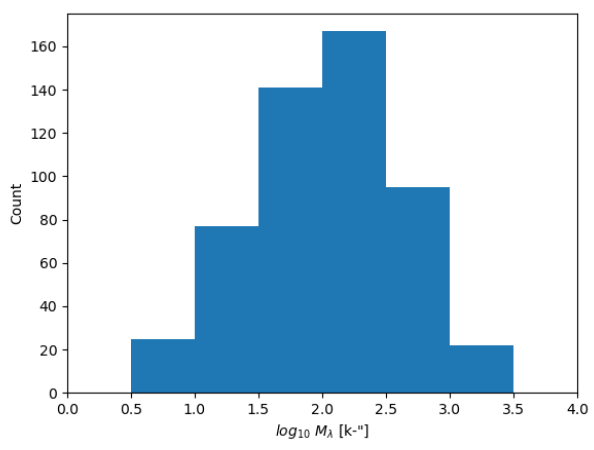

(c) Distribution of $M_{\lambda}$

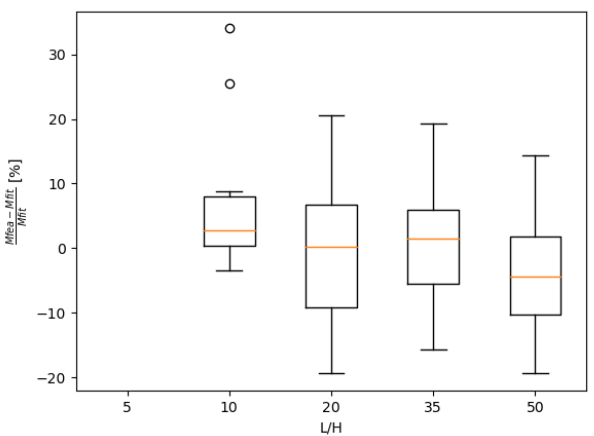

(b) Percent error vs. $L / H$

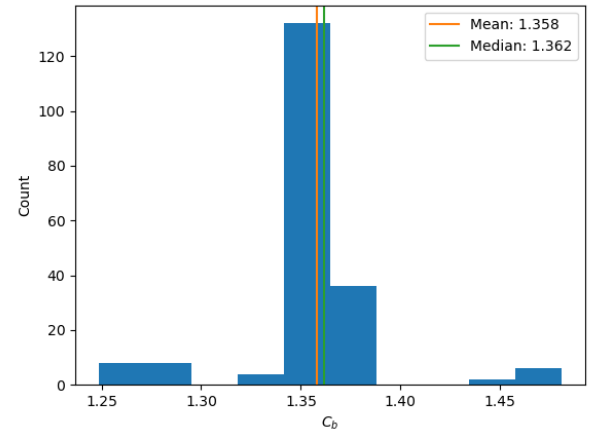

(d) Distribution of $C_{b}$ 
Figure 7.4: Comparison of nonlinear Riks vs Eigen analysis for WF with BC1 and 3 Point loading condition

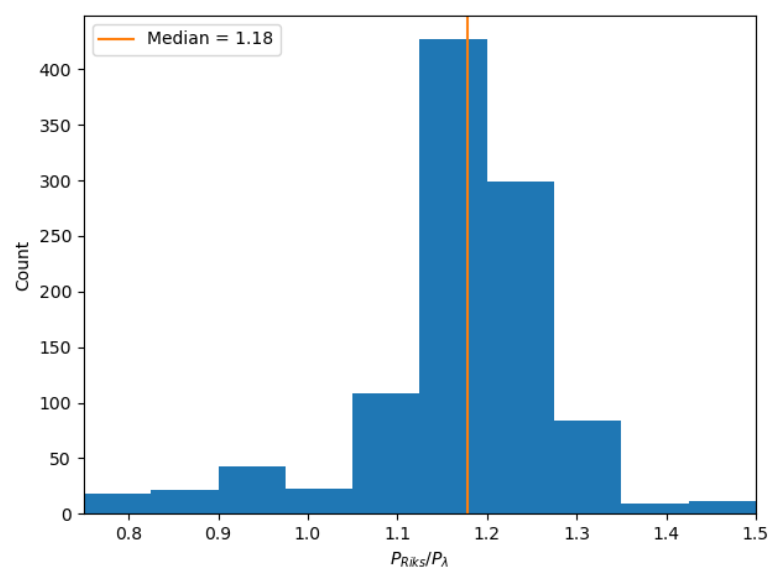

For the WF-BC1-UDL setup, 540 beams were analyzed and 332 had an Eigen shape classified as LTB. The results are summarized in Figure 7.5. $C_{1}$ and $C_{2}$ were fit to values of 0.89 and 0.48 which have an error of 21.2 and $6.7 \%$, respectively. The median of $C_{b}$ matches the expected value for the moment gradient factor. 
Figure 7.5: Results for wide flange section with $\mathrm{BC} 1$ and uniformly distributed loading condition

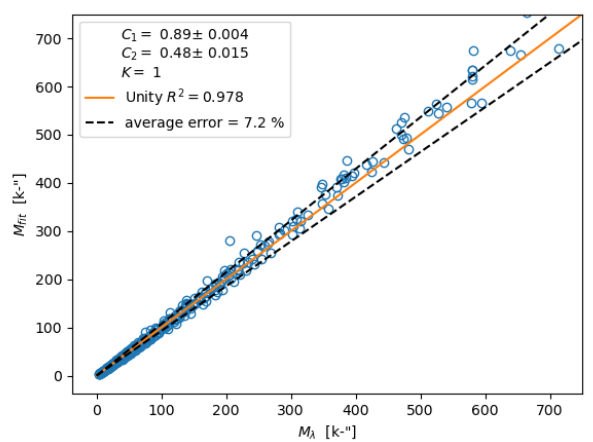

(a) Classical model vs. FEA critical moments

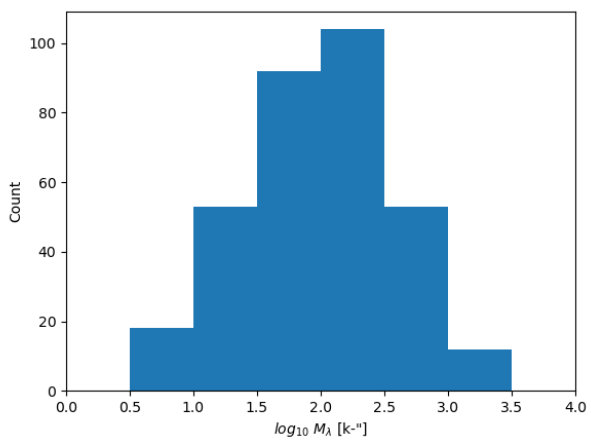

(c) Distribution of $M_{\lambda}$

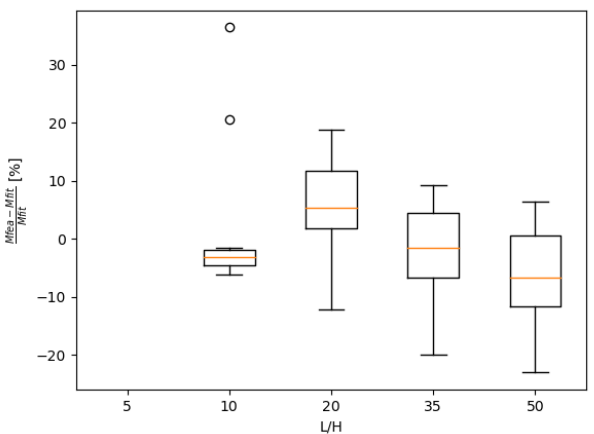

(b) Percent error vs. $L / H$

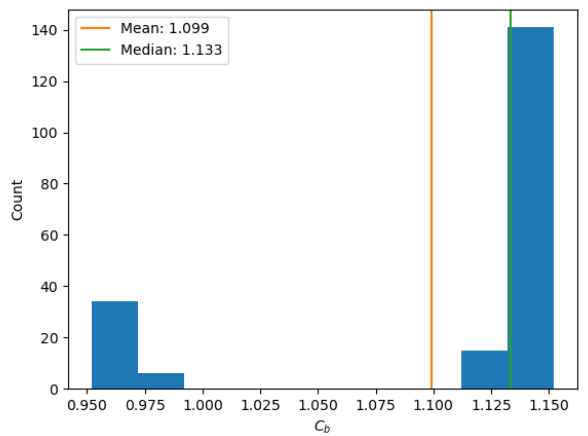

(d) Distribution of $C_{b}$

\subsection{Minor Axis Fixed}

This section shows the analysis results for WF orthotropic beams with lateral bending fixed. Figure 7.6 shows the vertical, lateral, and torsional displacements through the span of a WF beam at mid-height. These displacements are generated by three separate point load cases applied at the centroid of the beam, a vertical, lateral, and torque. The displacements are consistent with lateral bending and torsion being fixed as described by Equations 7.4 to 7.6. It should be noted that fixed torsion does not prevent warping as shown in Figure 7.7. There may be some partial warping restraint but this is assumed to be negligible in this study. 


$$
\begin{aligned}
& v(0)=v(L)=\left.\frac{d^{2} v}{d z^{2}}\right|_{z=0}=\left.\frac{d^{2} v}{d z^{2}}\right|_{z=L}=0 \\
& u(0)=u(L)=\left.\frac{d u}{d z}\right|_{z=0}=\left.\frac{d u}{d z}\right|_{z=L}=0 \\
& \phi(0)=\phi(L)=\left.\frac{d \phi}{d z}\right|_{z=0}=\left.\frac{d \phi}{d z}\right|_{z=L}=0
\end{aligned}
$$

Figure 7.6: Validation of $\mathrm{BC} 2$ for $\mathrm{WF}$ shapes
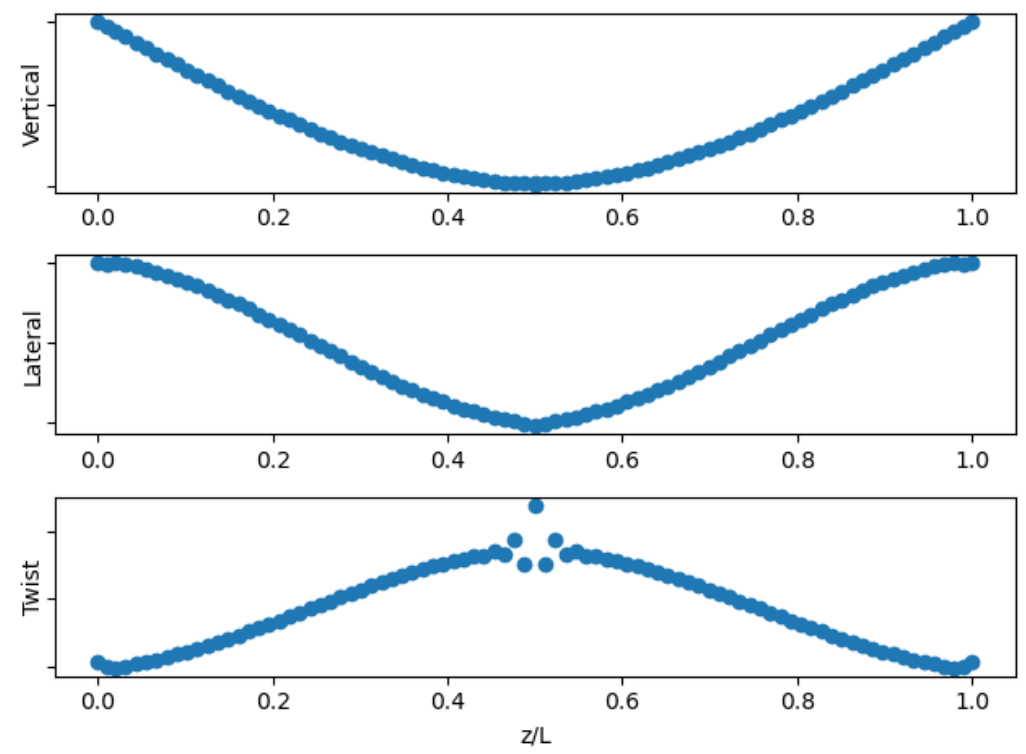
Figure 7.7: Visual warping of $\mathrm{BC} 1$ and $\mathrm{BC} 2$

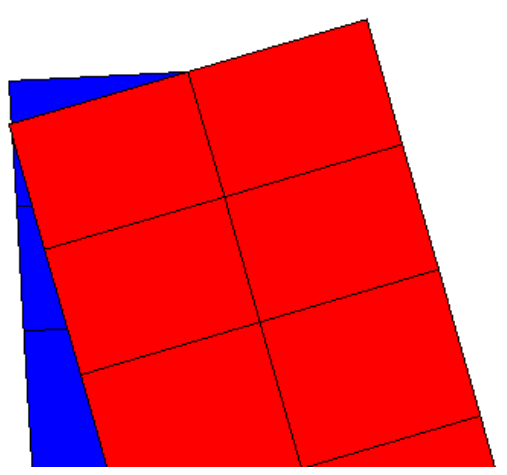

(a) $\mathrm{BC} 1$

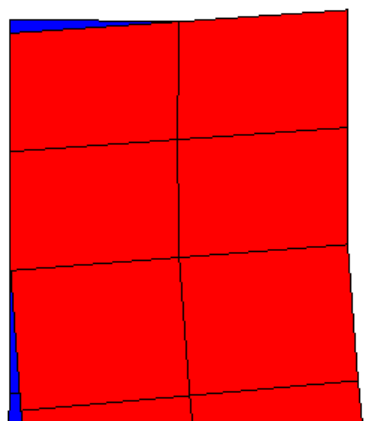

(b) $\mathrm{BC} 2$

Note: The upper compression flanges and lower tension flanges are shown in red and blue, respectively.

For the WF-BC2-Moment setup, 180 beams were analyzed and only 33 had an Eigen shape classified as LTB. Fewer LTB determinations are likely the result of local buckling affecting the twist. The results are summarized in Figure 7.8. $C_{1}$ was fit to value of 0.76 which has an error of $24 \%$. 
Figure 7.8: Results for wide flange section with $\mathrm{BC} 2$ and a pure bending loading condition

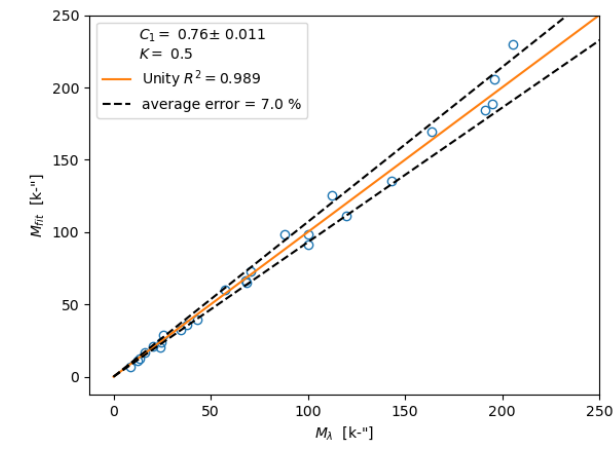

(a) Classical model vs. FEA critical moments

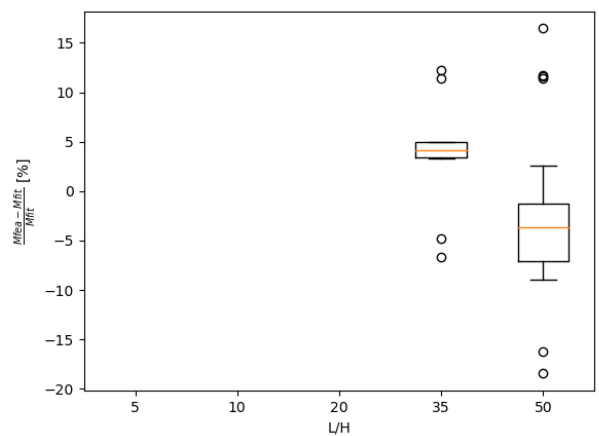

(b) Percent error vs. $L / H$

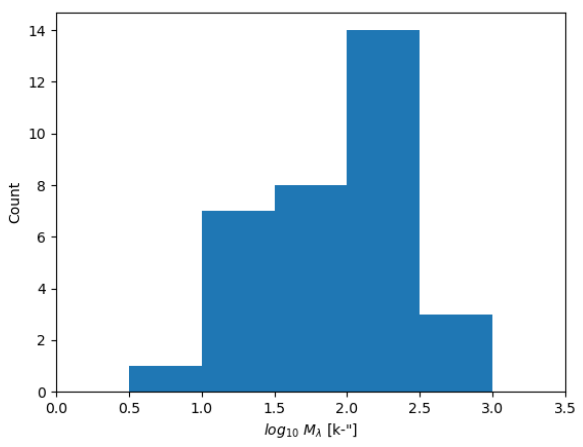

(c) Distribution of $M_{\lambda}$

For the WF-BC2-3Point setup, 900 beams were analyzed and 264 had an Eigen shape classified as LTB. The results are summarized in Figure 7.9. $C_{1}$ and $C_{2}$ were fit to values of 0.74 and 0.47 which have an error of 30.8 and $11.9 \%$, respectively. The ratio of critical Eigen moments of UDL to pure bending agrees much better with $C_{b}=1.08$. 
Figure 7.9: Results for wide flange section with BC2 and 3 Point loading condition

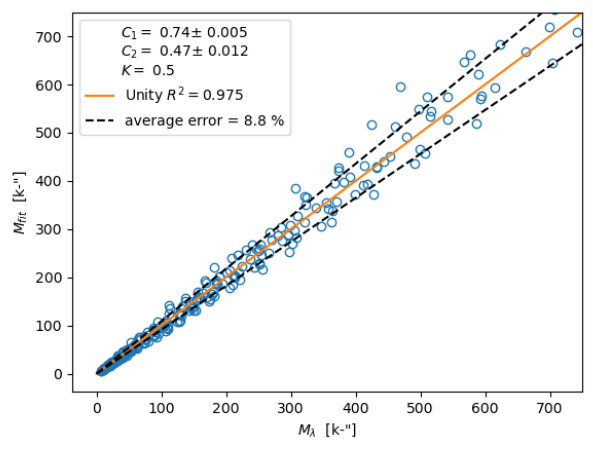

(a) Classical model vs. FEA critical moments

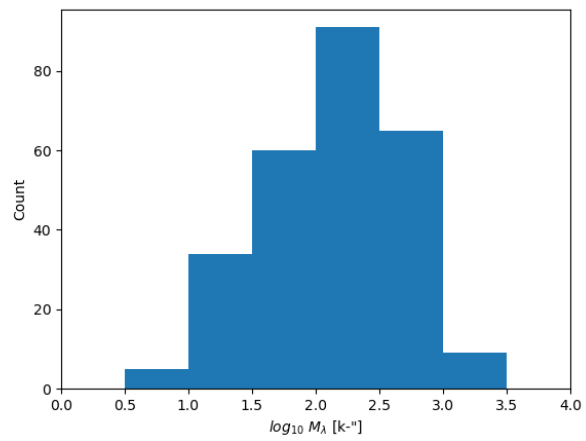

(c) Distribution of $M_{\lambda}$

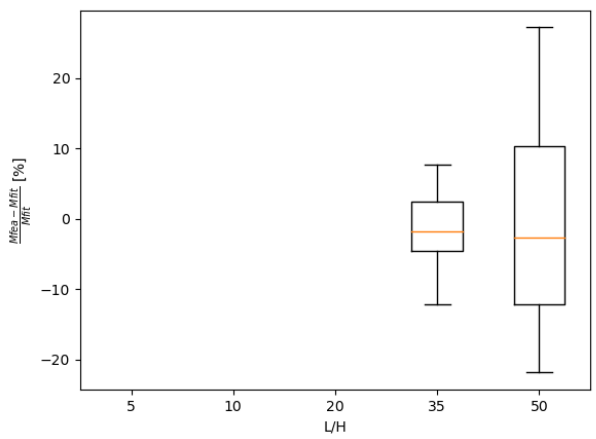

(b) Percent error vs. $L / H$

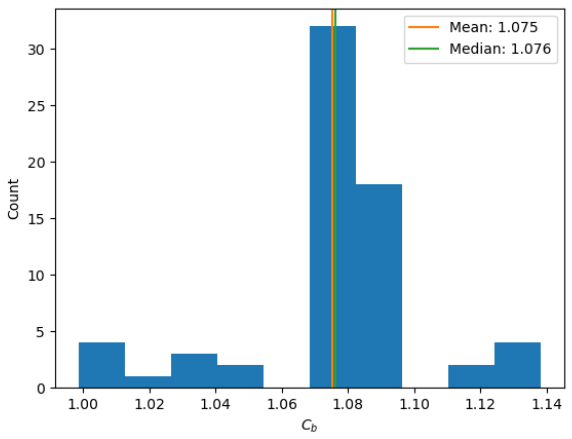

(d) Distribution of $C_{b}$

For the WF-BC2-UDL setup, 540 beams were analyzed and 150 had an Eigen shape classified as LTB. The results are summarized in Figure 7.10. $C_{1}$ and $C_{2}$ were fit to values of 0.71 and 0.27 which have an error of 26.8 and $6.9 \%$, respectively. The mean of the moment gradient distribution is 0.99 which has an error $2.1 \%$ compared to nominal steel values. 
Figure 7.10: Results for wide flange section with $\mathrm{BC} 2$ and uniformly distributed loading condition

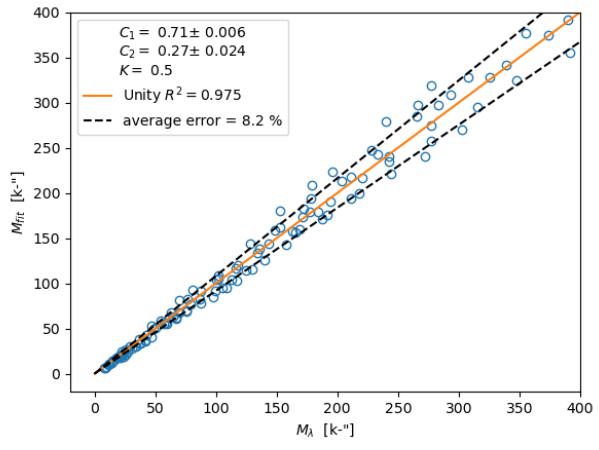

(a) Classical model vs. FEA critical moments

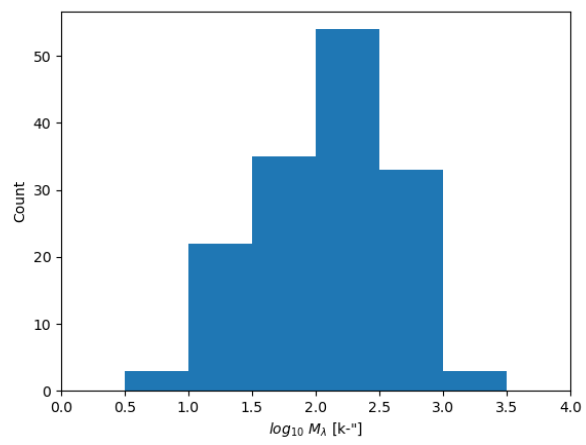

(c) Distribution of $M_{\lambda}$

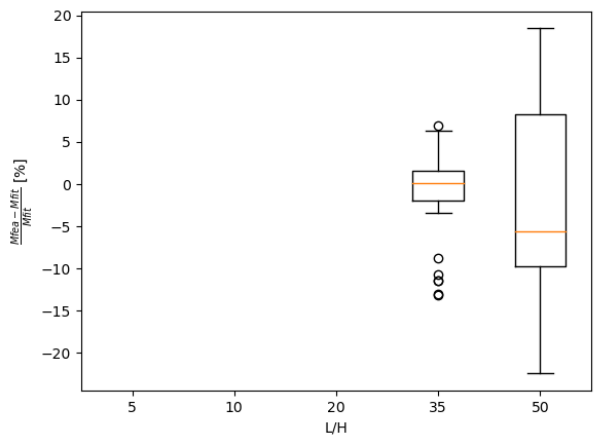

(b) Percent error vs. $L / H$

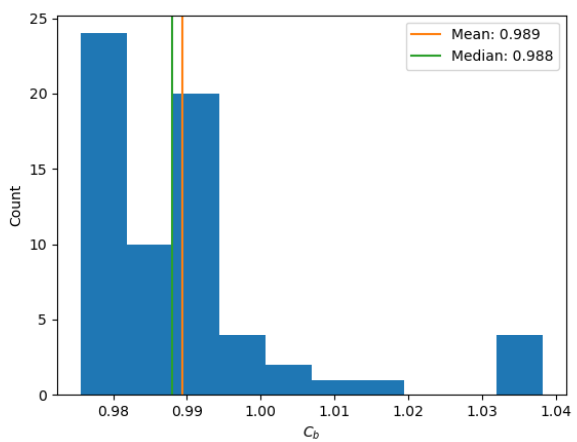

(d) Distribution of $C_{b}$

\subsection{Minor and Major Axes Fixed}

This section shows the analysis results for WF orthotropic beams with vertical and lateral bending fixed. Figure 7.11 shows the vertical, lateral, and torsional displacements through the span of a WF beam at mid-height. These displacements are generated by three separate point load cases applied at the centroid of the beam, a vertical, lateral, and torque. The displacements are consistent with fixed minor and major bending axes as described by Equations 7.7 to 7.9. The pure bending load case conflicts with the supports for BC3, so only 3-point and uniformly distributed load cases are analyzed. 


$$
\begin{aligned}
& v(0)=v(L)=\left.\frac{d v}{d z}\right|_{z=0}=\left.\frac{d v}{d z}\right|_{z=L}=0 \\
& u(0)=u(L)=\left.\frac{d u}{d z}\right|_{z=0}=\left.\frac{d u}{d z}\right|_{z=L}=0 \\
& \phi(0)=\phi(L)=\left.\frac{d \phi}{d z}\right|_{z=0}=\left.\frac{d \phi}{d z}\right|_{z=L}=0
\end{aligned}
$$

Figure 7.11: Validation of BC3 for WF shapes
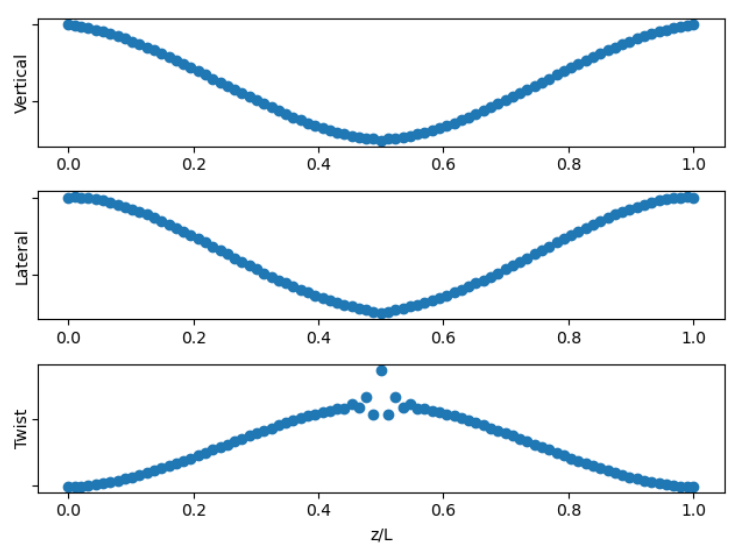

For the WF-BC3-3Point setup, 900 beams were analyzed and 297 had an Eigen shape classified as LTB. The results are summarized in Figure 7.12. $C_{1}$ and $C_{2}$ were fit to values of 0.72 and 0.88 which have an error of 30.8 and $4.8 \%$, respectively. Since there is no pure bending load case, the critical Eigen moments of 3-point loading was compared to UDL case. This comparison can be done for eccentric load heights because $C_{2}$ for the two cases differs by only $2.4 \%$. This results in $C_{b} *=1.22$ compared to $\frac{C_{1_{3}}}{C_{1_{U D L}}}=1.04 / 0.86=1.21$. 
Figure 7.12: Results for wide flange section with BC3 and 3 Point loading condition

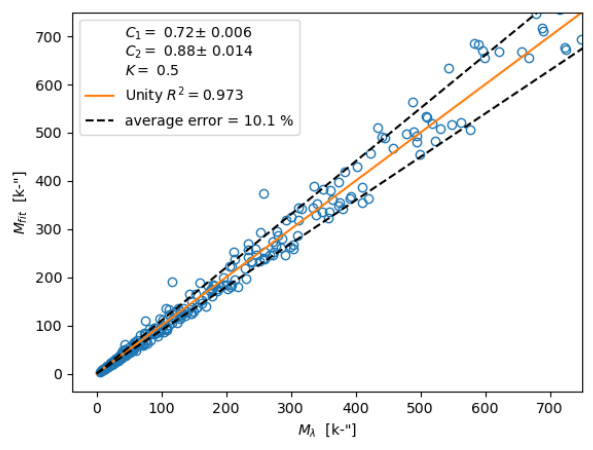

(a) Classical model vs. FEA critical moments

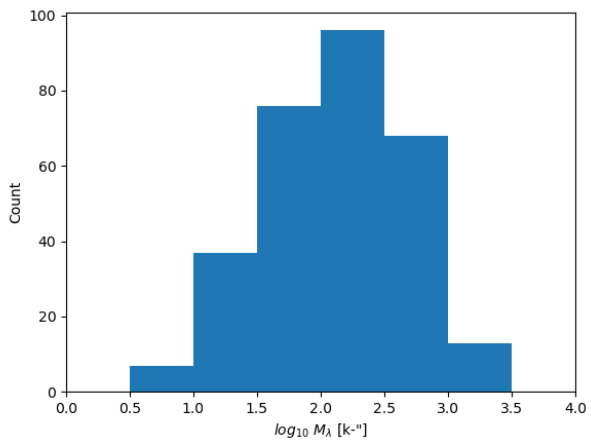

(c) Distribution of $M_{\lambda}$

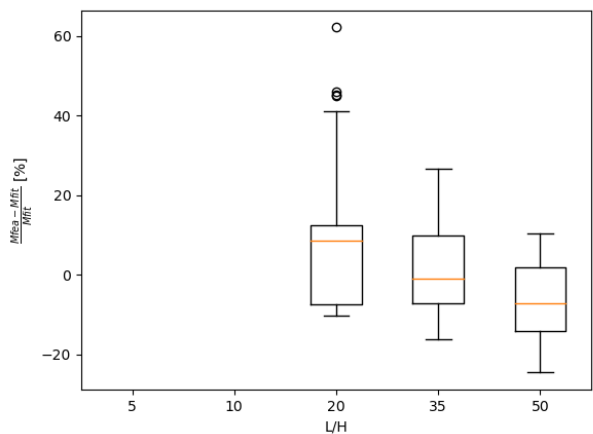

(b) Percent error vs. $L / H$

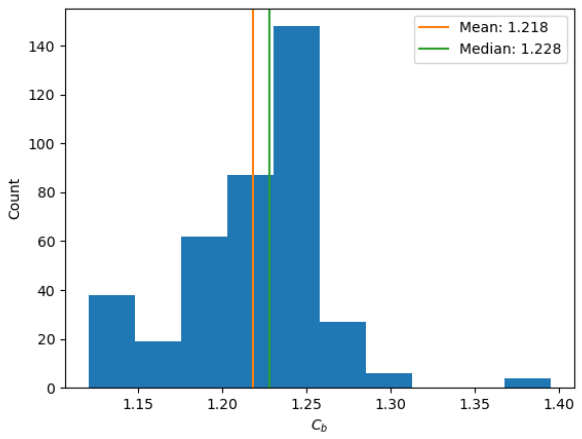

(d) Distribution of $C_{b} *$

For the WF-BC3-UDL setup, 540 beams were analyzed and 202 had an Eigen shape classified as LTB. The results are summarized in Figure 7.13. $C_{1}$ and $C_{2}$ were fit to values of 0.59 and 0.80 which have an error of 31.4 and $2.4 \%$, respectively. 
Figure 7.13: Results for wide flange section with BC3 and uniformly distributed loading condition

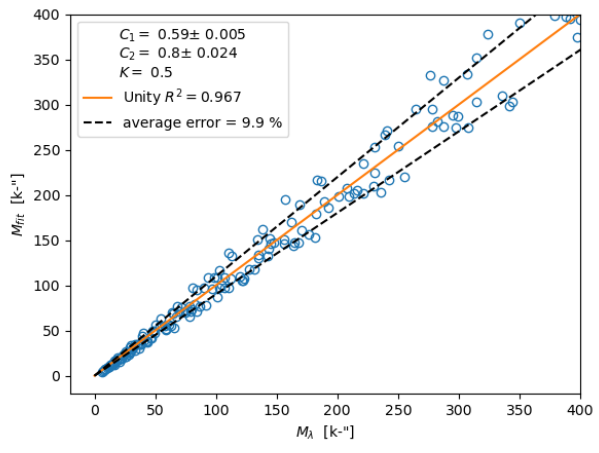

(a) Classical model vs. FEA critical moments

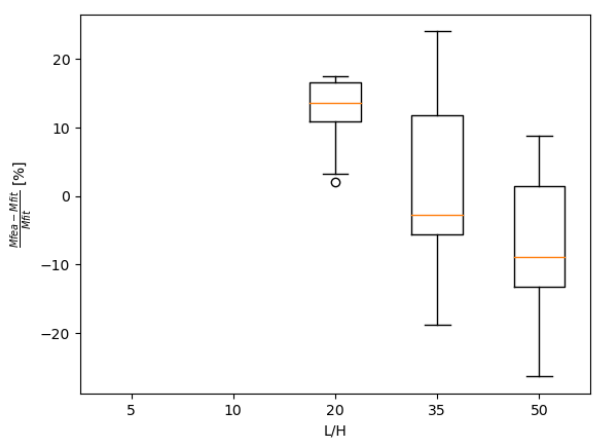

(b) Percent error vs. $L / H$

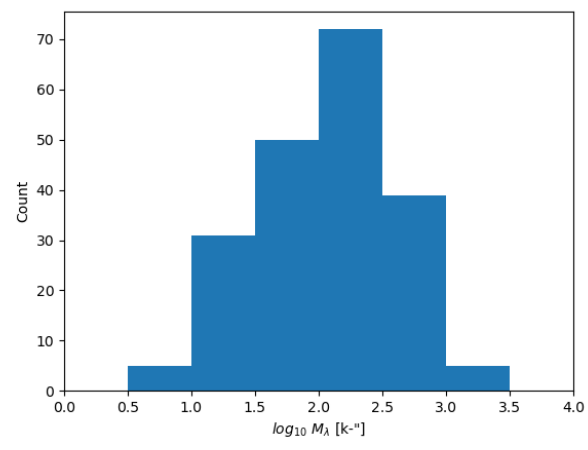

(c) Distribution of $M_{\lambda}$

\section{Channel Sections}

\subsection{Introduction}

The analysis for channel sections was approached similarly to the wide flange sections with the results presented in the same fashion. See Sec. 7.1 for more information. The largest difference between the analysis for the wide flanges and channels is related to the shear center. If the load is not applied exactly in line with the shear center, a twisting moment will develop and initiate LTB without bifurcation. Because the shear center for channels is not along a plane of symmetry 
Table 8.1: Channel dimensions for parametric study

\begin{tabular}{cccc}
\hline$H$ & $b_{f}$ & $t_{w}$ & $t_{f}$ \\
\hline 1.5 & 1 & 0.1875 & 0.1875 \\
2 & 0.56 & 0.125 & 0.125 \\
2.75 & 1 & 0.125 & 0.125 \\
3 & 0.875 & 0.25 & 0.25 \\
3 & 1 & 0.1875 & 0.1875 \\
3 & 1.5 & 0.25 & 0.25 \\
4 & 1.06 & 0.125 & 0.125 \\
4 & 1.75 & 0.1875 & 0.1875 \\
4 & 1.13 & 0.25 & 0.25 \\
4.5 & 2.5 & 0.25 & 0.25 \\
5 & 1.38 & 0.25 & 0.25 \\
6 & 1.63 & 0.25 & 0.25 \\
6 & 1.69 & 0.375 & 0.375 \\
7 & 2 & 0.25 & 0.25 \\
8 & 2.19 & 0.25 & 0.25 \\
8 & 2.19 & 0.375 & 0.375 \\
10 & 2.75 & 0.125 & 0.125 \\
10 & 2.75 & 0.5 & 0.5 \\
11.5 & 2.75 & 0.5 & 0.5 \\
14 & 6 & 0.5 & 0.5 \\
18 & 2.5 & 0.25 & 0.25 \\
24 & 3 & 0.25 & 0.25 \\
24 & 4 & 0.47 & 0.47 \\
\hline
\end{tabular}

Note: Dimensions are taken from The Pultex ${ }^{\circledR}$ Pultrusion Design Manual [28]. All dimensions are in inches.

or even located on the cross section, applying a load exactly at the shear center is difficult and bifurcation may still not be achieved. The twisting moment from this eccentricity softens the $P-\phi$ curve similar to using a beam with a larger initial deformation.

\subsection{Finding Shear Center}

The shear center for channels can be determined analytically by assuming a thin-walled section. However, when applying a load to a channel at this shear center, the section may still experience a small torque. This may be related to second-order effects from finite wall thickness, or to how the section was modeled. In either case, this extra torque needs reduced to prevent unintentional 
twisting that can modify LTB response.

An iterative method was used to find the eccentricity to minimize twist during loading, $S C_{f e a}$. The beam is first loaded at the shear center as calculated by Equation 8.1. First, a Riks analysis was performed without a perturbation. After the beam was loaded to approximately $10-20 \%$ of $P_{c r}$, the slope of the normalized load vs twist was calculated. The load was normalized to $P_{c r}$ to develop a consistent standard for the various beam dimensions. This slope was used to gauge how close the beam was loaded to the computational shear center. A slope approaching infinity would indicate zero twisting during loading. The secant method was used to calculate the next load eccentricity. This iteration was continued until the slope was greater than 5e7, which was usually achieved in four iterations.

$$
e=\frac{b}{2+\frac{t_{w} \cdot h}{3 t_{f} b}}+t_{w} / 2
$$

where,

$$
\begin{aligned}
& b=b_{f}-t_{w} / 2 \\
& h=H-t_{f}
\end{aligned}
$$

Figure 8.1: Determination of shear center $S C_{f e a}=e e^{\prime}$

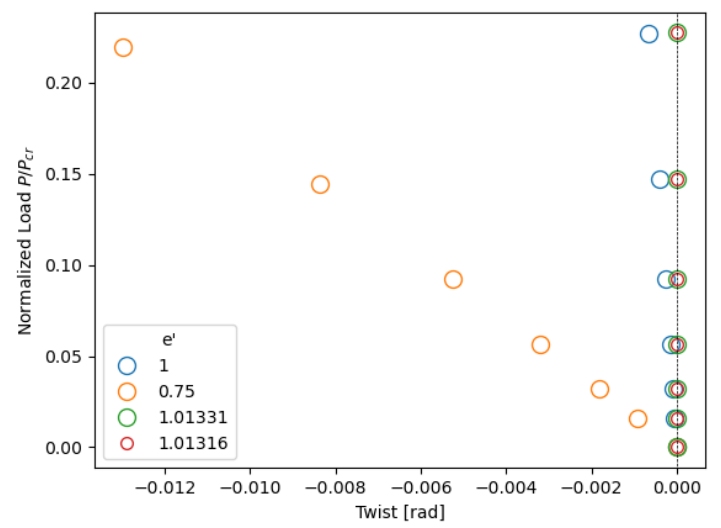


Figure 8.2: Effect of perturbation on LTB response for channels

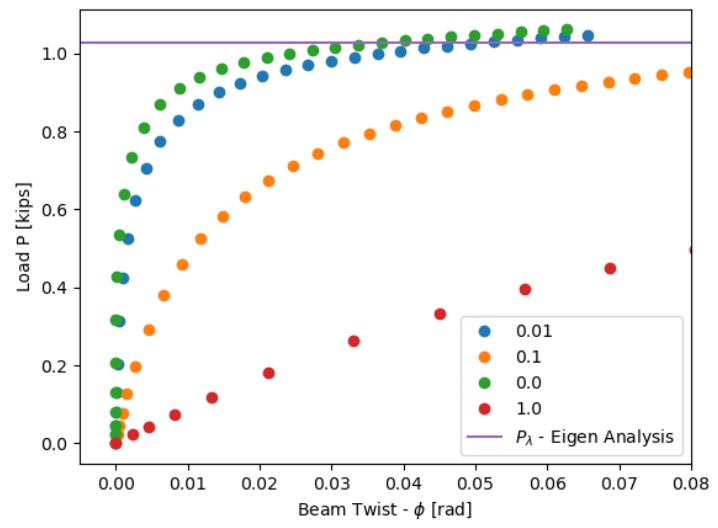

Note: Load is applied at $S C_{f e a}$.

Even after determining the $S C_{f e a}$, the channel sections did not experience bifurcation buckling for any size of perturbation. For consistency with the analysis on wide flange sections, a perturbation factor of 0.01 was used.

\subsection{Pinned}

This section shows the analysis results for pinned orthotropic channel beams. Figure 8.3 shows the vertical, lateral, and torsional displacements through the span of a WF beam at mid-height. These displacements are generated by three separate point load cases applied at the centroid of the beam, a vertical, lateral, and torque. The resulting displacement curves are consistent with the boundary conditions for a pinned beam as described by Equations 7.1 to 7.3. 
Figure 8.3: Validation of BC1 for Channels
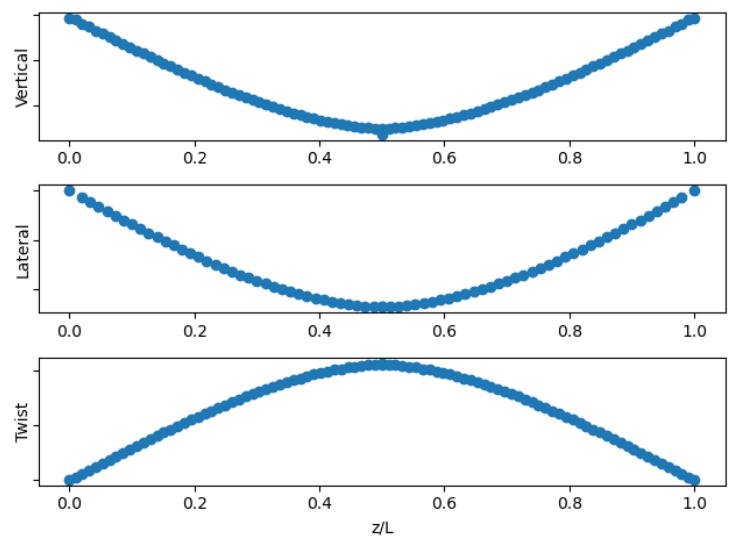

For the C-BC1-Moment setup, 460 beams were analyzed and 391 had an Eigen shape classified as LTB. The results are summarized in Figure 8.4. $C_{1}$ was fit to a value of 0.90 which has an error of $10.0 \%$. 
Figure 8.4: Results for channel section with $\mathrm{BC} 1$ and a pure bending loading condition

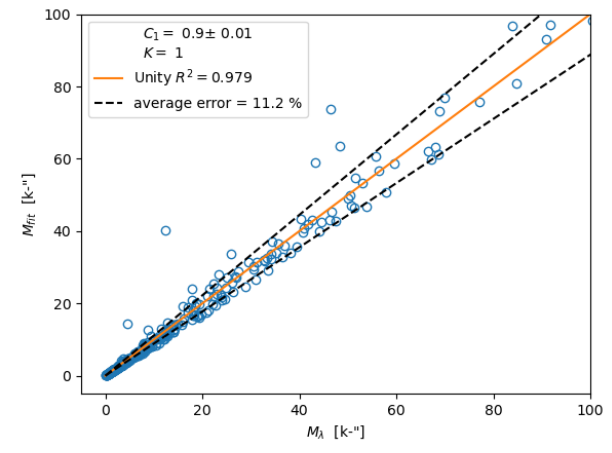

(a) Classical model vs. FEA critical moments

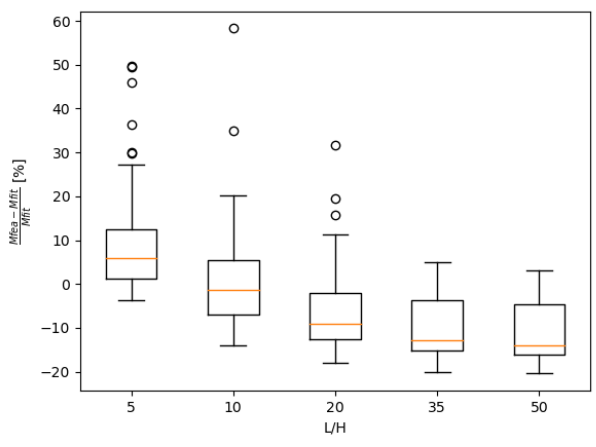

(b) Percent error vs. $L / H$

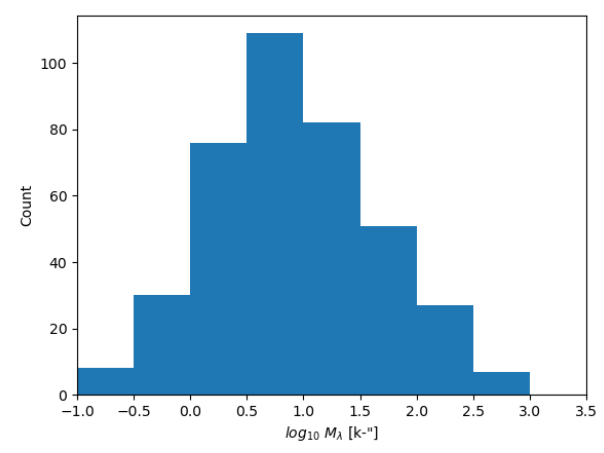

(c) Distribution of $M_{\lambda}$

For the C-BC1-3Point setup, 2300 beams were analyzed and 2005 had an Eigen shape classified as LTB. The results are summarized in Figure 8.5. $C_{1}$ and $C_{2}$ were fit to values of 0.99 and 0.63 which have an error of 26.7 and $14.5 \%$, respectively. The ratio of critical Eigen moments of 3-point loading to pure bending gives a $C_{b}=1.16$, which is $14.1 \%$ error. 
Figure 8.5: Results for channel section with $\mathrm{BC} 1$ and 3 Point loading condition

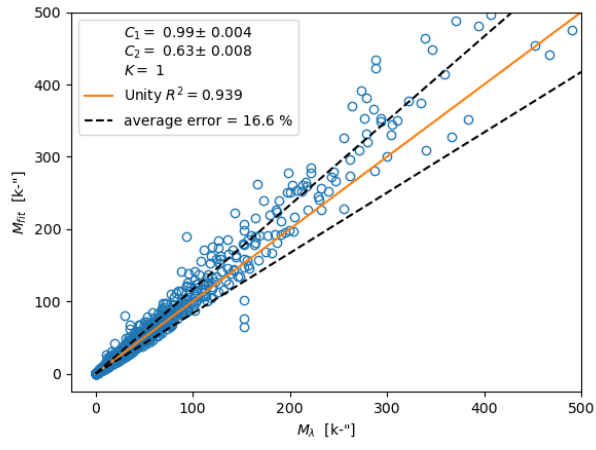

(a) Classical model vs. FEA critical moments

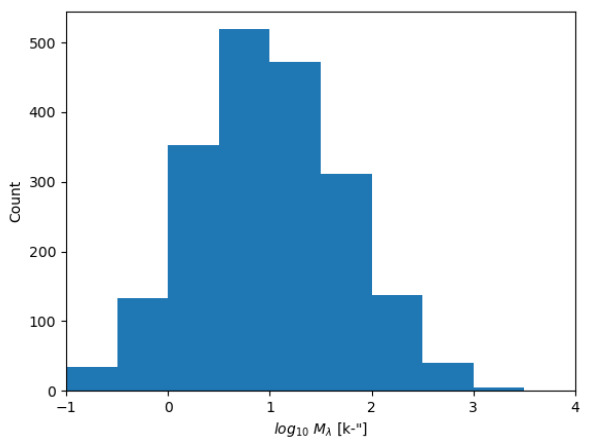

(c) Distribution of $M_{\lambda}$

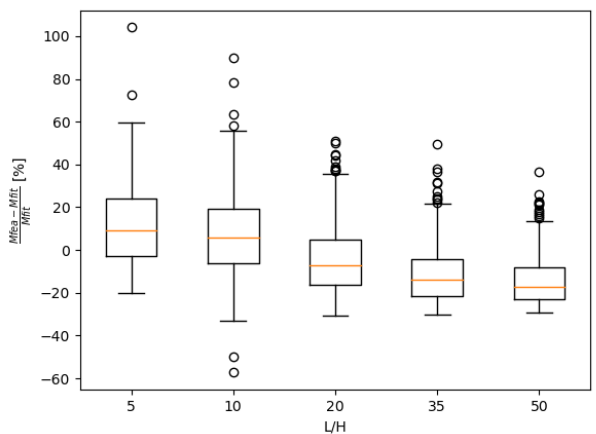

(b) Percent error vs. $L / H$

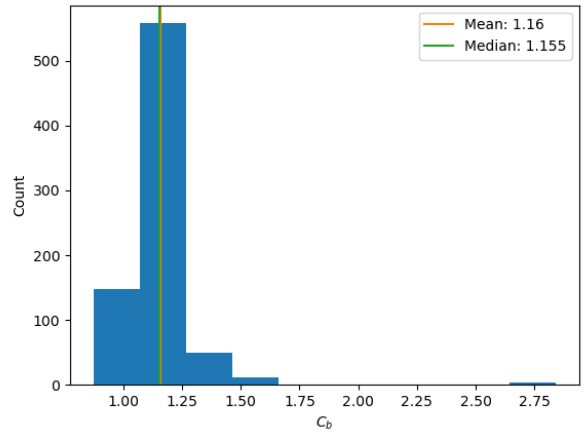

(d) Distribution of $C_{b}$

\subsection{Minor Axis Fixed}

This section shows the analysis results for orthotropic channels with lateral bending fixed. Figure 8.6 shows the vertical, lateral, and torsional displacements through the span of a $\mathrm{C}$ beam at mid-height. These displacements are generated by three separate point load cases applied at the centroid of the beam, a vertical, lateral, and torque. The displacements are consistent with lateral bending and torsion being fixed as described by Equations 7.4 to 7.6. 
Figure 8.6: Validation of $\mathrm{BC} 2$ for Channels
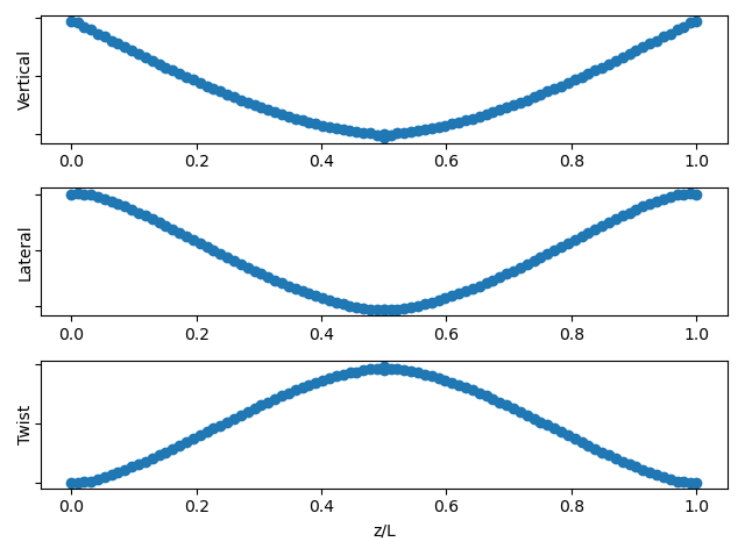

For the C-BC2-Moment setup, 460 beams were analyzed and 232 had an Eigen shape classified as LTB. The results are summarized in Figure 7.8. $C_{1}$ was fit to a value of 0.84 which has an error of $16 \%$. 
Figure 8.7: Results for channel section with $\mathrm{BC} 2$ and a pure bending loading condition

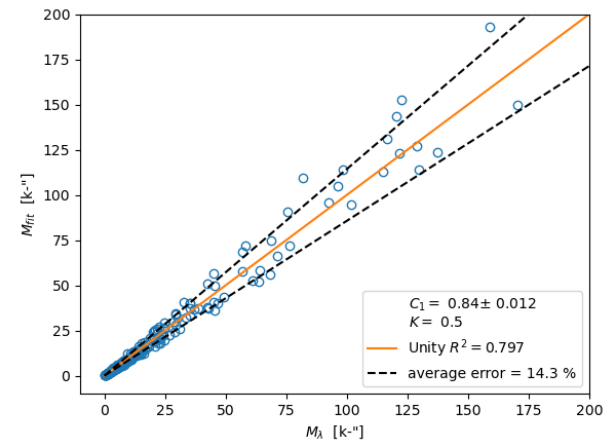

(a) Classical model vs. FEA critical moments

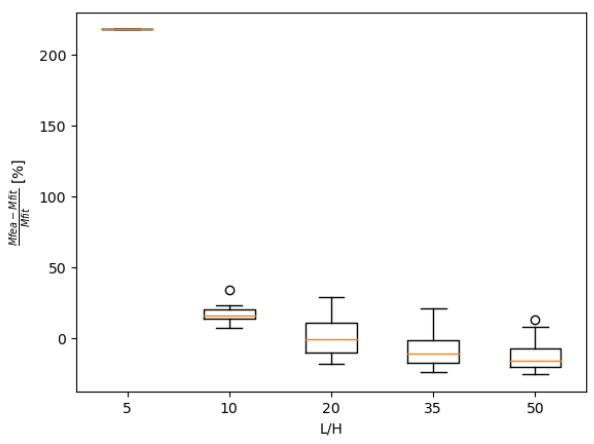

(b) Percent error vs. $L / H$

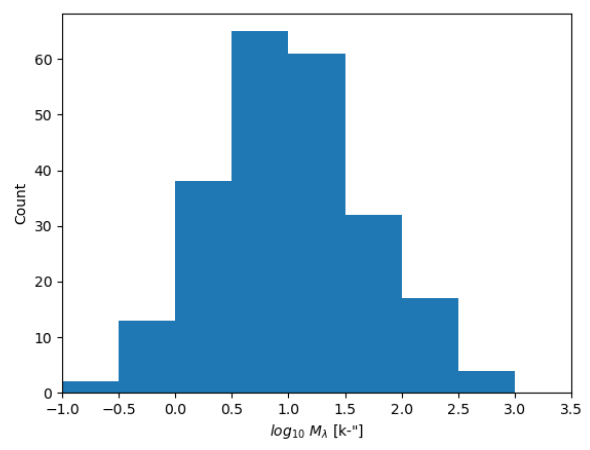

(c) Distribution of $M_{\lambda}$

For the C-BC2-3Point setup, 2300 beams were analyzed and 1311 had an Eigen shape classified as LTB. The results are summarized in Figure 8.8. $C_{1}$ and $C_{2}$ were fit to values of 0.58 and 0.64 which have errors of 46.0 and $52.4 \%$, respectively. The ratio of critical Eigen moments of 3-point loading to pure bending gives $C_{b}=0.89$, which is an error of $16.8 \%$ from nominal steel values. There is also significant spread in the scatter plot of $M_{f i t}$ vs. $M_{\lambda}$. This indicates that the closed form model is not capturing all the physics of LTB for channel sections. Eurocode 3 introduces a $k_{w}$ factor to account for warping stresses induced by boundary conditions. These constants were also determined using the Eurocode 3 formulation with $k_{w}=1$ for all BCs. This approximately halved the scatter in the plot of $M_{f i t}$ vs. $M_{\lambda}$ for the C-BC2-3Point and C-BC3-3Point setups. The 
results of this are summarized in Table 10.1.

Figure 8.8: Results for channel section with $\mathrm{BC} 2$ and 3 Point loading condition

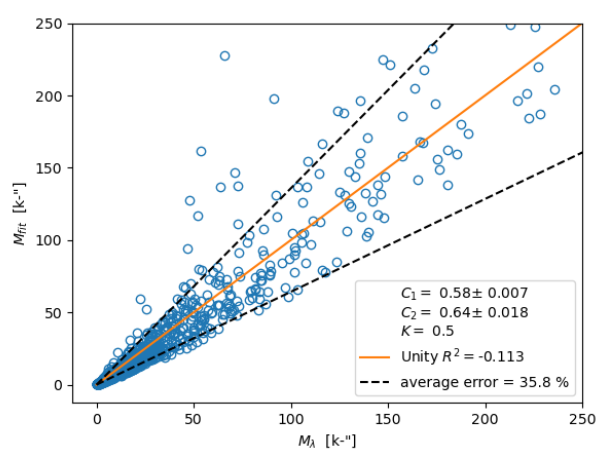

(a) Classical model vs. FEA critical moments

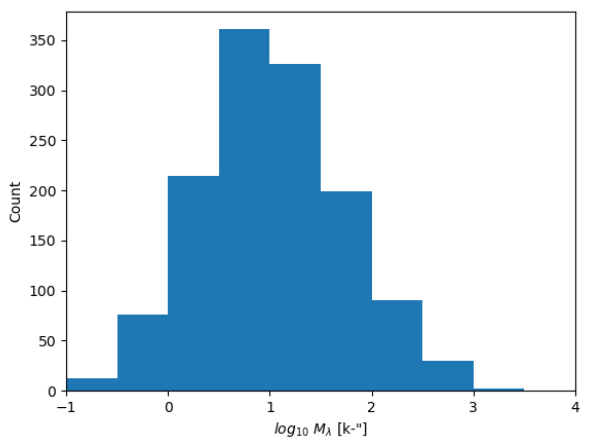

(c) Distribution of $M_{\lambda}$

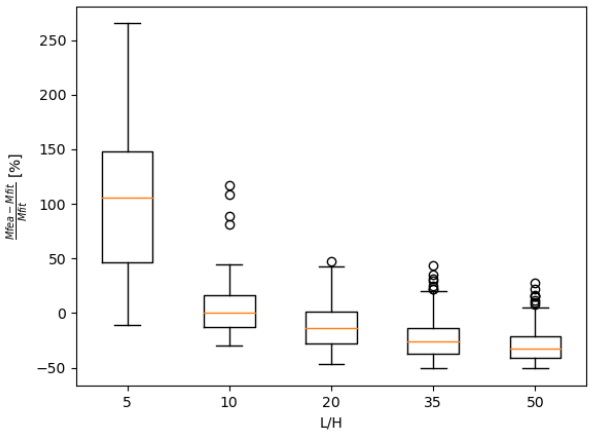

(b) Percent error vs. $L / H$

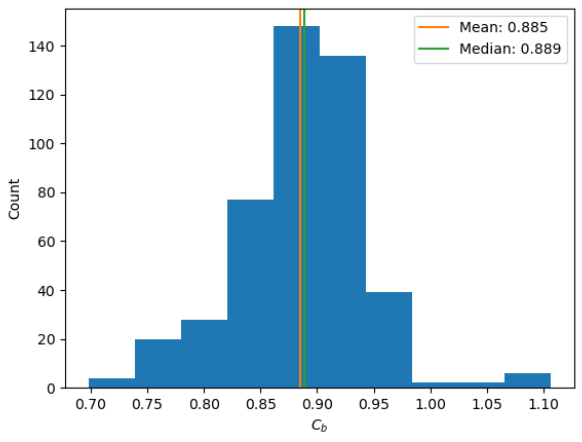

(d) Distribution of $C_{b}$

\subsection{Minor and Major Axes Fixed}

This section shows the analysis results for orthotropic channel beams with vertical and lateral bending fixed. Figure 8.9 shows the vertical, lateral, and torsional displacements through the span of a channel at mid-height. These displacements are generated by three separate point load cases applied at the centroid of the beam, a vertical, lateral, and torque. The displacements are consistent with fixed minor and major bending axes as described by Equations 7.7 to 7.9. The pure bending load case conflicts with the supports for BC3, so only the 3-point load cases were analyzed. 
Figure 8.9: Validation of BC3 for Channels
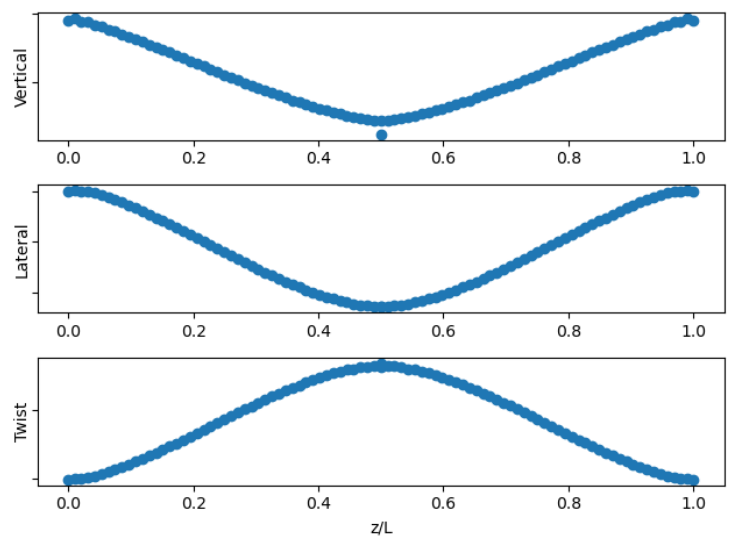

For the C-BC3-3Point setup, 2300 beams were analyzed and 1122 had an Eigen shape classified as LTB. The results are summarized in Figure 8.10. $C_{1}$ and $C_{2}$ were fit to values of 0.42 and 0.89 which have errors of 59.6 and $6.0 \%$ respectively. The BC3 setup produced even more scatter than $\mathrm{BC} 2$. 
Figure 8.10: Results for channel section with BC3 and 3 Point loading condition

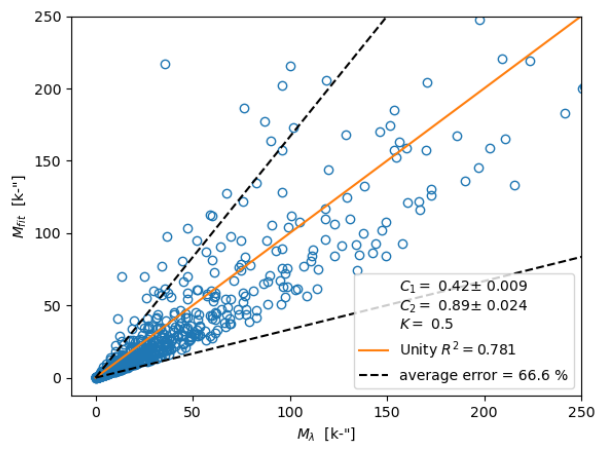

(a) Classical model vs. FEA critical moments

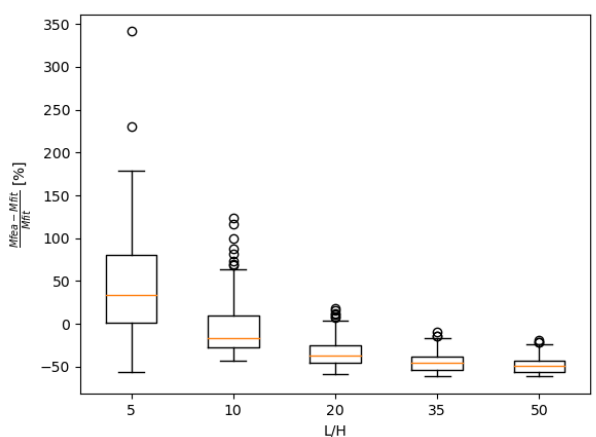

(b) Percent error vs. $L / H$

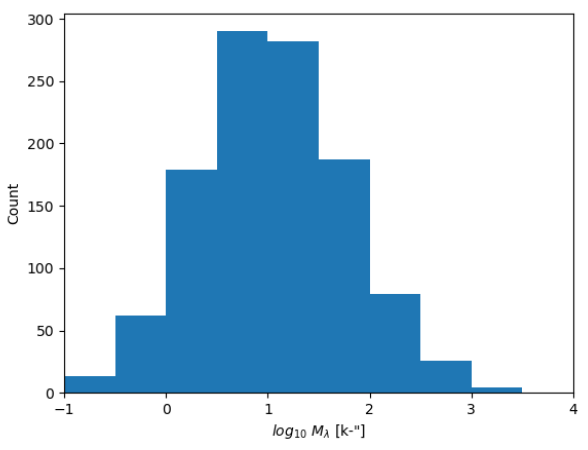

(c) Distribution of $M_{\lambda}$

\section{$9 \quad$ Narrow Rectangular Sections}

\subsection{Introduction}

The analysis for rectangular sections was approached similarly to the wide flange sections with the results presented in the same fashion. See Sec. 7.1 for more information. Thin rectangular beams have very little warping resistance compared to similarly sized wide flanged beams. 
Table 9.1: Narrow rectangular beam dimensions for parametric study

\begin{tabular}{cc}
\hline$H$ & $t$ \\
\hline 3 & 0.25 \\
4 & 0.25 \\
6 & 0.25 \\
8 & 0.38 \\
10 & 0.38 \\
12 & 0.5 \\
\hline
\end{tabular}

Note: Dimensions are taken from WF sections in The Pultex ${ }^{\circledR}$ Pultrusion Design Manual [28]. All dimensions are in inches.

\subsection{Pinned}

This section shows the analysis results for pinned orthotropic thin-rectangular beams. Figure 9.1 shows the vertical, lateral, and torsional displacements through the span of a thin-rectangular beam at mid-height. These displacements are generated by three separate point load cases applied at the centroid of the beam, a vertical, lateral, and torque. The resulting displacement curves are consistent with the boundary conditions for a pinned beam as described by Equations 7.1 to 7.3.

Figure 9.1: Validation of $\mathrm{BC} 1$ for narrow rectangular sections
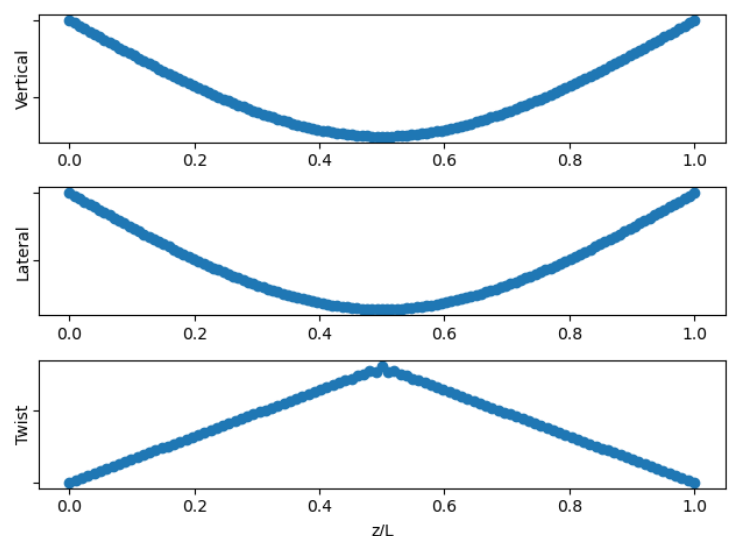

For the C-BC1-Moment setup, 120 beams were analyzed and all had an Eigen shape that classified as LTB. The results are summarized in Figure 9.2. $C_{1}$ was fit to a value of 1.10 which has an error of $10.0 \%$. 
Figure 9.2: Results for narrow rectangular section with $\mathrm{BC} 1$ and a pure bending loading condition

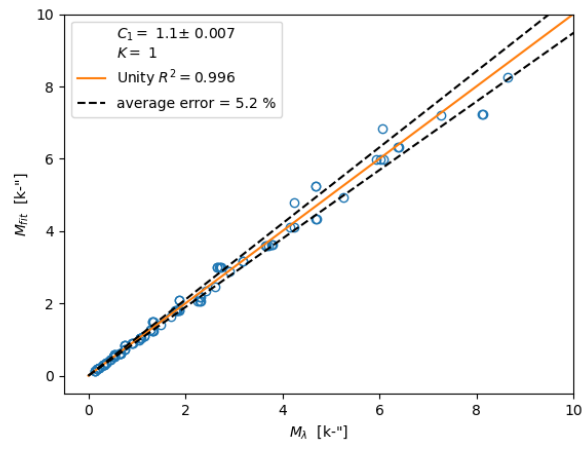

(a) Classical model vs. FEA critical moments

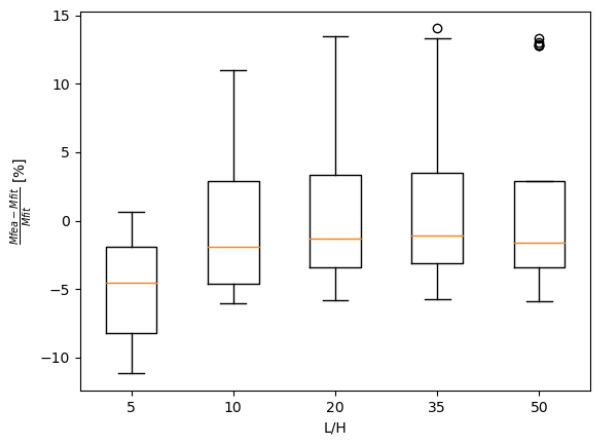

(b) Percent error vs. $L / H$

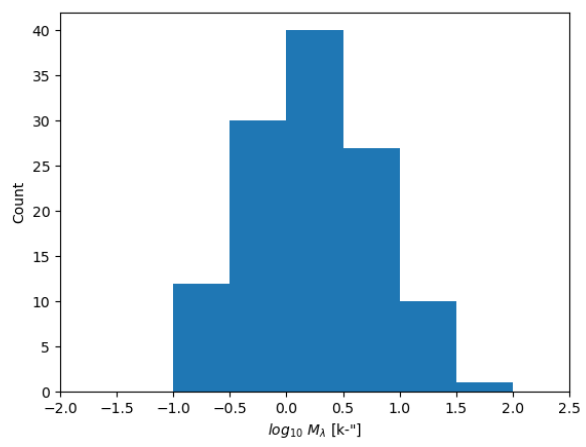

(c) Distribution of $M_{\lambda}$

For the P-BC1-3Point setup, 600 beams were analyzed and 522 had an Eigen shape classified as LTB. The results are summarized in Figure 9.3. $C_{1}$ and $C_{2}$ were fit to values of 1.46 and 0.52 which have errors of 8.1 and $5.5 \%$, respectively. The ratio of critical Eigen moments of 3-point loading to pure bending matched the expected with $C_{b}=1.35$. 
Figure 9.3: Results for narrow rectangular section with $\mathrm{BC} 1$ and 3 Point loading condition

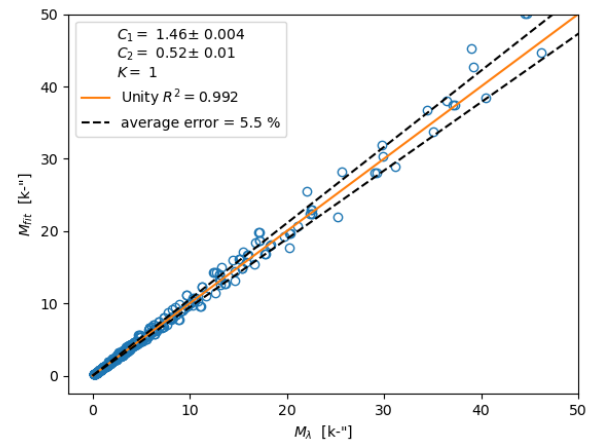

(a) Classical model vs. FEA critical moments

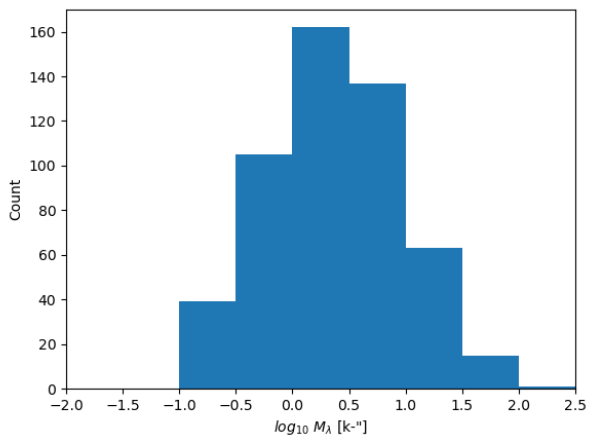

(c) Distribution of $M_{\lambda}$

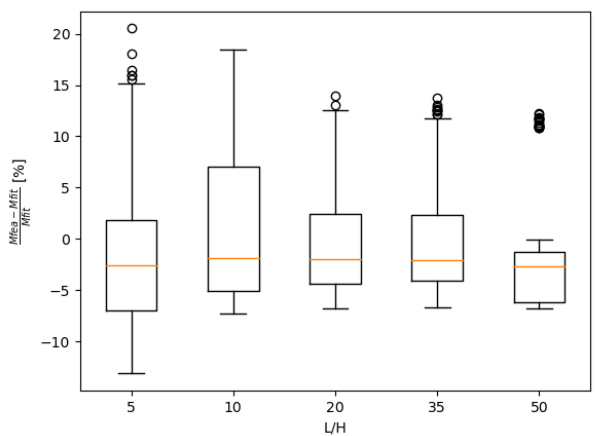

(b) Percent error vs. $L / H$

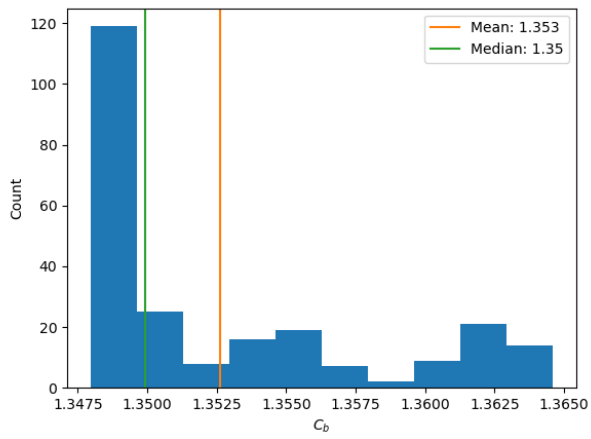

(d) Distribution of $C_{b}$

For the P-BC1-UDL setup, 360 beams were analyzed and all had an Eigen shape classified as LTB. The results are summarized in Figure 9.4. $C_{1}$ and $C_{2}$ were fit to values of 1.23 and 0.41 which have errors of 8.1 and $8.9 \%$, respectively. The median of the $C_{b}$ distribution matched the expected value of 1.13 . 
Figure 9.4: Results for narrow rectangular section with BC1 and uniformly distributed loading condition

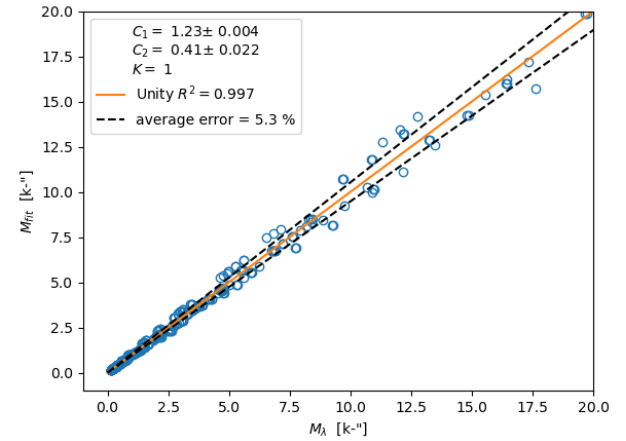

(a) Classical model vs. FEA critical moments

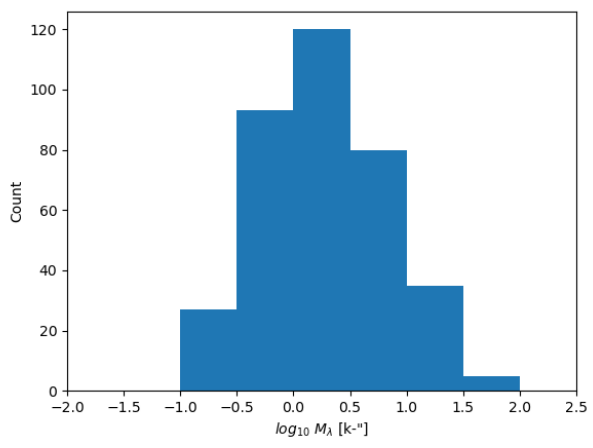

(c) Distribution of $M_{\lambda}$

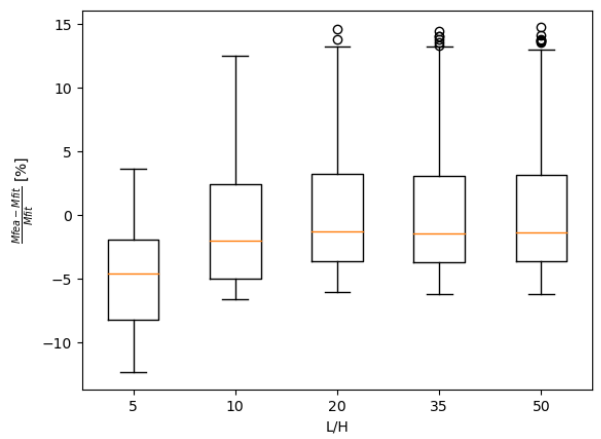

(b) Percent error vs. $L / H$

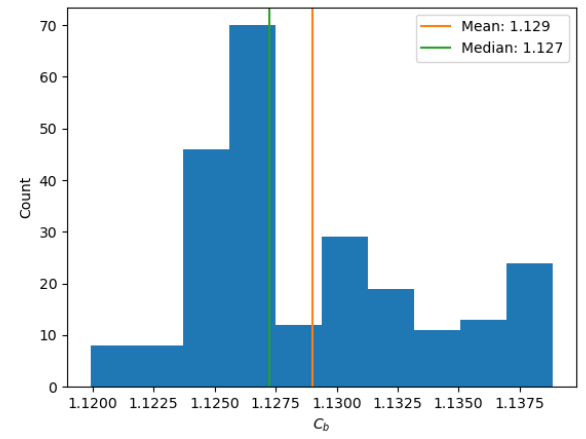

(d) Distribution of $C_{b}$

\subsection{Minor Axis Fixed}

This section shows the analysis results for orthotropic thin-rectangular beams with lateral bending fixed. Figure 9.5 shows the vertical, lateral, and torsional displacements through the span of a thin-rectangular beam at mid-height. These displacements are generated by three separate point load cases applied at the centroid of the beam, a vertical, lateral, and torque. The displacements are consistent with lateral bending and torsion being fixed as described by Equations 7.4 to 7.6. However, achieving sufficient torsional fixity of the narrow rectangular sections for LTB with a full wavelength mode was more difficult than for wide flange beams or channels. This is expected due 
to the plates' thickness. Thus, to increase the torsional fixity, the separation between the lateral supports was increased from $2 \%$ of the beam's length, to $4 \%$.

Figure 9.5: Validation of $\mathrm{BC} 2$ for narrow rectangular sections
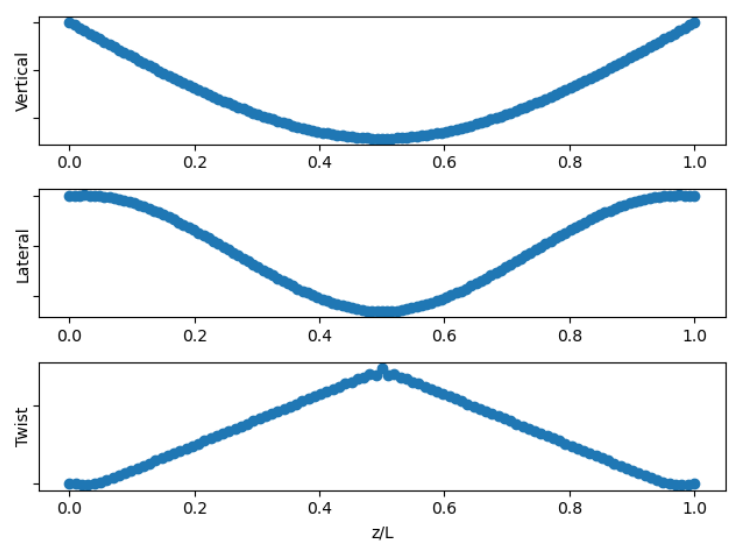

For the P-BC2-Moment setup, 120 beams were analyzed and 77 had an Eigen shape classified as LTB. Fewer LTB determinations are likely the result of local buckling affecting the twist. The results are summarized in Figure 9.6. $C_{1}$ was fit to a value of 1.24 which has an error of $24 \%$. 
Figure 9.6: Results for narrow rectangular section with $\mathrm{BC} 2$ and a pure bending loading condition

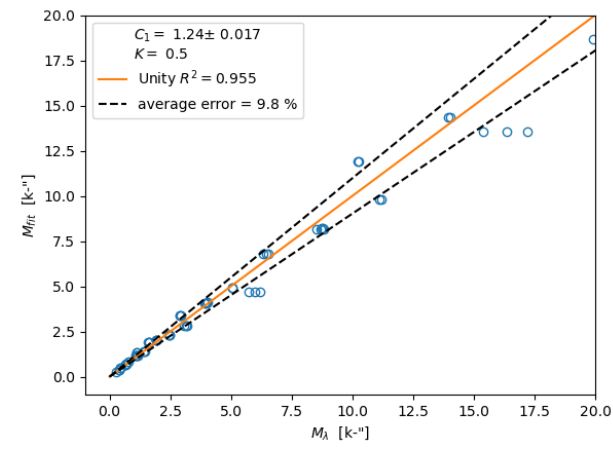

(a) Classical model vs. FEA critical moments

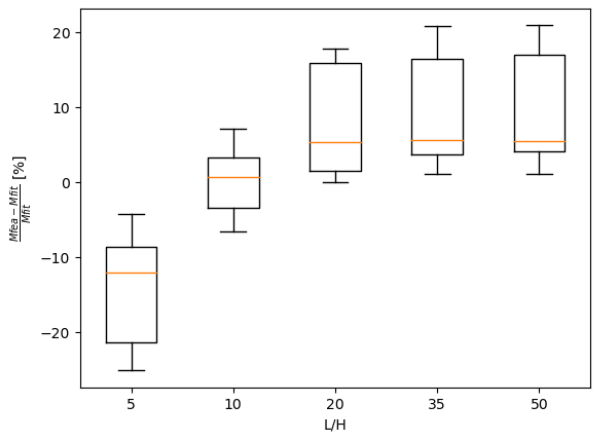

(b) Percent error vs. $L / H$

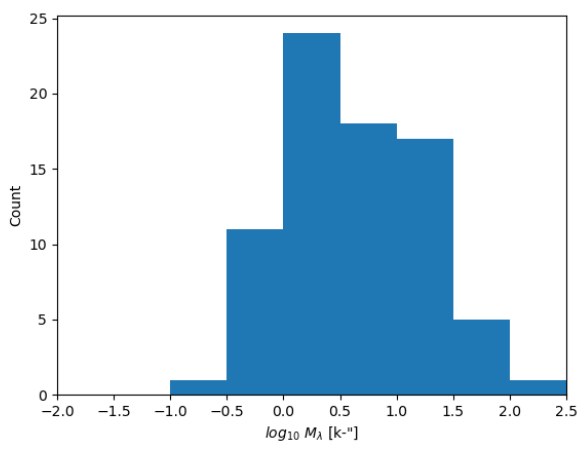

(c) Distribution of $M_{\lambda}$

For the P-BC2-3Point setup, 600 beams were analyzed and 396 had an Eigen shape classified as LTB. The results are summarized in Figure 9.3. $C_{1}$ and $C_{2}$ were fit to values of 1.19 and 0.38 which have errors of 11.2 and 9.5\%, respectively. The ratio of critical Eigen moments of UDL to pure bending gives a median value of $C_{b}=1.02$ which has a smaller error of $4.7 \%$. 
Figure 9.7: Results for narrow rectangular section with $\mathrm{BC} 2$ and 3 Point loading condition

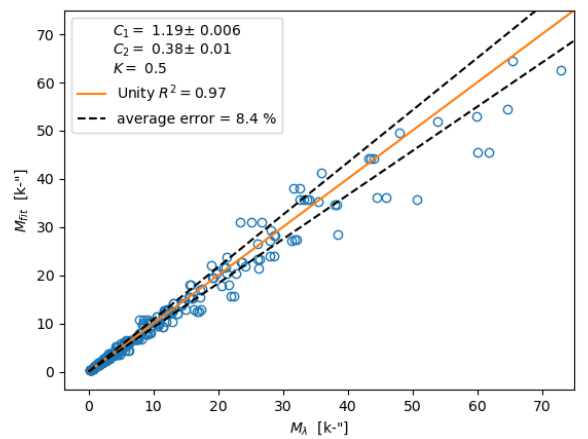

(a) Classical model vs. FEA critical moments

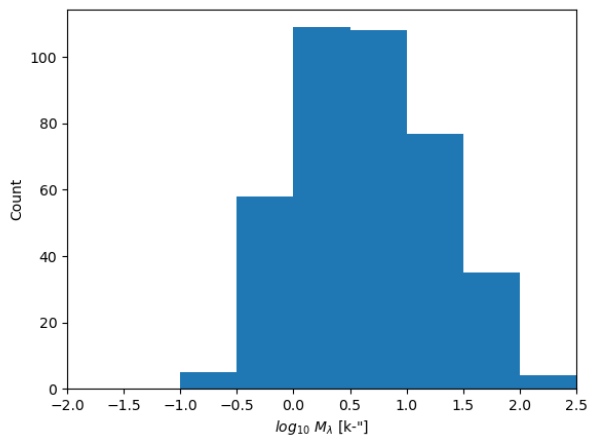

(c) Distribution of $M_{\lambda}$

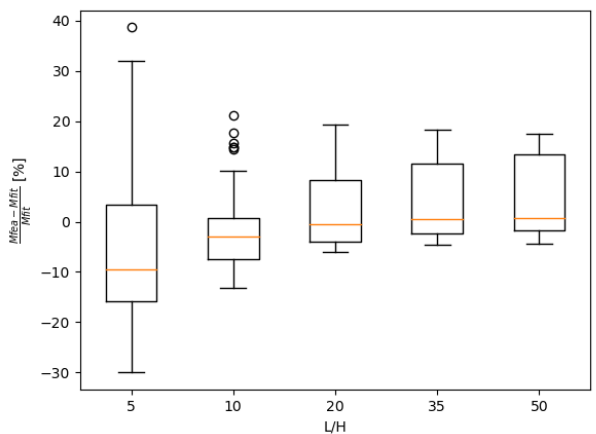

(b) Percent error vs. $L / H$

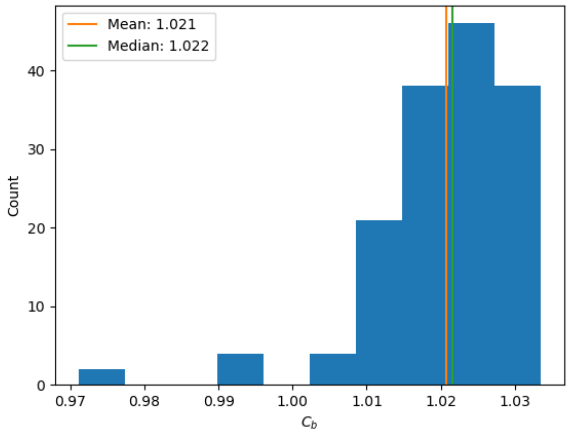

(d) Distribution of $C_{b}$

For the P-BC2-UDL setup, 360 beams were analyzed and 227 had an Eigen shape classified as LTB. The results are summarized in Figure 9.8. $C_{1}$ and $C_{2}$ were fit to values of 1.18 and 0.23 which have errors of 21.6 and $20.7 \%$, respectively. The median of the moment gradient distribution $C_{b}=0.98$ matches well to the expected value of 0.97 . 
Figure 9.8: Results for narrow rectangular section with BC2 and uniformly distributed loading condition

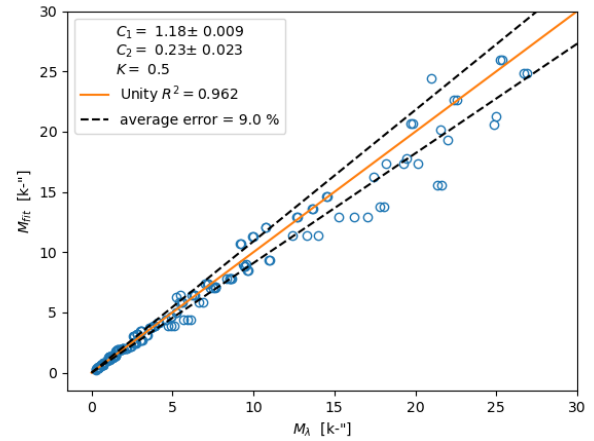

(a) Classical model vs. FEA critical moments

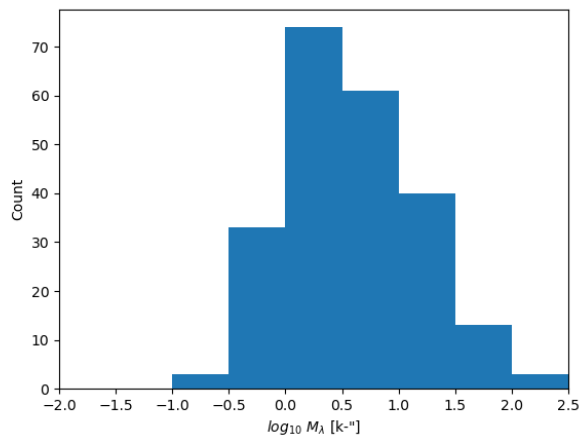

(c) Distribution of $M_{\lambda}$

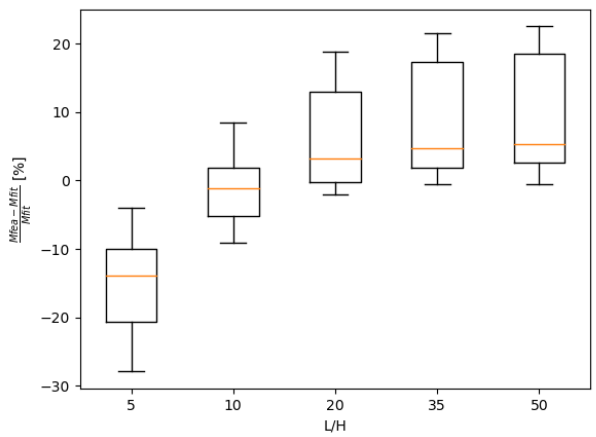

(b) Percent error vs. $L / H$

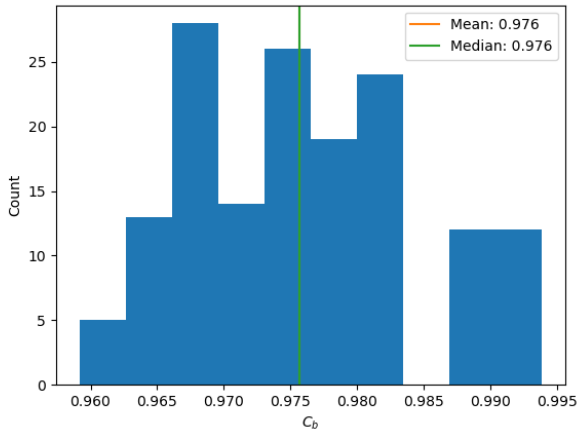

(d) Distribution of $C_{b}$

\subsection{Minor and Major Axes Fixed}

This section shows the analysis results for orthotropic, narrow rectangular beams with vertical and lateral bending fixed. Figure 9.9 shows the vertical, lateral, and torsional displacements through the span of a narrow rectangular beam at mid-height. These displacements are generated by three separate point load cases applied at the centroid of the beam, a vertical, lateral, and torque. The displacements are consistent with fixed minor and major bending axes as described by Equations 7.7 to 7.9. The pure bending load case conflicts with the supports for BC3 so only 3-point and uniformly distributed load cases are analyzed. 
Figure 9.9: Validation of $\mathrm{BC} 3$ for narrow rectangular sections
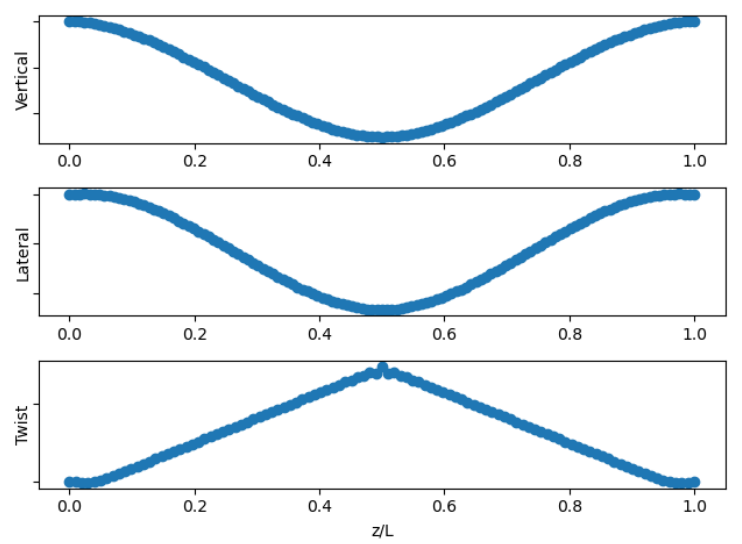

For the P-BC3-3Point setup, 600 beams were analyzed and 274 had an Eigen shape classified as LTB. The results are summarized in Figure 9.10. $C_{1}$ and $C_{2}$ were fit to values of 1.21 and 0.74 which have errors of 16.3 and $11.9 \%$, respectively. Since there is no pure bending load case, the critical Eigen moments of 3-point loading were compared to UDL case. This comparison can be done for eccentric load heights because $C_{2}$ for the two cases differs by only $2.4 \%$. This results in $C_{b} *=1.19$ compared to $\frac{C_{1_{3}}}{C_{1_{U D L}}}=1.04 / 0.86=1.21$. 
Figure 9.10: Results for narrow rectangular section with BC3 and 3 Point loading condition

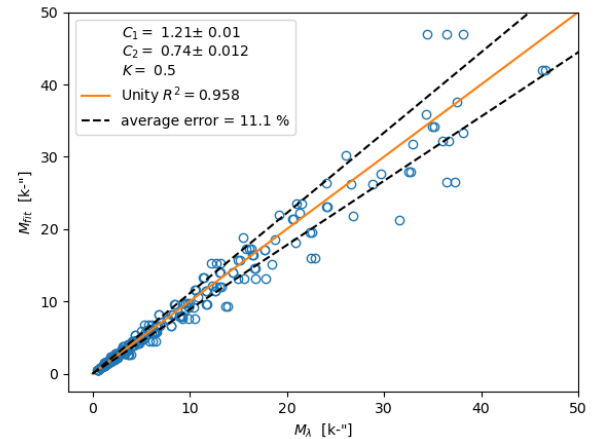

(a) Classical model vs. FEA critical moments

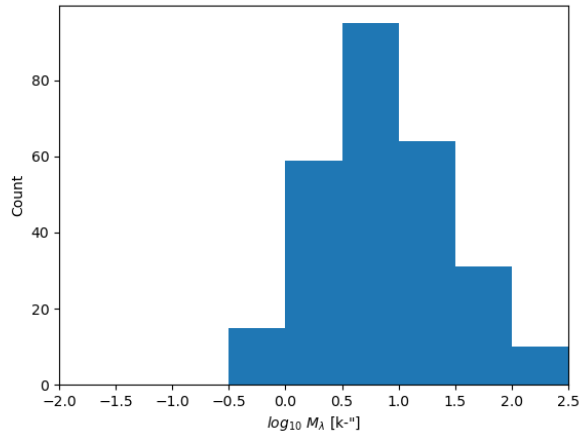

(c) Distribution of $M_{\lambda}$

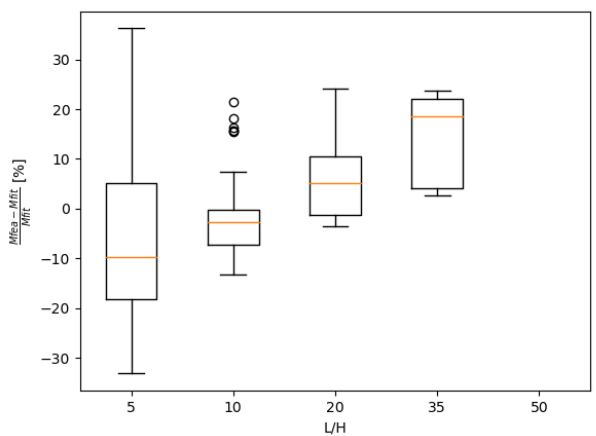

(b) Percent error vs. $L / H$

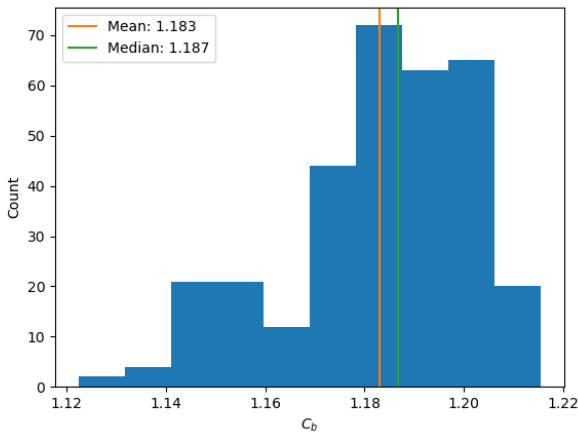

(d) Distribution of $C_{b} *$

For the P-BC3-UDL setup, 360 beams were analyzed and 166 had an Eigen shape classified as LTB. The results are summarized in Figure 9.11. $C_{1}$ and $C_{2}$ were fit to values of 1.10 and 0.64 which have errors of $27.9 \%$ and $22.0 \%$, respectively. 
Figure 9.11: Results for narrow rectangular section with BC3 and uniformly distributed loading condition

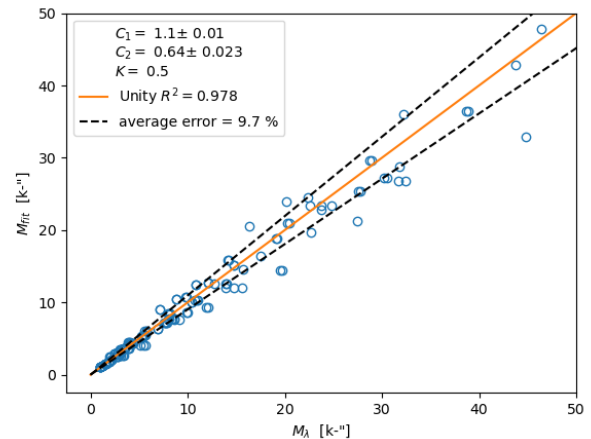

(a) Classical model vs. FEA critical moments

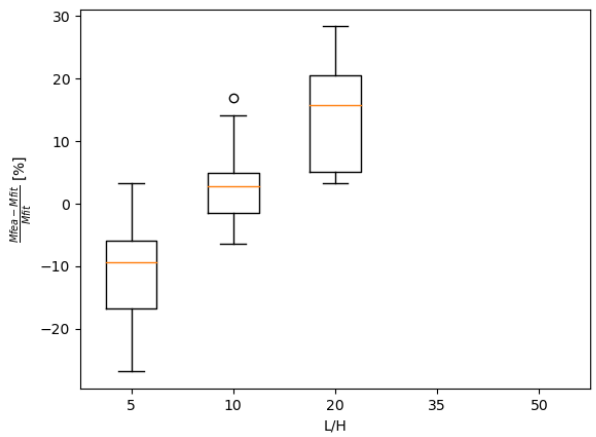

(b) Percent error vs. $L / H$

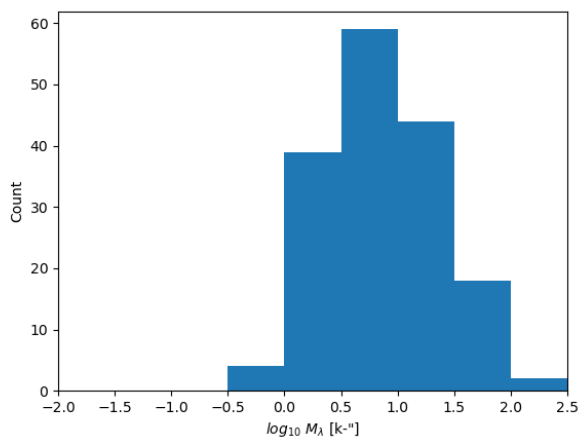

(c) Distribution of $M_{\lambda}$ 

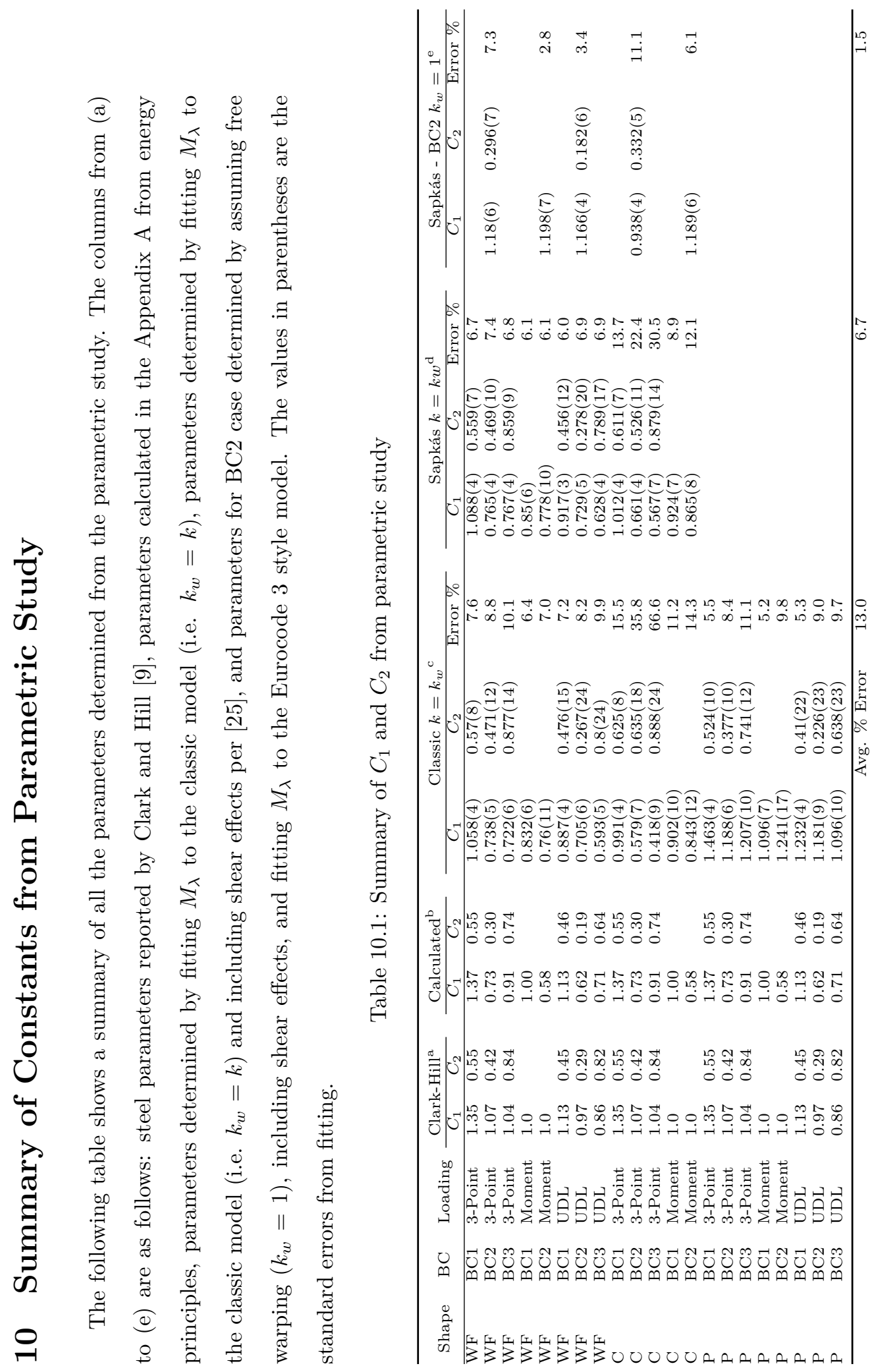


\section{Comparison to Experimental}

In this section, critical LTB loads are compared to the experimental data set generated by Nguyen et al. [23]. The experimental study by Nguyen et al. used two boundary conditions and three load heights. Comparisons to this data are shown in Tables 11.1 to 11.6 where the columns (a) through (e) are as follows: the experimental critical load, the critical load calculated with the classical model $\left(k_{w}=k\right)$, the critical load calculated using the parameters from Appendix A, including shear effects, and assuming warping as free $k_{w}=1$, the Eigen analysis buckling load, and the Riks analysis buckling load. The error from the experimental loads were calculated as shown below.

$$
\text { Error }=\frac{P_{t}-P}{P_{t}} \times 100 \%
$$

Table 11.1: Comparison of experimental data for pinned beams loaded on top flange

\begin{tabular}{|c|c|c|c|c|c|c|c|c|c|}
\hline \multirow{2}{*}{ Specimen } & \multirow{2}{*}{$\frac{P_{t}^{\mathrm{a}}}{\mathrm{kN}}$} & \multicolumn{2}{|c|}{$P_{0}\left(k_{w}=k\right)^{\mathrm{b}}$} & \multicolumn{2}{|c|}{$P_{0}^{S}\left(k_{w}=1\right)^{\mathrm{c}}$} & \multicolumn{2}{|c|}{$P_{\lambda}^{\mathrm{d}}$} & \multicolumn{2}{|c|}{$P_{R i k s}{ }^{\mathrm{e}}$} \\
\hline & & $\mathrm{kN}$ & $\%$ Error & $\mathrm{kN}$ & \%Error & $\mathrm{kN}$ & $\%$ Error & $\mathrm{kN}$ & \%Error \\
\hline I-4064 & 0.72 & 0.59 & 18.7 & 0.58 & 19.8 & 0.53 & 26.3 & 0.55 & 23.9 \\
\hline I-3454 & 1.08 & 0.82 & 23.8 & 0.81 & 25.1 & 0.73 & 32.3 & 0.75 & 30.1 \\
\hline I-2844 & 1.64 & 1.25 & 23.5 & 1.23 & 25.3 & 1.08 & 34.3 & 1.11 & 32.1 \\
\hline I- 2438 & 2.07 & 1.78 & 14.2 & 1.73 & 16.7 & 1.48 & 28.4 & 1.53 & 26.1 \\
\hline I-1828 & 3.79 & 3.53 & 6.9 & 3.38 & 10.7 & 2.74 & 27.7 & 2.83 & 25.3 \\
\hline C1-4064 & 0.65 & 0.70 & -7.9 & 0.72 & -10.7 & 0.54 & 16.7 & 0.53 & 18.1 \\
\hline C1-3454 & 1.00 & 0.98 & 2.3 & 1.01 & -0.8 & 0.74 & 25.5 & 0.82 & 18.2 \\
\hline C1-2844 & 1.45 & 1.47 & -1.6 & 1.53 & -5.5 & 1.07 & 26.0 & 0.94 & 35.0 \\
\hline C1-2438 & 1.82 & 2.07 & -13.6 & 2.15 & -18.2 & 1.44 & 21.0 & 1.45 & 20.3 \\
\hline C1-1828 & 3.31 & 4.05 & -22.5 & 4.18 & -26.3 & 3.10 & 6.5 & 3.23 & 2.4 \\
\hline C2-4064 & 0.64 & 0.65 & -1.9 & 0.67 & -4.0 & 0.51 & 19.7 & 0.52 & 18.8 \\
\hline $\mathrm{C} 2-3454$ & 0.97 & 0.90 & 7.1 & 0.92 & 4.6 & 0.69 & 28.6 & 0.69 & 28.7 \\
\hline C2-2844 & 1.29 & 1.34 & -4.0 & 1.39 & -7.5 & 1.01 & 22.1 & 2.44 & \\
\hline C2-2438 & 1.87 & 1.86 & 0.5 & 1.93 & -3.4 & 1.34 & 28.3 & 12.87 & \\
\hline C2-1828 & 4.03 & 3.55 & 11.9 & 3.71 & 8.1 & 2.82 & 29.9 & 3.00 & 25.6 \\
\hline C3-3454 & 0.38 & 0.35 & 7.0 & 0.35 & 6.9 & 0.30 & 22.1 & 0.29 & 23.3 \\
\hline C3-2844 & 0.60 & 0.51 & 14.4 & 0.51 & 14.4 & 0.43 & 28.5 & 0.43 & 27.7 \\
\hline C3-2438 & 0.78 & 0.69 & 11.3 & 0.69 & 11.2 & 0.57 & 26.5 & 0.58 & 25.9 \\
\hline C3-1828 & 1.12 & 1.22 & -9.3 & 1.22 & -9.2 & 0.98 & 12.3 & 0.99 & 12.0 \\
\hline$\overline{\text { Avg \%Erro }}$ & & & 4.2 & & 3.0 & & 24.3 & & 23.2 \\
\hline
\end{tabular}


Table 11.2: Comparison of experimental data for pinned beams loaded at shear center

\begin{tabular}{|c|c|c|c|c|c|c|c|c|c|}
\hline \multirow{2}{*}{ Specimen } & \multirow{2}{*}{$\frac{P_{t}^{\mathrm{a}}}{\mathrm{kN}}$} & \multicolumn{2}{|c|}{$P_{0}\left(k_{w}=k\right)^{\mathrm{b}}$} & \multicolumn{2}{|c|}{$P_{0}^{S}\left(k_{w}=1\right)^{\mathrm{c}}$} & \multicolumn{2}{|c|}{$P_{\lambda}^{\mathrm{d}}$} & \multicolumn{2}{|c|}{$P_{R i k s}{ }^{\mathrm{e}}$} \\
\hline & & $\mathrm{kN}$ & $\%$ Error & $\mathrm{kN}$ & $\%$ Error & $\mathrm{kN}$ & $\%$ Error & $\mathrm{kN}$ & $\%$ Error \\
\hline I-4064 & 0.90 & 0.71 & 20.9 & 0.70 & 21.8 & 0.64 & 28.6 & 0.67 & 25.5 \\
\hline I-3454 & 1.29 & 1.02 & 20.6 & 1.01 & 21.9 & 0.91 & 29.5 & 0.95 & 26.6 \\
\hline I-2844 & 2.09 & 1.60 & 23.4 & 1.57 & 25.0 & 1.39 & 33.5 & 1.45 & 30.7 \\
\hline I-2438 & 2.90 & 2.31 & 20.4 & 2.25 & 22.4 & 1.96 & 32.4 & 2.04 & 29.5 \\
\hline I-1828 & 6.12 & 4.72 & 22.9 & 4.55 & 25.6 & 3.80 & 38.0 & 3.98 & 35.0 \\
\hline C1-4064 & 0.80 & 0.91 & -14.3 & 0.93 & -15.9 & 0.69 & 14.1 & 0.75 & 6.5 \\
\hline C1-3454 & 1.49 & 1.31 & 12.3 & 1.33 & 10.9 & 0.98 & 34.2 & 1.06 & 28.6 \\
\hline C1-2844 & 1.96 & 2.03 & -3.4 & 2.06 & -5.1 & 1.48 & 24.6 & 1.61 & 17.7 \\
\hline C1-2438 & 3.03 & 2.90 & 4.3 & 2.94 & 2.9 & 2.06 & 32.1 & 2.25 & 25.8 \\
\hline C1-1828 & 5.54 & 5.85 & -5.5 & 5.82 & -5.1 & 4.83 & 12.9 & 5.12 & 7.6 \\
\hline $\mathrm{C} 2-4064$ & 0.81 & 0.83 & -2.4 & 0.84 & -3.7 & 0.63 & 21.7 & 0.70 & 13.7 \\
\hline C2-3454 & 1.34 & 1.18 & 12.2 & 1.20 & 10.7 & 0.88 & 34.2 & 0.97 & 27.3 \\
\hline C2-2844 & 1.60 & 1.81 & -12.9 & 1.84 & -15.1 & 1.34 & 16.3 & 1.47 & 8.1 \\
\hline $\mathrm{C} 2-2438$ & 2.66 & 2.56 & 3.7 & 2.62 & 1.6 & 1.85 & 30.4 & 2.04 & 23.4 \\
\hline $\mathrm{C} 2-1828$ & 5.85 & 5.05 & 13.6 & 5.15 & 11.9 & 4.29 & 26.6 & 4.86 & 16.8 \\
\hline C3-3454 & 0.44 & 0.42 & 4.4 & 0.42 & 4.8 & 0.34 & 22.0 & 0.36 & 18.3 \\
\hline C3-2844 & 0.62 & 0.63 & -1.5 & 0.62 & -0.7 & 0.51 & 17.4 & 0.54 & 13.6 \\
\hline C3-2438 & 0.88 & 0.87 & 1.3 & 0.86 & 2.4 & 0.70 & 20.2 & 0.74 & 16.3 \\
\hline C3-1828 & 1.47 & 1.61 & -9.6 & 1.57 & -7.1 & 1.27 & 13.5 & 1.34 & 8.7 \\
\hline Avg \%Erro & & & 5.8 & & 5.7 & & 25.4 & & 20.0 \\
\hline
\end{tabular}

Table 11.3: Comparison of experimental data for pinned beams loaded on bottom flange

\begin{tabular}{|c|c|c|c|c|c|c|c|c|c|}
\hline \multirow{2}{*}{ Specimen } & \multirow{2}{*}{$\frac{P_{t}^{\mathrm{a}}}{\mathrm{kN}}$} & \multicolumn{2}{|c|}{$P_{0}\left(k_{w}=k\right)^{\mathrm{b}}$} & \multicolumn{2}{|c|}{$P_{0}^{S}\left(k_{w}=1\right)^{\mathrm{c}}$} & \multicolumn{2}{|c|}{$P_{\lambda}^{\mathrm{d}}$} & \multicolumn{2}{|c|}{$P_{R i k s}{ }^{\mathrm{e}}$} \\
\hline & & $\mathrm{kN}$ & \%Error & $\mathrm{kN}$ & $\%$ Error & $\mathrm{kN}$ & $\%$ Error & $\mathrm{kN}$ & \%Error \\
\hline I-4064 & 1.11 & 0.90 & 18.7 & 0.89 & 19.5 & 0.78 & 29.9 & 0.82 & 26.6 \\
\hline I-3454 & 1.61 & 1.34 & 16.8 & 1.32 & 17.8 & 1.13 & 29.7 & 1.19 & 26.2 \\
\hline I-2844 & 2.59 & 2.18 & 15.8 & 2.15 & 17.1 & 1.79 & 30.9 & 1.89 & 27.1 \\
\hline I-2438 & 3.94 & 3.25 & 17.6 & 3.19 & 19.1 & 2.61 & 33.8 & 2.75 & 30.2 \\
\hline I-1828 & 9.12 & 7.02 & 23.1 & 6.84 & 25.0 & 5.37 & 41.1 & 5.72 & 37.3 \\
\hline C1-4064 & 1.11 & 1.30 & -16.7 & 1.29 & -15.9 & 0.87 & 21.9 & 0.95 & 14.8 \\
\hline C1-3454 & 1.76 & 1.94 & -10.5 & 1.92 & -8.9 & 1.28 & 27.4 & 1.42 & 19.2 \\
\hline C1-2844 & 2.65 & 3.21 & -21.0 & 3.11 & -17.4 & 2.01 & 24.0 & 2.27 & 14.4 \\
\hline C1-2438 & 4.23 & 4.82 & -13.9 & 4.59 & -8.4 & 2.90 & 31.4 & 3.31 & 21.8 \\
\hline C1-1828 & 7.57 & 10.58 & -39.8 & 9.48 & -25.3 & 5.09 & & 8.19 & \\
\hline C2-4064 & 1.10 & 1.12 & -2.2 & 1.13 & -2.4 & 0.78 & 29.3 & 0.86 & 21.5 \\
\hline C2-3454 & 1.59 & 1.67 & -5.1 & 1.67 & -5.0 & 1.11 & 29.9 & 1.23 & 22.5 \\
\hline C2-2844 & 2.67 & 2.72 & -1.9 & 2.70 & -1.2 & 1.76 & 34.0 & 2.00 & 25.1 \\
\hline C2-2438 & 4.12 & 4.05 & 1.8 & 3.99 & 3.2 & 2.52 & 38.8 & 2.88 & 30.1 \\
\hline C2-1828 & 7.32 & 8.74 & -19.4 & 8.35 & -14.1 & 6.36 & 13.1 & 7.42 & -1.4 \\
\hline C3-3454 & 0.47 & 0.52 & -9.8 & 0.51 & -8.5 & 0.40 & 15.7 & 0.42 & 11.2 \\
\hline C3-2844 & 0.94 & 0.80 & 14.4 & 0.79 & 16.1 & 0.61 & 35.4 & 0.65 & 31.3 \\
\hline C3-2438 & 1.07 & 1.15 & -7.9 & 1.12 & -4.7 & 0.85 & 20.2 & 0.91 & 14.5 \\
\hline C3-1828 & 1.92 & 2.32 & -20.9 & 2.18 & -13.5 & 1.63 & 15.0 & 1.78 & 7.1 \\
\hline
\end{tabular}


Table 11.4: Comparison of experimental data for beams with minor axis fixed and loaded on top flange

\begin{tabular}{|c|c|c|c|c|c|c|c|c|c|}
\hline \multirow{2}{*}{ Specimen } & \multirow{2}{*}{$\frac{P_{t}^{\mathrm{a}}}{\mathrm{kN}}$} & \multicolumn{2}{|c|}{$P_{0}\left(k_{w}=k\right)^{\mathrm{b}}$} & \multicolumn{2}{|c|}{$P_{0}^{S}\left(k_{w}=1\right)^{\mathrm{c}}$} & \multicolumn{2}{|c|}{$P_{\lambda}{ }^{\mathrm{d}}$} & \multicolumn{2}{|c|}{$P_{\text {Riks }}{ }^{\mathrm{e}}$} \\
\hline & & $\mathrm{kN}$ & $\%$ Error & $\mathrm{kN}$ & $\%$ Error & $\mathrm{kN}$ & $\%$ Error & $\mathrm{kN}$ & \%Error \\
\hline I-4064 & 1.03 & 1.16 & -12.3 & 0.64 & 37.4 & 0.95 & 8.2 & 0.95 & 8.1 \\
\hline I-3454 & 1.47 & 1.73 & -17.8 & 0.91 & 37.8 & 1.35 & 8.0 & 1.36 & 7.7 \\
\hline I-2844 & 2.10 & 2.86 & -36.2 & 1.41 & 32.8 & 2.10 & -0.1 & 2.11 & -0.6 \\
\hline I-2438 & 3.33 & 4.31 & -29.6 & 2.02 & 39.5 & 3.01 & 9.8 & 3.03 & 9.0 \\
\hline I-1828 & 6.29 & 9.56 & -52.0 & 4.06 & 35.5 & 5.91 & 6.1 & 5.98 & 4.9 \\
\hline C1-4064 & 1.01 & 1.37 & -35.7 & 0.79 & 22.0 & 0.87 & 14.0 & 0.83 & 17.4 \\
\hline C1-3454 & 1.46 & 2.04 & -39.8 & 1.10 & 24.5 & 1.26 & 14.0 & 1.30 & 11.0 \\
\hline C1-2844 & 1.87 & 3.35 & -79.3 & 1.65 & 11.6 & 1.88 & -0.3 & 1.82 & 2.8 \\
\hline C1-2438 & 3.28 & 5.04 & -53.7 & 2.29 & 30.3 & 2.59 & 20.9 & 2.67 & 18.6 \\
\hline C1-1828 & 5.02 & 11.11 & -121.4 & 4.17 & 16.9 & 6.22 & -23.9 & 6.48 & -29.1 \\
\hline C2-4064 & 0.80 & 1.21 & -50.7 & 0.74 & 7.7 & 0.81 & -1.3 & 0.75 & 6.4 \\
\hline $\mathrm{C} 2-3454$ & 1.22 & 1.77 & -45.0 & 1.03 & 15.3 & 1.10 & 9.4 & 0.96 & 21.5 \\
\hline C2-2844 & 1.81 & 2.85 & -57.7 & 1.56 & 13.9 & 1.68 & 6.9 & 3.85 & \\
\hline C2-2438 & 2.62 & 4.24 & -61.7 & 2.17 & 17.2 & 2.30 & 12.0 & 2.25 & 13.9 \\
\hline C2-1828 & 5.47 & 9.16 & -67.5 & 4.06 & 25.9 & 5.42 & 0.8 & 5.69 & -4.0 \\
\hline C3-3454 & 0.52 & 0.58 & -12.1 & 0.37 & 28.7 & 0.46 & 12.3 & 0.40 & 23.3 \\
\hline C3-2844 & 0.80 & 0.88 & -10.2 & 0.53 & 33.3 & 0.68 & 15.2 & 0.69 & 14.2 \\
\hline C3-2438 & 1.12 & 1.24 & -10.7 & 0.71 & 36.5 & 0.92 & 18.3 & 0.93 & 17.2 \\
\hline C3-1828 & 1.90 & 2.43 & -27.8 & 1.21 & 36.1 & 1.61 & 15.1 & 1.63 & 14.1 \\
\hline$\overline{\text { Avg \%Errc }}$ & & & -43.2 & & 26.5 & & 7.7 & & 8.7 \\
\hline
\end{tabular}

Table 11.5: Comparison of experimental data for beams with minor axis fixed and loaded at shear center

\begin{tabular}{|c|c|c|c|c|c|c|c|c|c|}
\hline \multirow{2}{*}{ Specimen } & \multirow{2}{*}{$\frac{P_{t}^{\mathrm{a}}}{\mathrm{kN}}$} & \multicolumn{2}{|c|}{$P_{0}\left(k_{w}=k\right)^{\mathrm{b}}$} & \multicolumn{2}{|c|}{$P_{0}^{S}\left(k_{w}=1\right)^{\mathrm{c}}$} & \multicolumn{2}{|c|}{$P_{\lambda}^{\mathrm{d}}$} & \multicolumn{2}{|c|}{$P_{\text {Riks }}{ }^{\mathrm{e}}$} \\
\hline & & $\mathrm{kN}$ & $\%$ Error & $\mathrm{kN}$ & $\%$ Error & $\mathrm{kN}$ & $\%$ Error & $\mathrm{kN}$ & \%Error \\
\hline I-4064 & 1.34 & 1.42 & -6.0 & 0.76 & 43.5 & 1.21 & 9.7 & 1.21 & 9.8 \\
\hline I-3454 & 2.01 & 2.15 & -6.9 & 1.08 & 46.2 & 1.77 & 11.9 & 1.80 & 10.2 \\
\hline I- 2844 & 3.24 & 3.58 & -10.6 & 1.68 & 48.2 & 2.82 & 12.9 & 2.83 & 12.7 \\
\hline I-2438 & 4.53 & 5.44 & -20.0 & 2.40 & 46.9 & 4.09 & 9.8 & 4.11 & 9.4 \\
\hline I-1828 & & 12.13 & & 4.82 & & 8.16 & & 8.23 & \\
\hline C1-4064 & 1.26 & 1.77 & -40.4 & 0.94 & 25.6 & 1.19 & 5.7 & 1.18 & 6.6 \\
\hline C1-3454 & 2.01 & 2.65 & -32.1 & 1.31 & 34.6 & 1.77 & 11.8 & 1.76 & 12.6 \\
\hline C1-2844 & 3.49 & 4.38 & -25.6 & 1.97 & 43.5 & 2.75 & 21.3 & 2.74 & 21.6 \\
\hline C1-2438 & 4.92 & 6.61 & -34.3 & 2.72 & 44.7 & 3.89 & 20.9 & 3.91 & 20.4 \\
\hline C1-1828 & 8.44 & 14.59 & -72.9 & 4.97 & 41.2 & 9.67 & -14.5 & 15.57 & \\
\hline C2-4064 & 1.24 & 1.54 & -24.3 & 0.88 & 29.4 & 1.08 & 13.0 & 1.06 & 14.2 \\
\hline C2-3454 & 1.91 & 2.28 & -19.6 & 1.23 & 35.5 & 1.52 & 20.6 & 1.41 & 26.0 \\
\hline C2-2844 & 2.37 & 3.72 & -56.8 & 1.86 & 21.6 & 2.41 & -1.5 & 2.40 & -1.1 \\
\hline $\mathrm{C} 2-2438$ & 3.83 & 5.54 & -44.6 & 2.58 & 32.5 & 3.39 & 11.5 & 3.40 & 11.3 \\
\hline C2-1828 & & 12.02 & & 4.81 & & 8.40 & & 11.57 & \\
\hline C3-3454 & 0.66 & 0.72 & -8.7 & 0.43 & 35.4 & 0.56 & 14.9 & 0.55 & 16.0 \\
\hline C3-2844 & 1.02 & 1.11 & -8.5 & 0.62 & 39.1 & 0.86 & 15.2 & 0.85 & 16.2 \\
\hline C3-2438 & 1.38 & 1.58 & -14.3 & 0.83 & 39.5 & 1.20 & 13.1 & 1.19 & 14.0 \\
\hline C3-1828 & 2.66 & 3.15 & -18.3 & 1.44 & 45.9 & 2.23 & 16.3 & 2.22 & 16.5 \\
\hline$\overline{\text { Avg \%Erro }}$ & & & -26.1 & & 38.4 & & 11.3 & & 13.5 \\
\hline
\end{tabular}


Table 11.6: Comparison of experimental data for beams with minor axis fixed and loaded on bottom flange

\begin{tabular}{|c|c|c|c|c|c|c|c|c|c|}
\hline \multirow{2}{*}{ Specimen } & \multirow{2}{*}{$\frac{P_{t}^{\mathrm{a}}}{\mathrm{kN}}$} & \multicolumn{2}{|c|}{$P_{0}\left(k_{w}=k\right)^{\mathrm{b}}$} & \multicolumn{2}{|c|}{$P_{0}^{S}\left(k_{w}=1\right)^{\mathrm{c}}$} & \multicolumn{2}{|c|}{$P_{\lambda}^{\mathrm{d}}$} & \multicolumn{2}{|c|}{$P_{R i k s}{ }^{\mathrm{e}}$} \\
\hline & & $\mathrm{kN}$ & $\%$ Error & $\mathrm{kN}$ & $\%$ Error & $\mathrm{kN}$ & $\%$ Error & $\mathrm{kN}$ & $\%$ Error \\
\hline I-4064 & 1.68 & 1.92 & -14.2 & 1.01 & 39.8 & 1.55 & 7.6 & 1.55 & 7.9 \\
\hline I-3454 & 2.63 & 2.97 & -13.1 & 1.51 & 42.6 & 2.33 & 11.4 & 2.33 & 11.5 \\
\hline I- 2844 & 4.48 & 5.08 & -13.5 & 2.47 & 44.8 & 3.83 & 14.5 & 3.84 & 14.4 \\
\hline I-2438 & 6.04 & 7.85 & -29.9 & 3.70 & 38.8 & 5.70 & 5.6 & 5.72 & 5.3 \\
\hline I-1828 & & 17.94 & & 7.99 & & 11.97 & & 12.11 & \\
\hline C1-4064 & 1.59 & 2.80 & -76.0 & 1.37 & 13.8 & 1.62 & -1.9 & 1.43 & 9.9 \\
\hline C1-3454 & & 4.37 & & 2.00 & & 2.48 & & 2.48 & \\
\hline C1-2844 & 4.29 & 7.52 & -75.2 & 3.11 & 27.4 & 3.97 & 7.4 & 3.99 & 6.9 \\
\hline C1-2438 & 7.32 & 11.65 & -59.2 & 4.39 & 40.0 & 5.77 & 21.2 & 5.68 & 22.4 \\
\hline C1-1828 & 12.70 & 26.80 & -111.0 & 8.12 & 36.1 & 5.08 & & 10.57 & \\
\hline C2-4064 & 1.68 & 2.34 & -39.3 & 1.24 & 26.1 & 1.43 & 15.1 & 1.24 & 26.3 \\
\hline C2-3454 & 2.37 & 3.62 & -52.6 & 1.83 & 23.0 & 2.07 & 12.6 & 1.57 & 33.8 \\
\hline $\mathrm{C} 2-2844$ & 3.71 & 6.16 & -66.2 & 2.90 & 21.7 & 3.39 & 8.7 & 3.38 & 8.8 \\
\hline C2-2438 & 4.95 & 9.49 & -91.7 & 4.19 & 15.4 & 4.89 & 1.2 & 4.88 & 1.5 \\
\hline $\mathrm{C} 2-1828$ & & 21.63 & & 8.18 & & 8.68 & & 9.54 & \\
\hline C3-3454 & 0.80 & 0.97 & -21.7 & 0.53 & 33.3 & 0.69 & 13.7 & 0.67 & 16.0 \\
\hline C3-2844 & 1.35 & 1.58 & -17.2 & 0.81 & 40.3 & 1.10 & 18.9 & 1.09 & 19.4 \\
\hline C3-2438 & 2.22 & 2.35 & -5.9 & 1.12 & 49.7 & 1.56 & 29.7 & 1.55 & 30.0 \\
\hline C3-1828 & 3.72 & 5.07 & -36.2 & 2.02 & 45.7 & 3.05 & 18.0 & 3.03 & 18.5 \\
\hline$\overline{\text { Avg \%Erro }}$ & & & -45.2 & & 33.7 & & 12.3 & & 15.5 \\
\hline
\end{tabular}

\section{Conclusion}

In this report, a parametric study was performed with the finite element analysis software ABAQUS to better characterize lateral-torsional buckling for pultruded FRP beams. Wide flange, channel, and narrow rectangular beams were analyzed with a linear eigen analysis and a non-linear geometric modified Riks analysis for LTB with three loading and three support conditions. The parameters $C_{1}$ and $C_{2}$ in the classical expressions for critical LTB moment were determined by a non-linear regression fitting with the critical buckling from the eigen analysis. These parameters were determined for three conditions: $k=k_{w}$, including torsional and lateral shear deformation effects with $k=k_{w}$, and shear deformation effects with $k_{w}=1$ for $\mathrm{BC} 2$. The parameters were also calculated from energy principles via the integration expressions from [9] using the same shape function to classify LTB of eigen modes.

- The calculated parameters, $C_{1}$ and $C_{2}$, matched the nominal values for BC1. However, they 
differed significantly for $\mathrm{BC} 2$ and $\mathrm{BC} 3$.

- The nominal $C_{1}$ factors for steel were found to agree well with the ratio of critical LTB moments between a load case and the pure bending for WF and narrow rectangular profiles. Channel profiles had about $15 \%$ and $17 \%$ error for their ratio of critical moments for the 3 point load case for $\mathrm{BC} 1$ and $\mathrm{BC} 2$, respectively. This may be from non-perfect loading placement resulting in a slight eccentricity (i.e. bifurcation buckling was not achieved for channels).

- While $C_{1}$ had a consistent error from the nominal values for each boundary condition and shape, $C_{2}$ matched the nominal values well for $\mathrm{BC} 1$ and $\mathrm{BC} 3$ once lateral and torsional shear effects were taken into account, roughly $2 \%$ when using $k=k_{w}$.

- There were larger errors associated with $\mathrm{BC} 2$ when warping was assumed fixed with lateral bending, $k=k_{w}=0.5$. The fit values of $C_{2}$ with $k_{w}=1$ matched the calculated values better than the nominal values with $k_{w}=0.5$. The error of $C_{2}$ reduced on average for the 3 cases from $13.7 \%$ to $5.2 \%$ and the average error between $M_{\lambda}$ and $M_{f i t}$ decreased by up to $50 \%$ when considering warping as free.

In addition to the parametric study, two smaller analyses looked into the effect of the transverse elastic modulus $E_{T}$ and asymmetric longitudinal elastic modulus $\left(E_{L_{c}} \neq E_{L_{t}}\right)$ on lateral-torsional buckling. While $E_{T}$ may roughly be estimated as $E_{L} / 2.45$ for GFRP [7], $E_{T}$ was not found to have a significant effect on LTB through FEA. Likewise, $E_{L_{t}}$ was found to minimally impact LTB which can be attributed to the shear center deviating from the center of gravity. Thus, the critical LTB moment of a beam with an asymmetric $E_{L}$ was found to be controlled only by the compressive modulus. While this asymmetry may be insignificant to a designer using GFRP beams, measuring $E_{L_{c}}$ may be important to researchers for reducing errors in LTB prediction. 


\section{References}

[1] Ahmadi, Habiburrahman. "Lateral torsional buckling of anisotropic laminated composite beams subjected to various loading and boundary conditions." PhD thesis. Kansas State University, 2017.

[2] ANSI/AISC-360. "Specification for structural steel buildings." In: American Institute of Steel Construction, Chicago, IL (2016).

[3] Bank, Lawrence C. "Flexural and shear moduli of full-section fiber reinforced plastic (FRP) pultruded beams." In: Journal of Testing and Evaluation 17.1 (1989), pp. 40-45.

[4] Barbero, Ever J. Introduction to composite materials design. CRC press, 2010.

[5] Barbero, Ever J. and Raftoyiannis, Ioannis G. "Lateral and distortional buckling of pultruded I-beams." In: Composite Structures 27.3 (1994), pp. 261-268.

[6] Bauld Jr, Nelson R and Lih-Shyng, Tzeng. "A Vlasov theory for fiber-reinforced beams with thin-walled open cross sections." In: International Journal of Solids and Structures 20.3 (1984), pp. $277-297$.

[7] Bendidi, Rachid. "Modeling and testing of FRP structural shapes under bending." xv, 167 leaves : illustrations ; $29 \mathrm{~cm}$. PhD thesis. West Virginia University, 1996.

[8] Brooks, R.J. and Thrvey, G.J. "Lateral buckling of pultruded GRP I-section cantilevers." In: Composite Structures 32.1 (1995). Eighth International Conference on Composite Structures, pp. $203-215$.

[9] Clark, J. W. and Hill, H. N. "Lateral Buckling of Beams." In: Transactions of the American Society of Civil Engineers 127.2 (1962), pp. 180-201. DOI: 10.1061/TACEAT . 0008498. eprint: https : / / ascelibrary . org/doi /pdf / 10 . 1061/ TACEAT . 0008498. URL: https : //ascelibrary.org/doi/abs/10.1061/TACEAT.0008498.

[10] Eurocode 3-Design of steel structures. British Standard. 2006.

[11] Flint, Anthony Ray. "On the lateral stability of beams." PhD thesis. University of Bristol, 1948. 
[12] GangaRao, Hota V. S. and Prachasaree, Woraphot. FRP composite structures : theory, fundamentals, and design. English. Boca Raton, FL, 2022. URL: https://www.taylorfrancis. com/books/9781003196754.

[13] Goodier, James Norman. The buckling of compressed bars by torsion and flexure. Cornell University Engineering Experiment Station, 1941.

[14] Khan, Q. S., Sheikh, M. Neaz., and Hadi, M. N. S. "Tension and compression testing of fibre reinforced polymer (FRP) bars." In: 5th Asia-Pacific Conference on Fiber Reinforced Polymers in Structures (APFIS-2015) (2015), pp. 1-6.

[15] Khorramian, Koosha and Sadeghian, Pedram. "Material characterization of GFRP bars in compression using a new test method." In: Journal of Testing and Evaluation 49.2 (2019), pp. 1037-1052.

[16] Lopez-Anido, Roberto and GangaRao, Hota VS. "Warping solution for shear lag in thin-walled orthotropic composite beams." In: Journal of engineering mechanics 122.5 (1996), pp. 449457.

[17] Michell, AG Ml. "XXXII. Elastic stability of long beams under transverse forces." In: The London, Edinburgh, and Dublin Philosophical Magazine and Journal of Science 48.292 (1899), pp. $298-309$.

[18] Mottram, JT. "Lateral-torsional buckling of a pultruded I-beam." In: Composites 23.2 (1992), pp. 81-92.

[19] Mottram, JT. "Lateral-torsional buckling of thin-walled composite I-beams by the finite difference method." In: Composites Engineering 2.2 (1992), pp. 91-104.

[20] Nethercot, DA. "The effective lengths of cantilevers as governed by lateral buckling." In: The Structural Engineer 51.5 (1973), pp. 161-168.

[21] Nguyen, TT, Chan, Tak Ming, and Mottram, JT. "Influence of boundary conditions and geometric imperfections on lateral-torsional buckling resistance of a pultruded FRP I-beam by FEA." In: Composite Structures 100 (2013), pp. 233-242. 
[22] Nguyen, TT, Chan, Tak Ming, and Mottram, JT. "Lateral-Torsional Buckling design for pultruded FRP beams." In: Composite Structures 133 (2015), pp. 782-793.

[23] Nguyen, TT, Chan, Tak Ming, and Mottram, JT. "Lateral-torsional buckling resistance by testing for pultruded FRP beams under different loading and displacement boundary conditions." In: Composites Part B: Engineering 60 (2014), pp. 306-318.

[24] Prandtl, Ludwig. "Kipperscheinungen: Ein Fall von instabilem elastischem Gleichgewicht." PhD thesis. Fakultät, Sekt. IId. Ludwigs-Maximilians-Universität München, 1899.

[25] Sapkás, Ákos and Kollár, László P. "Lateral-torsional buckling of composite beams." In: International Journal of Solids and Structures 39.11 (2002), pp. 2939-2963.

[26] Sherbourne, Archibald N and Kabir, Mohammad Z. "Shear strain effects in lateral stability of thin-walled fibrous composite beams." In: Journal of engineering mechanics 121.5 (1995), pp. $640-647$.

[27] Smith, Michael. ABAQUS/Standard User's Manual, Version 6.9. English. United States: Dassault Systèmes Simulia Corp, 2009.

[28] The Pultex® Pultrusion Design Manual. CREATIVE PULTRUSIONS, INC. 2004.

[29] Timoshenko, SP. Theory of Elastic Stability. First. McGraw-Hill, 1936.

[30] Timoshenko, SP and Gere, JM. "Lateral buckling of beams." In: Bulletin Polytechnical Institute 4.5 (1905).

[31] Timoshenko, SP and Gere, JM. Theory of Elastic Stability. Second. McGraw-Hill, 1963.

[32] Vlasov, VZ. Thin-walled Elastic Bars. 1940.

[33] Vries, Karl de. "Strength of beams as determined by lateral buckling." In: Transactions of the American Society of Civil Engineers 112.1 (1947), pp. 1245-1271.

[34] Winter, George. "Lateral stability of unsymmetrical I-beams and trusses in bending." In: Transactions of the American Society of Civil Engineers 108.1 (1943), pp. 247-260. 
[35] Yu, Liang et al. "Experimental study on mechanical properties of FRP components and comparison of steel properties." In: Proceedings of the 5th International Conference on Advanced Design and Manufacturing Engineering. Atlantis Press, 2015, pp. 1715-1723. ISBN: 978-94-6252-113-1. DOI: https ://doi . org/10 . 2991/icadme-15 . 2015 . 317. URL: https : //doi.org/10.2991/icadme-15.2015.317.

\section{Appendix A Clark and Hill Constants}

The equations for the constants in the Clark-Hill formulation are shown again here but with prime notation for shorthand. The results of this section are included in 10.1. The results for BC1 agree well with what is presented in [9] but there are significant differences for BCs 2 and 3.

$$
\begin{gathered}
C_{1}=\frac{\int_{0}^{1} \beta^{\prime 2} d Z}{\sqrt{\int_{0}^{1} m^{2} \beta^{2} d Z \int_{0}^{1} \beta^{\prime \prime 2} d Z}} \\
C_{2}=-\frac{1 / 2 \int_{0}^{1} m^{\prime \prime} \beta^{2} d Z}{\sqrt{\int_{0}^{1} m^{2} \beta^{2} d Z \int_{0}^{1} \beta^{\prime \prime 2} d Z}} \\
C_{3}=\frac{\int_{0}^{1} m \beta^{\prime 2} d Z}{\sqrt{\int_{0}^{1} m^{2} \beta^{2} d Z \int_{0}^{1} \beta^{\prime \prime 2} d Z}} \\
K^{2}=\pi^{2} \frac{\int_{0}^{1} \beta^{\prime 2} d Z}{\int_{0}^{1} \beta^{\prime \prime 2} d Z}
\end{gathered}
$$

Where the twist of the beam during LTB is given by Eqs A.2a and A.2b for torsionally simply supported and torsionally fixed, respectively. In this study, BC1 is a simple torsion support while $\mathrm{BC} 2$ and $\mathrm{BC} 3$ are fixed torsion supports. It is assumed that these shape functions are applicable for the 3 load cases used in this study. Through visual inspection and comparison with twist of the buckled beams, they do appear to match.

$$
\beta=A \sin (\pi Z)
$$




$$
\beta=\frac{A}{2}\left(1-\cos (2 \pi Z)=A \sin ^{2}(\pi Z)\right.
$$

\section{A.1 Simple Torsion}

$$
\begin{gathered}
\beta^{\prime}=\pi A \cos (\pi Z) \\
\beta^{\prime \prime}=-\pi^{2} A \sin (\pi Z) \\
\int_{0}^{1} \beta^{\prime 2}=\pi^{2} A^{2} \int_{0}^{1} \cos ^{2}(\pi Z) d Z=\frac{\pi^{2} A^{2}}{2} \\
\int_{0}^{1} \beta^{\prime \prime 2}=\pi^{4} A^{2} \int_{0}^{1} \sin ^{2} \pi Z=\frac{\pi^{4} A^{2}}{2}
\end{gathered}
$$

The integrals above of $\beta^{\prime}$ and $\beta^{\prime \prime}$ are used in the calculations for $K, C_{1}$, and $C_{2}$ for each load case with $\mathrm{BC} 1$. Likewise, the calculation for $K$ does not depend on bending moment through the beam.

$$
K^{2}=\frac{\pi^{2}\left[\pi^{2} A^{2} / 2\right]}{\pi^{4} A^{2} / 2}=1
$$

\section{A.2 Torsion Fixed}

These calculations are a repeat of the previous section but with $\beta$ given by eq A.2b.

$$
\begin{gathered}
\beta^{\prime}=\pi A \sin (2 \pi Z) \\
\beta^{\prime \prime}=2 \pi^{2} A \cos (2 \pi Z) \\
\int_{0}^{1} \beta^{\prime 2} d Z=\int_{0}^{1} \pi^{2} A^{2} \sin ^{2}(2 \pi Z) d Z=\pi^{2} A^{2} / 2 \\
\int_{0}^{1} \beta^{\prime \prime 2} d Z=\int_{0}^{1} 4 \pi^{4} A^{2} \cos ^{2}(2 \pi Z) d Z=2 \pi^{4} A^{2}
\end{gathered}
$$




$$
K^{2}=\pi^{2} \frac{\pi^{2} A^{2} / 2}{2 \pi^{4} A^{2}}=1 / 4
$$

\section{A.3 Pinned Beams}

In this section, calculations for $C_{1}$ and $C_{2}$ are shown for pinned beams. The results match expected values due to the simplicity of the setup.

\section{A.3.1 Pure Bending}

For the pure bending case only $C_{1}$ is applicable and the moment distribution is constant, $m=1$.

$$
\begin{gathered}
\int_{0}^{1} m^{2} \beta^{2} d Z=\int_{0}^{1} A^{2} \sin ^{2}(\pi Z) d Z=\frac{A^{2}}{2} \\
C_{1}=\frac{\pi^{2} A^{2} / 2}{\sqrt{\left[A^{2} / 2\right]\left[\pi^{4} A^{2} / 2\right]}}=1
\end{gathered}
$$

\section{A.3.2 3 Point Loading}

For a pinned beam with 3 point loading, the moment distribution is a linear absolute value function with a maximum at $\mathrm{Z}=0.5$.

$$
\begin{gathered}
m=2 Z \text { for } 0 \leq Z \leq 0.5 \\
m^{\prime \prime}=-4 \delta(Z-0.5)
\end{gathered}
$$

where $\delta$ is the Dirac delta function.

$$
\int_{0}^{1} m^{2} \beta^{2} d Z=2\left[\int_{0}^{0.5}(2 Z)^{2}(A \sin (\pi Z))^{2} d Z\right]=0.268 A^{2}
$$


The integration was able to split at $Z=0.5$ due to symmetry.

$$
\begin{gathered}
C_{1}=\frac{\pi^{2} A^{2} / 2}{\sqrt{\left(0.268 A^{2}\right)\left(\pi^{4} A^{2} / 2\right)}}=1.366 \\
\int_{0}^{1} m^{\prime \prime} \beta^{2} d Z=\int_{0}^{1}(-4 \delta(Z-1 / 2))\left(A^{2} \sin ^{2}(\pi Z)\right) d Z=-4 A^{2} \\
C_{2}=\frac{(1 / 2)\left(4 A^{2}\right)}{\sqrt{\left(0.268 A^{2}\right)\left(\pi^{4} A^{2} / 2\right)}}=0.554
\end{gathered}
$$

\section{A.3.3 Uniform Distributed Loading}

The normalized moment distribution for a pinned, uniformly loaded beam is $m=4 Z(1-Z)$.

$$
\begin{gathered}
\int_{0}^{1} m^{2} \beta^{2} d Z=\int_{0}^{1}\left(4 Z-4 Z^{2}\right)^{2}(A \sin (\pi Z))^{2} d Z=0.390 A^{2} \\
C_{1}=\frac{\pi^{2} A^{2} / 2}{\sqrt{\left(0.390 A^{2}\right)\left(\pi^{4} A^{2} / 2\right)}}=1.132 \\
\int_{0}^{1} m^{\prime \prime} \beta^{2} d Z=\int_{0}^{1}(-8)\left(A^{2} \sin ^{2}(\pi Z)\right) d Z=-4 A^{2} \\
C_{2}=\frac{2 A^{2}}{\sqrt{\left(0.390 A^{2}\right)\left(\pi^{4} A^{2} / 2\right)}}=0.459
\end{gathered}
$$

\section{A.4 Minor Axis Fixed}

This section applies to beams with $\mathrm{BC} 2$. These beams are laterally and torsionally fixed so a different shape function, Equation A.2b, is applied. The beams are pinned to major rotation so the same bending moments as the previous section are used here. The results in this section differ significantly from what is normally accepted but are presented here for completeness.

\section{A.4.1 Pure Bending}

Again, $m(Z)=1$.

$$
\int_{0}^{1} m^{2} \beta^{2} d Z=\int_{0}^{1} A^{2} \sin ^{4}(\pi z) d Z=\frac{3 A^{2}}{8}
$$




$$
C_{1}=\frac{\pi^{2} A^{2} / 2}{\sqrt{\left(3 A^{2} / 8\right)\left(2 \pi^{4} A^{2}\right)}}=0.577
$$

\section{A.4.2 3 Point Loading}

The symmetric, ramp profile of 3-point loading leads to splitting the integral of $(m \beta)^{2}$.

$$
\begin{aligned}
\int_{0}^{1} m^{2} \beta^{2} d Z & =2 \int_{0}^{0.5}(2 Z)^{2} A^{2} \sin ^{2}(\pi z) d Z=0.233 A^{2} \\
C_{1} & =\frac{\pi^{2} A^{2} / 2}{\sqrt{0.233 A^{2}\left(2 \pi^{4} A^{2}\right)}}=0.733 \\
\int_{0}^{1} m^{\prime \prime} \beta^{2} d Z & =\int_{0}^{1}-4 \delta(Z-0.5) A^{2} \sin ^{4}(\pi Z) d Z=-4 A^{2} \\
C_{2} & =\frac{(-1 / 2)\left(-4 A^{2}\right)}{\sqrt{0.0 .233 A^{2}\left(2 \pi^{4} A^{2}\right)}}=0.297
\end{aligned}
$$

$C_{1}$ and $C_{2}$ are both lower than the expected values of 1.07 and 0.42 , respectively.

\section{A.4.3 Uniform Distributed Loading}

The normalized moment distribution for a uniformly loaded beam is $m=4 Z(1-Z)$.

$$
\begin{gathered}
\int_{0}^{1} m^{2} \beta^{2} d Z=16 A^{2} \int_{0}^{1} Z^{2}(1-Z)^{2} \sin ^{4}(\pi Z) d Z=0.321 A^{2} \\
C_{1}=\frac{\pi^{2} A^{2} / 2}{\sqrt{0.321 A^{2}\left(2 \pi^{4} A^{2}\right)}}=0.624 \\
\int_{0}^{1} m^{\prime \prime} \beta^{2} d Z=\int_{0}^{1}(-8) A^{2} \sin ^{4}(\pi Z) d Z=-3 A^{2} \\
C_{2}=\frac{(-1 / 2)\left(-3 A^{2}\right)}{\sqrt{0.321 A^{2}\left(2 \pi^{4} A^{2}\right)}}=0.190
\end{gathered}
$$

$C_{1}$ and $C_{2}$ are both lower than the expected values of 0.97 and 0.29 , respectively. 


\section{A.5 Major and Minor Axes Fixed}

$\mathrm{BC} 3$ adds major axis fixity to $\mathrm{BC} 2$. There is no pure bending case because the loading would conflict with the supports. With both load cases having negative moments near the supports, it would be reasonable to assume an extra higher order cosine term in Equation A.2b that would similarly cause a negative twist. However, this was not done as the Equation A.2b appeared to match the Eigen shapes from the buckling analyses well. In addition, more fitting parameters in the shape function could increase the likelihood of misclassifying non-LTB modes. For consistency to the parametric study, the same shape function is used in the calculations for $K, C_{1}$, and $C_{2}$.

\section{A.5.1 3 Point Loading}

The moment distribution for the 3-Point load case is a symmetric ramp profile but the moments close to the supports are negative.

$$
\begin{gathered}
m=4 Z-1 \text { for } 0 \leq Z \leq 0.5 \\
m^{\prime \prime}=-8 \delta(Z-0.5)
\end{gathered}
$$

where $\delta$ is the Dirac delta function. The symmetric, ramp profile of 3-point loading leads to splitting the integral of $(m \beta)^{2}$.

$$
\begin{aligned}
\int_{0}^{1} m^{2} \beta^{2} d Z & =2 \int_{0}^{0.5}(4 Z-1)^{2} A^{2} \sin ^{4}(\pi Z)=0.150 A^{2} \\
C_{1} & =\frac{\pi^{2} A^{2} / 2}{\sqrt{0.150 A^{2}\left(2 \pi^{4} A^{2}\right)}}=0.912 \\
\int_{0}^{1} m^{\prime \prime} \beta^{2} d Z & =\int_{0}^{1}-8 \delta(Z-0.5) A^{2} \sin ^{4}(\pi Z) d Z=-8 A^{2} \\
C_{2} & =\frac{(-1 / 2)\left(-8 A^{2}\right)}{\sqrt{0.150 A^{2}\left(2 \pi^{4} A^{2}\right)}}=0.739
\end{aligned}
$$

$C_{1}$ and $C_{2}$ are both lower than the expected values of 1.04 and 0.84 , respectively. 


\section{A.5.2 Uniform Distributed Loading}

The bending moments for the UDL case near the supports are negative and are larger than the positive moment at mid-span. The moment distribution was normalized to the smaller, positive moment at mid-span because it has the greater effect when combined with the twist of the beam.

$$
\begin{gathered}
\int_{0}^{1} m^{2} \beta^{2} d Z=4 A^{2} \int_{0}^{1}\left(-1+6 Z-6 Z^{2}\right)^{2} \sin ^{4}(\pi Z) d Z=0.252 A^{2} \\
C_{1}=\frac{\pi^{2} A^{2} / 2}{\sqrt{0.252 A^{2}\left(2 \pi^{4} A^{2}\right)}}=0.705 \\
\int_{0}^{1} m^{\prime \prime} \beta^{2} d Z=\int_{0}^{1}(-24) A^{2} \sin ^{4}(\pi Z) d Z=-9 A^{2} \\
C_{2}=\frac{(-1 / 2)\left(-9 A^{2}\right)}{\sqrt{0.252 A^{2}\left(2 \pi^{4} A^{2}\right)}}=0.643
\end{gathered}
$$

$C_{1}$ and $C_{2}$ are both lower than the expected values of 0.86 and 0.82 , respectively. 